ARTICLE

DOI: $10.1038 / \mathrm{s} 41467-018-04459-3$

\title{
Structural and functional analysis of mRNA export regulation by the nuclear pore complex
}

Daniel H. Lin ${ }^{1}$, Ana R. Correia ${ }^{1}$, Sarah W. Cai ${ }^{1}$, Ferdinand M. Huber ${ }^{1}$, Claudia A. Jette ${ }^{1} \&$ André Hoelz (iD ${ }^{1}$

The nuclear pore complex (NPC) controls the passage of macromolecules between the nucleus and cytoplasm, but how the NPC directly participates in macromolecular transport remains poorly understood. In the final step of mRNA export, the DEAD-box helicase DDX19 is activated by the nucleoporins Gle1, Nup214, and Nup42 to remove Nxf1•Nxt1 from mRNAs. Here, we report crystal structures of Gle1•Nup42 from three organisms that reveal an evolutionarily conserved binding mode. Biochemical reconstitution of the DDX19 ATPase cycle establishes that human DDX19 activation does not require $\mathrm{IP}_{6}$, unlike its fungal homologs, and that Gle1 stability affects DDX19 activation. Mutations linked to motor neuron diseases cause decreased Gle1 thermostability, implicating nucleoporin misfolding as a disease determinant. Crystal structures of human Gle1•Nup42•DDX19 reveal the structural rearrangements in DDX19 from an auto-inhibited to an RNA-binding competent state. Together, our results provide the foundation for further mechanistic analyses of mRNA export in humans.

\footnotetext{
${ }^{1}$ Division of Chemistry and Chemical Engineering, California Institute of Technology, 1200 East California Boulevard, Pasadena, CA 91125, USA. These authors contributed equally: Ana R. Correia, Sarah W. Cai. Correspondence and requests for materials should be addressed to

A.H. (email: hoelz@caltech.edu)
} 
T he flow of genetic information requires newly transcribed and processed mRNAs to be exported from the nucleus to the cytoplasm through nuclear pore complexes (NPCs). NPCs are massive macromolecular machines perforating the nuclear envelope, each composed of $\sim 1000$ protein subunits (collectively termed nucleoporins) totaling to a molecular mass of $\sim 120 \mathrm{MDa}$ in humans ${ }^{1}$. By fusing the inner and outer nuclear membranes, NPCs create pores through the nuclear envelope and simultaneously generate a passive diffusion barrier composed of disordered protein sequences enriched in phenylalanine-glycine
(FG) repeats. Each NPC is composed of a $\sim 60 \mathrm{MDa}$ symmetric core that is decorated by different proteins on its nuclear and cytoplasmic faces, which are referred to as the nuclear basket and cytoplasmic filament nucleoporins, respectively (Fig. 1a).

The architecture of the symmetric core of the human NPC has recently been elucidated ${ }^{2,3}$. In humans, the symmetric core is composed of an inner ring that resides in the plane of the membrane and two concentric outer rings that reside above the inner and outer nuclear membranes. The outer rings, which serve as the attachment sites for the nuclear basket and cytoplasmic

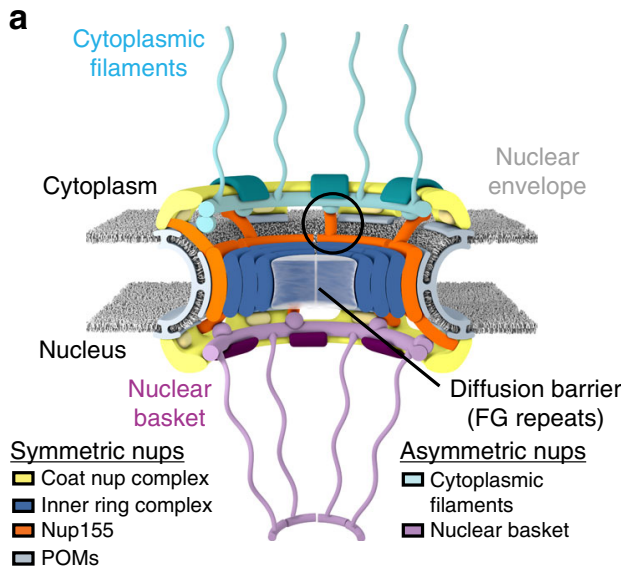

b

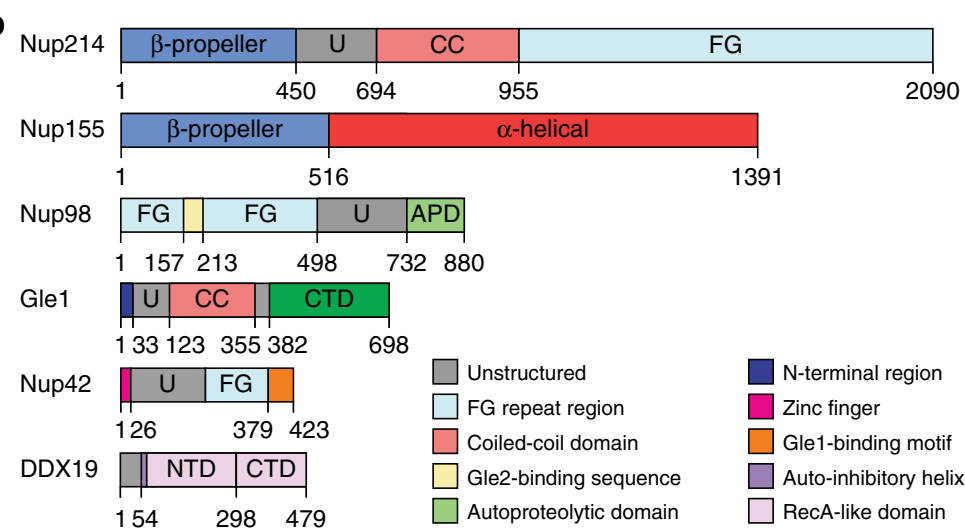

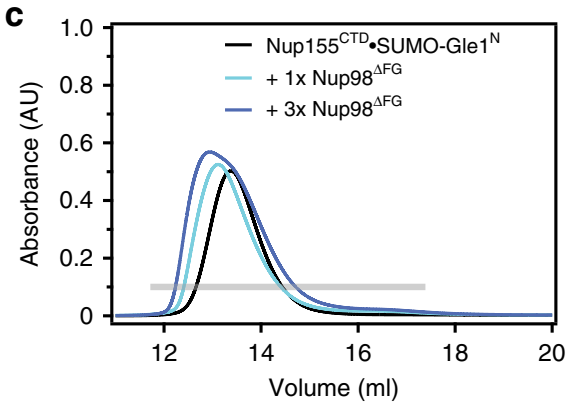

d

Nup155 Nup98 Gle1 mutant binding binding E1146A -+ $\begin{array}{lll}\mathrm{K} 1147 \mathrm{~A} & + & - \\ \mathrm{L} 1182 \mathrm{~A} & + & +\end{array}$ Y1189A - $\quad-$ F1192A - I1206A - -

Mutation disrupts: Gle1 Neither Nup98 Both

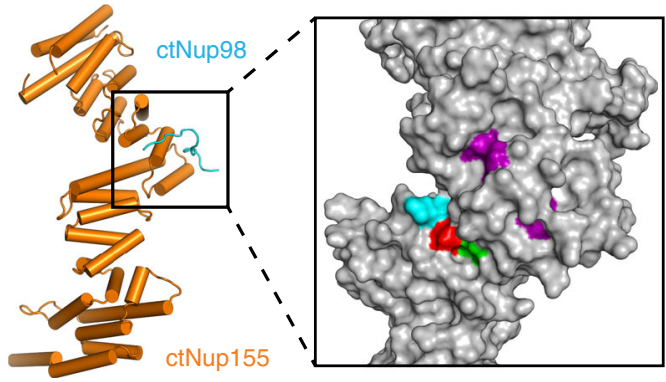

e

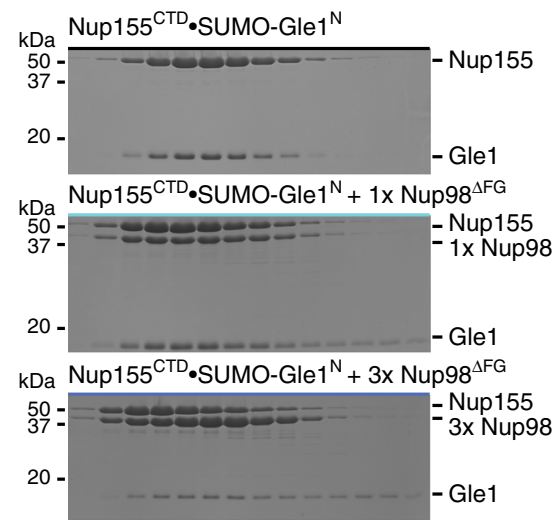

Gle1: MPSEGRCWETLKALRSSDKGRLCYYRDWLLRRE $\begin{array}{cccc}1 & 10 & 20 & 30 \quad 33 \\ \text { Mutation effect: } & \text { None } & \text { - Moderate } & \text { No binding }\end{array}$

$\mathbf{f}$

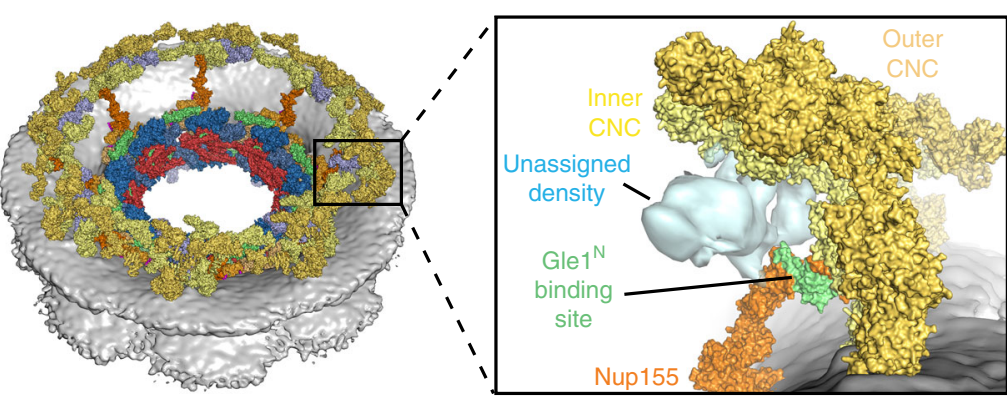

Fig. $1 \mathrm{Gle} 1$ is anchored to the nuclear pore complex through a competitive interaction with Nup98. a Cartoon schematic of the human nuclear pore complex (NPC). The circle highlights the region of the NPC to which the proteins used in this study localize. $\mathbf{b}$ Domain schematics for nucleoporins used in this study. Protein names and boundaries correspond to the human proteins. c Size exclusion chromatography (SEC) analysis of the interaction between Nup155 CTD , SUMO-Gle1 ${ }^{\mathrm{N}}$, and Nup98 ${ }^{\mathrm{AFG}}$. Purified Nup155 ${ }^{\mathrm{CTD}} \cdot \mathrm{SUMO}-\mathrm{Gle} 1^{\mathrm{N}}$ complex was mixed with the indicated amounts of Nup98 ${ }^{\mathrm{AFG}}$ and loaded onto a Superdex 200 10/300 GL column. The gray bar indicates the fractions visualized with Coomassie-stained SDS-PAGE gels. d Left: table summarizing

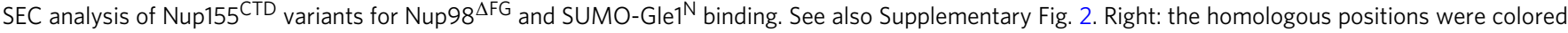
on the C. thermophilum Nup170•Nup145N structure (PDB ID 5HBO), indicating that the same binding surface is recognized by Nup98 ${ }^{\Delta \mathrm{FG}}$ and SUMO-Gle ${ }^{\mathrm{N}}$ [2]. e Summary of the effect of Gle $1^{\mathrm{N}}$ alanine substitution variants on Nup155 ${ }^{\mathrm{CTD}}$ binding. Colored dots above the sequence of Gle $1^{\mathrm{N}}$ indicate the effect of the substitution, green for wild-type levels of complex formation, orange for reduced binding, or red for complete disruption. See also Supplementary Fig. 2. f Identification of the Gle1 binding site suggests that the unassigned cytoplasmic density adjacent to bridging Nup155 molecules could contain Gle1 and its binding partners. Left: surface representation of the composite structure of the NPC ${ }^{2}$. Right: zoomed view of unassigned cytoplasmic density, with Nup155 shown in orange, Gle1 ${ }^{\mathrm{N}}$ binding site colored in green, and coat nucleoporin complexes shown in yellow 
filaments, are structurally connected to the inner ring via bridging Nup155 molecules. In addition to large interaction interfaces between scaffold proteins, the assembly of the symmetric core requires interactions mediated by flexible linker sequences residing in Nup98, Nup53, and Nup93 $3^{2,4,5}$. In contrast, the molecular organization of the cytoplasmic filaments and nuclear basket remains poorly understood.

Preparation of mRNAs for nuclear export is a highly coordinated process that begins co-transcriptionally and results in the addition and removal of mRNA-binding proteins during transcription and nuclear processing until an export-competent messenger ribonucleoprotein particle (mRNP) is formed ${ }^{6}$. Although some mRNAs may be exported through specialized pathways, the bulk of mRNA export is mediated by the evolutionarily conserved, heterodimeric transport factor complex $\mathrm{Nxf} 1 \bullet \mathrm{Nxt1}^{7}$. Nxf1•Nxt1 binds mRNAs without strong sequence preference and can shuttle mRNAs through the NPC diffusion barrier by binding to FG repeats. At the cytoplasmic face of the NPC, Nxf1•Nxt1-bound mRNPs encounter the cytoplasmic filament nucleoporins Gle1, Nup42, and Nup214, which specifically activate the DEAD-box helicase DDX19 to remove Nxf1•Nxt1 from the $\mathrm{mRNP}^{8}$. This spatial regulation of activity prevents reimport of mRNPs into the nucleus, and thus ensures the directionality of mRNA export.

DDX19 is a member of the DEAD-box helicase family, which are RNA-dependent ATPases composed of two RecA domains (referred to as DDX19 ${ }^{\mathrm{NTD}}$ and DDX19 ${ }^{\mathrm{CTD}}$ throughout the text) (Fig. 1b). Many insights into the regulation of DDX19 come from studies of the fungal homolog, Dbp5. Genetic, biochemical, and structural studies of the yeast proteins have revealed that the interaction between Gle1 and Dbp5 occurs via their C-terminal domains (CTDs) and is bridged by the small molecule inositol hexaphosphate $\left(\mathrm{IP}_{6}\right)^{9-12}$. In yeast, Gle1, $\mathrm{IP}_{6}$, and RNA cooperate to stimulate the ATPase activity of Dbp5, although the precise mechanism remains debated ${ }^{10,13}$. The functional roles of Nup42 and Nup214 are also unclear. The interaction between Nup214 and DDX19 is required for steady-state localization of DDX19 to the NPC, but Nup214 binding also inhibits DDX19 activity ${ }^{14-17}$. Nup42 binds to Gle1, but its contributions to DDX19 activity are unknown ${ }^{18,19}$. DDX19 and Gle1 have been implicated in other cellular processes including transcription regulation, DNA damage response, translation initiation, and RNA processing ${ }^{20-25}$.

Impairment of nucleocytoplasmic transport through the NPC has been linked to both Huntington's disease and amyotrophic lateral sclerosis (ALS) ${ }^{26-30}$. Nucleocytoplasmic transport factors and nucleoporins, including Gle1, are genetic modifiers of disease in model systems and are mislocalized in both model organism and patient samples ${ }^{26-29,31,32}$. Specific mutations of Gle1 are associated with lethal contracture congenital syndrome 1 (LCCS1), lethal arthrogryposis with anterior horn cell disease (LAAHD), and ALS ${ }^{33,34}$. However, deciphering how defects in nucleocytoplasmic transport can lead to disease will require an improved understanding of the regulation of transport through the NPC.

To gain further mechanistic insight into the role of nucleoporins in mRNA export, we characterized the molecular architecture of the cytoplasmic filament nucleoporins involved in regulating DDX19 activity. We mapped the Gle1-binding site on Nup155 and found that it overlaps with the Nup98 binding site, thereby acquiring a spatial restraint for Gle1 localization in the NPC. Crystal structures of the Gle1•Nup42 complex from Saccharomyces cerevisiae, Chaetomium thermophilum, and Homo sapiens revealed the evolutionarily conserved structural basis of their interaction. Nup42 is critical for the thermostability of human Gle1, enabling Gle1 purification from a recombinant source and characterization of its role in human DDX19 activation, which unlike the yeast system does not require $\mathrm{IP}_{6}$ binding. Crystal structures of the human Gle1•Nup42•DDX19 complex bound to ADP and AMP-PNP• $\mathrm{Mg}^{2+}$ uncovered the adaptations that facilitate $\mathrm{IP}_{6}$-independent activation in humans and the specific Gle1-induced conformational changes that release DDX19 from an auto-inhibited state. Lastly, Gle1 mutations that are associated with motor neuron diseases possess severe thermostability defects, suggesting that nucleoporin misfolding contributes to disease.

\section{Results}

Gle1 and Nup98 recognize overlapping surfaces on Nup155. To gain a better understanding of the molecular architecture of the nucleoporins that regulate mRNA export, we set out to reconstitute the interactions with purified, recombinant proteins. We use the names of the human proteins unless otherwise specified. In humans, there are two splice variants of the Gle1 transcript, Gle1A and Gle1B, which encode proteins that are primarily localized in the cytoplasm or at the cytoplasmic face of the NPC, respectively ${ }^{35}$. We focused on the NPC-localized Gle1B, referred to as Gle1 throughout the text. Human Glel can be divided into three structural domains: an unstructured N-terminal region $\left(\mathrm{Gle}^{\mathrm{N}}\right.$, residues $\left.1-123\right)$, a coiled-coil region $\left(\mathrm{Gle} 1^{\mathrm{CC}}\right.$, residues 124-355), and a highly conserved CTD (Gle1 ${ }^{\mathrm{CTD}}$, residues 382-698) (Fig. 1b). Gle1 ${ }^{\text {CTD }}$ is the domain that binds and stimulates DDX19, but previous studies have identified features in all three regions that are important for NPC localization ${ }^{19,36,37}$.

We began our analysis by focusing on the interaction between Gle1 and the adaptor nucleoporin Nup155 (Nup170 in fungi). Although the first 28 residues of Gle1 were previously shown to be sufficient for an interaction, we used a SUMO-fusion construct that also included several charged residues at the C-terminus to enhance protein solubility $\left(\text { SUMO-Gle }{ }^{\mathrm{N}} \text {, residues } 2-33\right)^{37}$. The Nup155 CTD (Nup155 CTD, residues 870-1391) and SUMO$\mathrm{Gle}^{\mathrm{N}}$ formed a stoichiometric complex in size exclusion chromatography (SEC) experiments (Fig. 1c; Supplementary Fig. 1a). Nup $155^{\mathrm{CTD}}$ also contains a binding site for Nup98, which is both a component of the symmetric core of the NPC and of the cytoplasmic filaments ${ }^{2,4}$. Stoichiometric complex formation also occurred between Nup155 ${ }^{\text {CTD }}$ and a construct of Nup98 lacking the $\mathrm{FG}$ repeat region (Nup98 ${ }^{\triangle \mathrm{FG}}$, residues $498-880$ ) (Supplementary Fig. 1b). However, when we attempted to reconstitute a heterotrimeric complex by adding Nup $98^{\Delta \mathrm{FG}}$ to Nup155 ${ }^{\text {CTD }}$.SUMO-Gle ${ }^{\mathrm{N}}$, complex formation between Nup155 ${ }^{\mathrm{CTD}}$ and Nup98${ }^{\triangle \mathrm{FG}}$ coincided with displacement of SUMO-Gle ${ }^{\mathrm{N}}$, suggesting that the interactions were mutually exclusive (Fig. 1c; Supplementary Fig. 1a). Similarly, addition of SUMO-Gle ${ }^{\mathrm{N}}$ to Nup155 $15 \mathrm{CD} \cdot \mathrm{Nup} 98^{\Delta \mathrm{FG}}$ failed to yield a heterotrimeric complex (Supplementary Fig. 1b). This effect was specific to Nup98, as addition of the N-terminal domain of Nup214 (Nup214 ${ }^{\mathrm{NTD}}$ ) to Nup155 ${ }^{\mathrm{CTD}}$. SUMO-Gle1 ${ }^{\mathrm{N}}$ did not displace SUMO-Gle $1^{\mathrm{N}}$ (Supplementary Fig. 1c). In GST-pulldown experiments, Gle $1^{\mathrm{N}}$ efficiently outcompeted Nup $98^{\Delta \mathrm{FG}}$ for Nup155 ${ }^{\mathrm{CTD}}$ binding, whereas conversely, Nup $98^{\triangle \mathrm{FG}}$ could not outcompete $\mathrm{Gle}^{\mathrm{N}}$, suggesting that Gle ${ }^{\mathrm{N}}$ binds with greater affinity to Nup155 ${ }^{\mathrm{CTD}}$ than Nup98 ${ }^{\triangle \mathrm{FG}}$ (Supplementary Fig. 1d).

We next expanded upon previous mutational and structural analyses using the $C$. thermophilum proteins ${ }^{2}$. Amino acid substitutions at positions homologous to those that abolished binding for the C. thermophilum proteins also disrupted binding between human Nup155 ${ }^{\mathrm{CTD}}$ and Nup98${ }^{\mathrm{AFG}}$, demonstrating that the mechanism of interaction between these two nucleoporins is evolutionarily conserved (Fig. 1d; Supplementary Fig. 2a). Moreover, most residues that were critical for Nup $98^{\Delta \mathrm{FG}}$ binding were 
also important for $\mathrm{Gle} 1^{\mathrm{N}}$ binding, except for two residues that each affected only one nucleoporin, indicating that $\mathrm{Gle}^{\mathrm{N}}$ and Nup9 ${ }^{\Delta \mathrm{FG}}$ recognize overlapping surfaces on Nup155 ${ }^{\mathrm{CTD}}$ (Fig. 1d; Supplementary Fig. 2b). Hydrophobic residues in $\mathrm{Gle}^{\mathrm{N}}{ }^{\mathrm{N}}$ were critical for Nup155 ${ }^{\text {TD }}$ binding, consistent with utilization of the same hydrophobic pockets as Nup98 ${ }^{\Delta \mathrm{FG}}$ (Fig. 1e; Supplementary Fig. 2c).

In summary, we found that $\mathrm{Gle} 1^{\mathrm{N}}$ and $\mathrm{Nup} 98^{\Delta \mathrm{FG}}$ recognize overlapping surfaces on Nup155 ${ }^{\mathrm{CTD}}$. Nup155 molecules bridge the inner ring to the cytoplasmic and nuclear outer coat nucleoporin complex $(\mathrm{CNC})$ double rings (Fig. 1a) ${ }^{2,3}$. Because Gle ${ }^{\mathrm{N}}$ efficiently outcompetes Nup $98^{\Delta \mathrm{FG}}$ for binding, Gle1 would likely prevail for binding to Nup155 molecules exposed to the cytoplasmic face. Indeed, in the cytoplasmic outer ring, but not the nuclear outer ring, there is a volume of unaccounted density directly adjacent to the Nup155 $5^{\mathrm{CTD}}$ surface that binds Gle1 $\mathrm{N}$ (Fig. 1f). Our analysis suggests this density contains the remainder of the Gle1 molecule and its binding partners.

Identification of a minimal Nup42 Gle1-binding fragment. We next focused on the interaction between Gle1 ${ }^{\text {CTD }}$ and Nup42. Previous studies have shown that the C-terminal, non-FG repeat region of Nup42 binds Gle ${ }^{\text {CTD } 19,38}$. To identify the minimally sufficient fragment of Nup42 that recognizes Gle1, we monitored the localization of Gle1-GFP and mCherry-HA-tagged Nup42 variants in S. cerevisiae ${ }^{39}$. Nup42 truncations that contained residues 397-430 displayed nuclear rim staining consistent with localization to the NPC, whereas an Nup42 variant containing only residues 410-430 did not (Fig. 2a). From these results, we concluded that the Nup42 Gle1-binding motif (Nup42 ${ }^{\mathrm{GBM}}$ ) is located within residues 397-430 (See Supplementary Note 1).

When we recombinantly purified the minimal $S$. cerevisiae Gle1 ${ }^{\mathrm{CTD}} \cdot$ Nup $42^{\mathrm{GBM}}$ complex, we noticed that the purified complex was more stable than apo Gle1 ${ }^{\mathrm{CTD}}$, which typically requires the addition of $\mathrm{IP}_{6}$ in purification buffers for stability ${ }^{10}$. This observation led us to test the effect of $\mathrm{IP}_{6}$ and Nup42 4 GBM on the stability of Gle1 ${ }^{\text {CTD }}$ using two different assays: differential scanning fluorimetry and a protein solubility assay. In both experiments, $\mathrm{IP}_{6}$ potently improved $\mathrm{Gle} 1^{\mathrm{CTD}}$ stability, with saturating amounts of $\mathrm{IP}_{6}$ shifting the melting temperature $\left(T_{\mathrm{m}}\right)$ from 22 to $37^{\circ} \mathrm{C}$ (Fig. 2b; Supplementary Fig. 4a). Nup42 $2^{\mathrm{GBM}}$ had an even more dramatic effect, increasing the $T_{\mathrm{m}}$ from 22 to $46^{\circ} \mathrm{C}$, and the presence of both $\mathrm{IP}_{6}$ and Nup42 $4 \mathrm{GBM}$ shifted the $T_{\mathrm{m}}$ of Gle $1^{\mathrm{CTD}}$ to $53^{\circ} \mathrm{C}$ (Fig. 2b; Supplementary Fig. 4a).

The difficulty of purifying human Gle $1^{\text {CTD }}$ has previously prevented a detailed biochemical analysis of the human proteins, but the dramatic effect of yeast Nup42 $2^{\mathrm{GBM}}$ on Gle1 ${ }^{\mathrm{CTD}}$ stability led us to test whether human Nup42 ${ }^{\mathrm{GBM}}$ has the same effect on human Gle1 ${ }^{\text {CTD }}$. Co-purification of a homologous human Gle1 ${ }^{\mathrm{CTD}} \cdot \mathrm{Nup} 42^{\mathrm{GBM}}$ complex (containing Gle1 residues 382 -698 and Nup42 residues $379-423$ ) resulted in dramatic improvements in the stability of Gle1 ${ }^{\text {CTD }}$ and the yields increased from $\sim 0.5$ to $\sim 50 \mathrm{mg} / 100 \mathrm{l}$ of bacterial culture. In thermostability experiments, the $T_{\mathrm{m}}$ of human Gle $1^{\mathrm{CTD}}$ increased from 37 to $50^{\circ}$ $\mathrm{C}$ in the presence of Nup42 GBM (Fig. 2c; Supplementary Fig. 4b). However, in contrast to the yeast proteins, $\mathrm{IP}_{6}$ had almost no effect on thermostability for human Gle ${ }^{\text {CTD }}$ (Fig. 2c; Supplementary Fig. 4b). In summary, we identified an evolutionarily conserved C-terminal fragment of Nup42 that binds Gle1 and has a profound effect on Gle1 stability in both yeast and humans.

Evolutionary conservation of the Gle1-Nup42 interaction. To understand the molecular basis for the interaction between Gle $1^{\text {CTD }}$ and Nup42 $\mathrm{GBM}$ and the resulting stabilization of Gle1 ${ }^{\mathrm{CTD}}$, we determined the crystal structure of $S$. cerevisiae
Gle ${ }^{\mathrm{CTD}} \cdot \mathrm{Nup} 42^{\mathrm{GBM}}$ at $1.75 \AA$ resolution (Fig. 2d; Supplementary Table 1). Nup $42^{\mathrm{GBM}}$ folds into a compact domain with a hydrophobic core that buries a solvent-exposed hydrophobic surface on Gle1 ${ }^{\mathrm{CTD}}$, yielding an interaction interface area of $\sim 835 \AA^{2}$ (Fig. 2d; Supplementary Fig. 5a; See Supplementary Note 2 for details). Consistent with the extensive interaction surface, the interaction between Gle1 ${ }^{\mathrm{CTD}}$ and Nup $42^{\mathrm{GBM}}$ was robust against several individual alanine substitutions in SEC experiments (Supplementary Fig. 6a). Instead, highly disruptive substitutions that introduced negative charge into the hydrophobic core (F414D or F409D/F414D) were required to completely disrupt the interaction between Gle1 ${ }^{\mathrm{CTD}}$ and Nup $42^{\mathrm{GBM}}$ (Supplementary Fig. 6b). In agreement with these results, Nup42 variants containing the F414D or F409D/F414D substitutions were unable to rescue Nup42 deletion in S. cerevisiae (Supplementary Fig. 3). In contrast, the F409D substitution in the Nup42 hydrophobic core did not ablate binding, but did alter the elution profile, suggesting a conformational difference in the complex (Supplementary Fig. 6b). Accordingly, an Nup42 variant harboring the F409D substitution only had a mild effect on growth at $37^{\circ} \mathrm{C}$ (Supplementary Fig. 3a).

To evaluate whether the mode of interaction observed for S. cerevisiae Gle ${ }^{\mathrm{CTD}} \cdot \mathrm{Nup} 42^{\mathrm{GBM}}$ was conserved in other eukaryotes, we determined the crystal structures of human Gle $1^{\mathrm{CTD}} \cdot \mathrm{Nup} 42^{\mathrm{GBM}}$ at $2.8 \AA$ resolution and of C. thermophilum Gle ${ }^{\mathrm{CTD}} \cdot \mathrm{Nup} 42^{\mathrm{GBM}}$ in the presence and absence of $\mathrm{IP}_{6}$ at 2.17 and $2.65 \AA$ resolution, respectively (Fig. 2e, f; Supplementary Fig. 7a; Supplementary Tables 1 and 2). The overall structure of Gle $1^{\text {CTD }}$ is conserved between fungi and humans, with minor differences resulting from small insertions or different loop sizes (Fig. 2g; Supplementary Fig. 8 and Supplementary Movie 1). Both human and $C$. thermophilum Nup $42^{\mathrm{GBM}}$ adopt the same fold as S. cerevisiae Nup $42^{\mathrm{GBM}}$ and recognize the same surface on Gle ${ }^{\text {CTD }}$, with the critical hydrophobic residues nearly universally conserved (Fig. 2i, j; Supplementary Figs. 8-11; See Supplementary Note 2 for details). Many of the critical interaction interfaces in the NPC likely possess a similar degree of structural conservation. Burial of the exposed hydrophobic residues and the thermodynamic favorability of Nup $42^{\mathrm{GBM}}$ binding and folding explain the large effect Nup42 $\mathrm{GBM}$ has on Gle1 ${ }^{\mathrm{CTD}}$ stability. Nup42GBM binding may also help prevent Gle1 CTD from sampling partially unfolded states that could lead to aggregation. The remainder of Nup42 is comprised primarily of FG repeats. In yeast, deletion of these FG repeats was detrimental when combined with the deletion of other FG repeats in the cytoplasmic filaments ${ }^{40}$. Thus, in addition to ensuring the stability of Gle $1^{\mathrm{CTD}}$, Nup42 $2^{\mathrm{GBM}}$ also has a role in anchoring FG repeats proximal to Gle1 in the NPC.

The $\mathrm{IP}_{\mathbf{6}}$ binding pocket is not conserved in metazoan Gle1. In yeast, activation of Dbp5, the fungal homolog of DDX19, requires the small molecule $\mathrm{IP}_{6}$, which binds to a highly positively charged pocket in Gle $1^{\mathrm{CTD}}$ adjacent to the Dbp5 binding surface and bridges the two proteins ${ }^{9-11}$. Our Gle $1^{\mathrm{CTD}} \cdot \mathrm{Nup} 42^{\mathrm{GBM}}$ structure reveals that Nup42 $2^{\mathrm{GBM}}$ interacts with Gle1 ${ }^{\mathrm{CTD}}$ at a surface that is distinct and well separated from the $\mathrm{IP}_{6}$ binding pocket and the Dbp5 interface (Supplementary Fig. 5a) ${ }^{10}$. Thus, in order for Nup42 4 GBM binding to affect Dbp5 activation, it would have to do so through an allosteric mechanism. However, there were minimal conformational differences in Gle1 CTD between our Gle1 ${ }^{\mathrm{CTD}} \cdot \mathrm{Nup} 42^{\mathrm{GBM}}$ structure and the previously reported structure of $\mathrm{Gle}^{\mathrm{CTD}} \cdot \mathrm{IP}_{6} \cdot \mathrm{Dbp} 5$ (Supplementary Fig. $\left.7 \mathrm{~b}\right)^{10}$. Similarly, $C$. thermophilum Gle1 $1^{\mathrm{CTD}}$.Nup42 GBM undergoes minimal conformational changes upon $\mathrm{IP}_{6}$ binding, which are mostly limited to a loop directly adjacent to the $\mathrm{IP}_{6}$ pocket. $\mathrm{IP}_{6}$ 
a

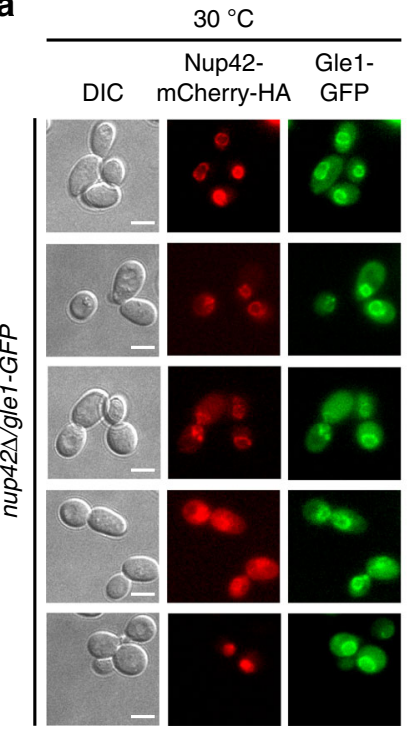

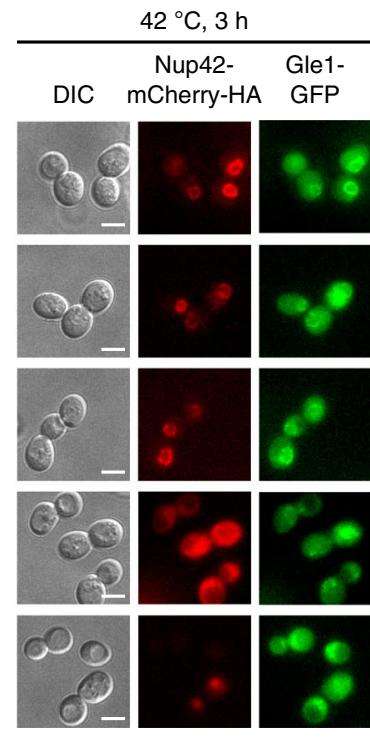

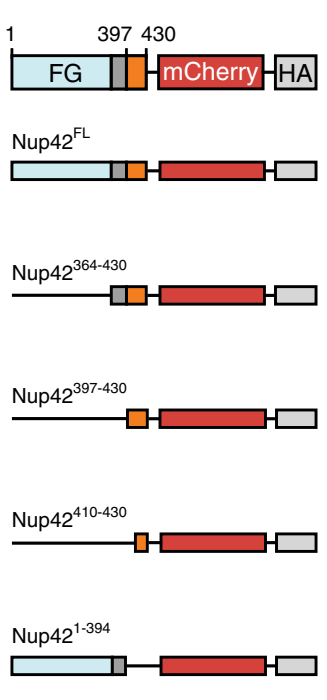

b
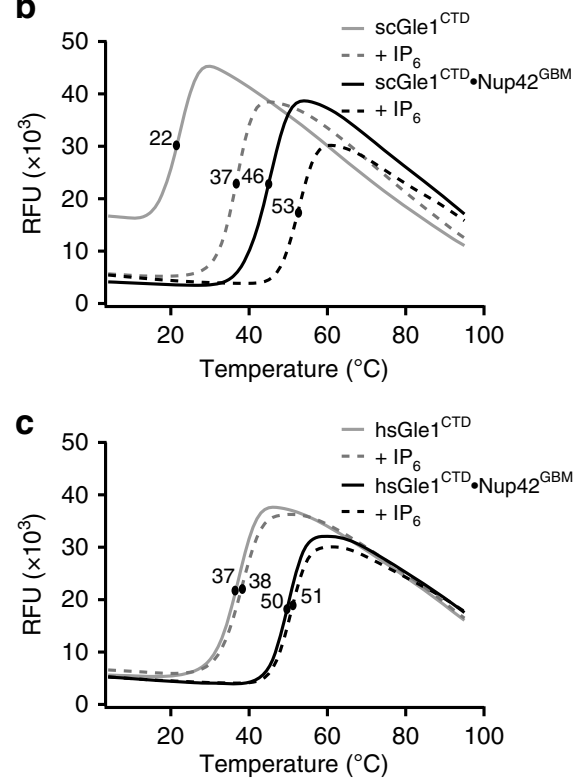

d

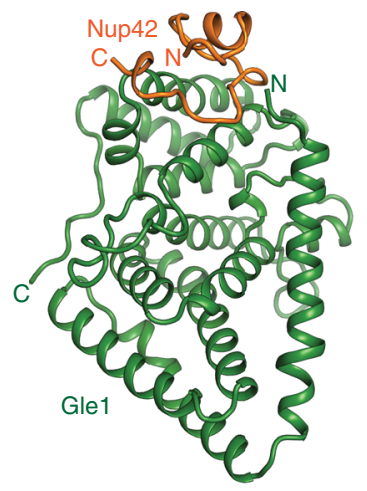

g

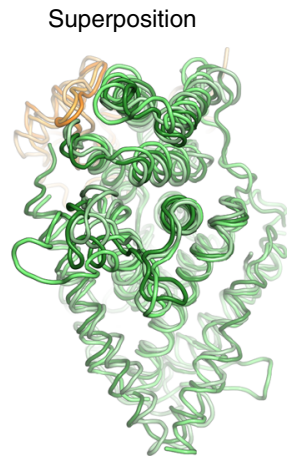

scGle ${ }^{\mathrm{CTD} \cdot N u p 42^{\mathrm{GBM}}}$

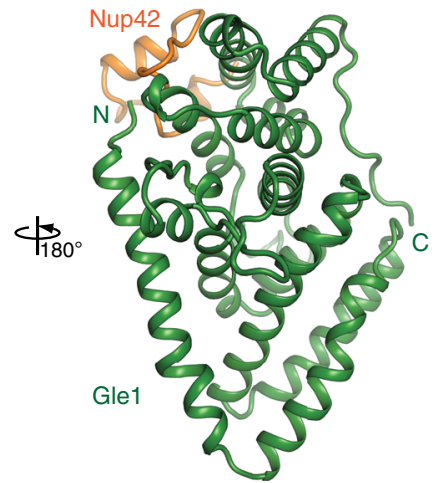

e f $\mathrm{ctGle}^{\mathrm{CTD}} \cdot \mathrm{Nup} 42^{\mathrm{GBM}}$
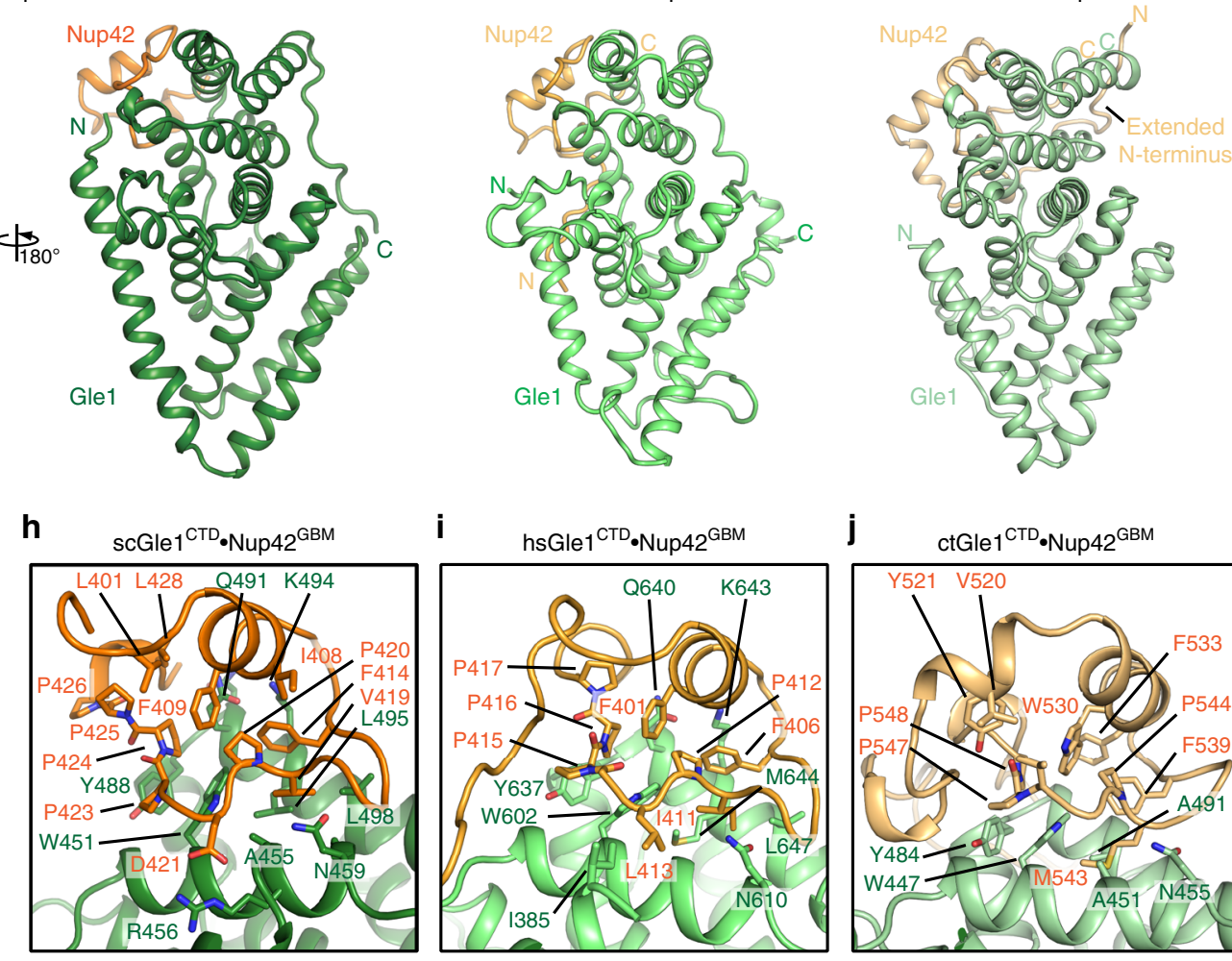

j

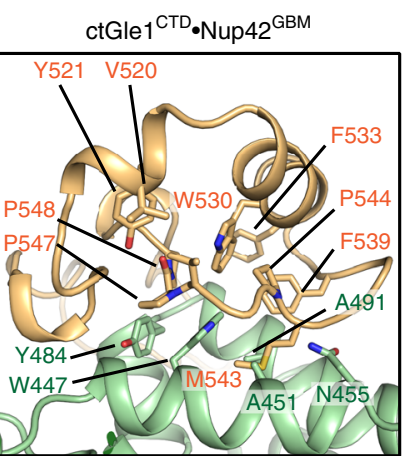

Fig. 2 A conserved mechanism for Gle1•Nup42 complex formation. a In vivo localization analysis of Gle1-GFP and Nup42-mCherry-HA variants in nup42 gle1-GFP S. cerevisiae cells. Scale bar is $5 \mu \mathrm{m}$. Schematics on the right indicate the Nup42 fragments that were included in the construct, with omitted fragments indicated by replacement of the domain with a solid line. Residue numbers indicate the fragment included in each construct. See also Supplementary Fig. 3. b, c Differential scanning fluorimetry analysis of $\mathbf{b}$ S. cerevisiae or $\mathbf{c} H$. sapiens Gle $1^{\text {CTD }}$ thermostability in the presence and absence of Nup42 ${ }^{\mathrm{GBM}}$ and $\mathrm{IP}_{6}$. Exposure of hydrophobic residues was monitored by an increase in relative fluorescence units (RFUs). Curves represent the average of three experiments. See also Supplementary Fig. 4. d-f Crystal structures of $\mathbf{d}$ S. cerevisiae, e H. sapiens, or $\mathbf{f}$ C. thermophilum Gle1 ${ }^{C T D} \cdot{ }^{N}$ Nup42 ${ }^{G B M}$. See also

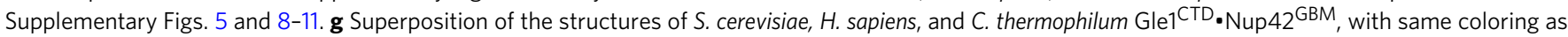
in $\mathbf{d}-\mathbf{f}$. See also Supplementary Movie 1. $\mathbf{h}-\mathbf{j}$ Zoom views of $\mathbf{h}$ S. cerevisiae, i H. sapiens, or $\mathbf{j}$ C. thermophilum Gle1 ${ }^{\mathrm{CTD}} \cdot \mathrm{N}_{\mathrm{Nup}} 2_{2}^{\mathrm{GBM}}$ interactions with residues mediating the interaction labeled

binds to C. thermophilum Gle1 ${ }^{\mathrm{CTD}}$ and to S. cerevisiae Gle ${ }^{\mathrm{CTD}}$ in a similar orientation, suggesting that $\mathrm{IP}_{6}$ could function similarly in C. thermophilum as in S. cerevisiae (Fig. 3a, b, d, e; Supplementary Fig. 7d; See Supplementary Note 3). However, because there are no apo Gle1 ${ }^{\mathrm{CTD}}$ structures available, we could not exclude the possibility that Nup42 GBM binding caused Gle1 ${ }^{\text {CTD }}$ to adopt the same conformation as the one observed upon $\mathrm{IP}_{6}$ and Dbp5 binding. 
In contrast to the $\mathrm{IP}_{6}$ binding pockets of $S$. cerevisiae and $C$. thermophilum Gle1 ${ }^{\mathrm{CTD}}$, the same location on the surface of the $H$. sapiens molecule was significantly altered, resulting in a substantial reduction in positive electrostatic potential (Fig. 3a $-\mathrm{f})$. This was the consequence of several positively charged residues that are essentially invariant in fungi ( $S$. cerevisiae residues $\mathrm{K} 264, \mathrm{~K} 286, \mathrm{~K} 333$, and $\mathrm{R} 374$; C. thermophilum residues K225, R249, K327, and K374), but are not conserved in humans (V401, Q423, E482, and H523) (Fig. 3a-c). This trend held for all the metazoan sequences inspected, indicating that the altered

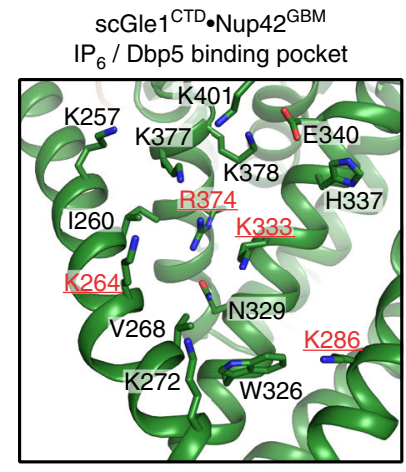

d

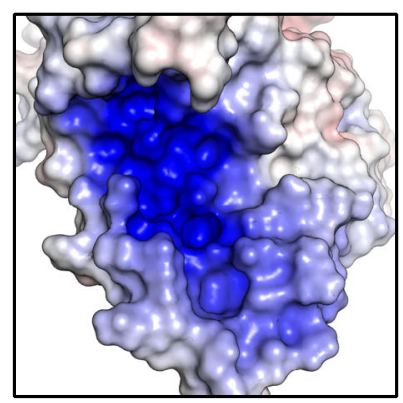

$-10 \mathrm{kT} / \mathrm{e} \rightleftharpoons+10 \mathrm{kT} / \mathrm{e}$

g $\bullet \mathrm{Dbp} 5$

- $\mathrm{Gle}^{\mathrm{CTD}} \cdot{ }^{\mathrm{T}} \cdot \mathrm{Nup} 42^{\mathrm{GBM}}+\mathrm{IP}_{6}$

- $\mathrm{Dbp} 5+\mathrm{Gle}^{\mathrm{CTD}} \cdot \mathrm{Nup} 42^{\mathrm{GBM}}+\mathrm{IP}_{6}$

- $\mathrm{Gle}^{\mathrm{CTD}} \cdot \mathrm{Nup} 42^{\mathrm{GBM}}$ no $\mathrm{IP}_{6}$

- Dbp5 + Gle $1^{\mathrm{CTD}} \cdot \mathrm{NNup}_{2}{ }^{\mathrm{GBM}}$ no $\mathrm{IP}_{6}$

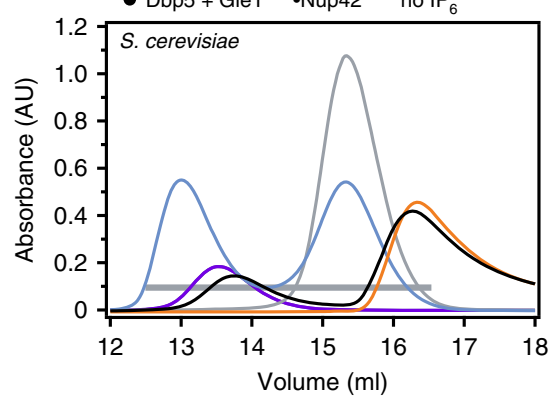

$\mathrm{kDa}$ Dbp5

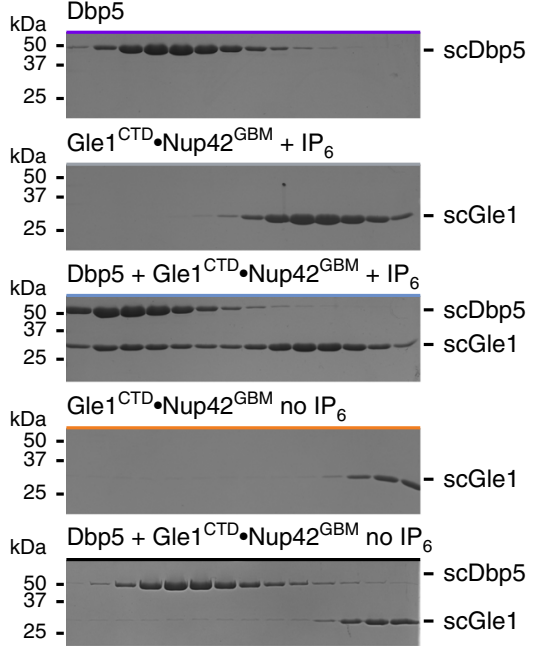

b

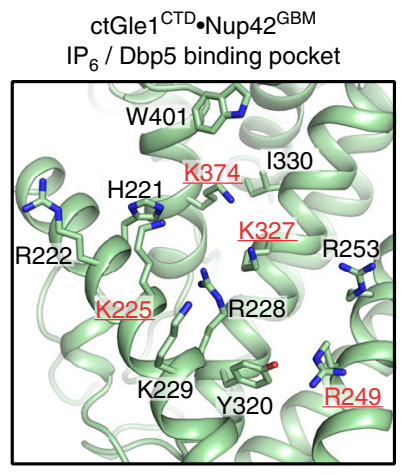

e

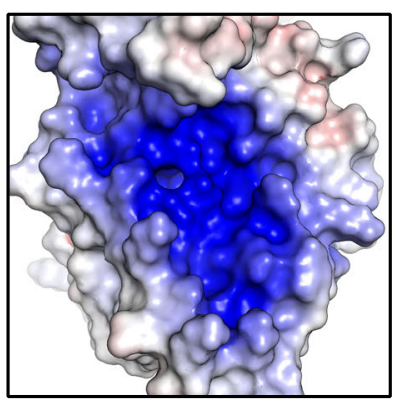

$-10 \mathrm{kT} / \mathrm{e} \square+10 \mathrm{kT} / \mathrm{e}$

h $\bullet$ Dbp5

- $\mathrm{Gle}^{\mathrm{CTD}} \cdot \mathrm{Nup} 42^{\mathrm{GBM}}+\mathrm{IP}_{6}$

- $\mathrm{Dbp} 5+\mathrm{Gle}^{\mathrm{CTD}} \cdot \mathrm{Nup}^{\mathrm{G}} 2^{\mathrm{GBM}}+\mathrm{IP}_{6}$

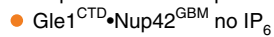

- Dbp5 $+\mathrm{Gle}^{\mathrm{CTD}} \cdot{ }^{\mathrm{N}} \mathrm{Nup} 2^{\mathrm{GBM}}$ no IP
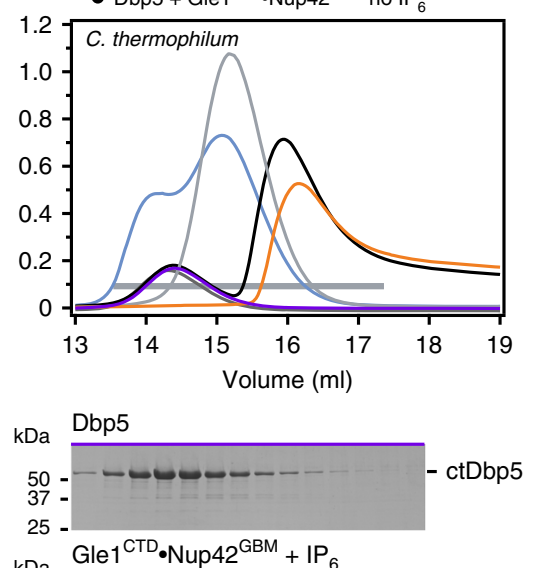

$\mathrm{kDa} \quad \mathrm{Gle}^{\mathrm{CTD}} \cdot \mathrm{Nup} 42^{\mathrm{GBM}}+\mathrm{IP}_{6}$

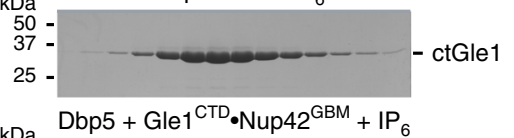

$\mathrm{kDa} \quad \mathrm{Dbp} 5+\mathrm{Gle}^{\mathrm{CTD}} \cdot \mathrm{Nup} 42^{\mathrm{GBM}}+\mathrm{IP}_{6}$

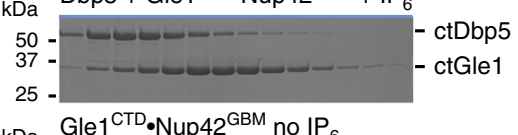

$\mathrm{kDa}$ Gle ${ }^{\mathrm{CTD}} \cdot \mathrm{Nup} 42^{\mathrm{GBM}}$ no $\mathrm{IP}_{6}$

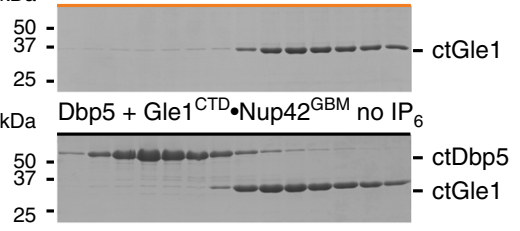

C

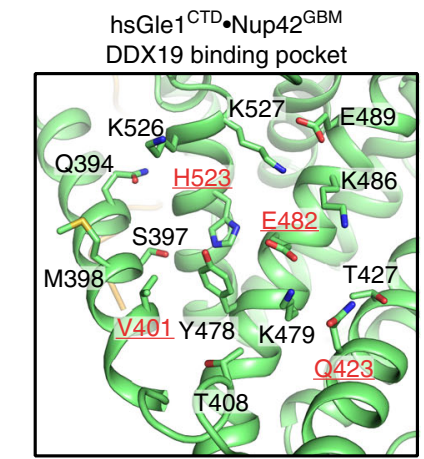

f

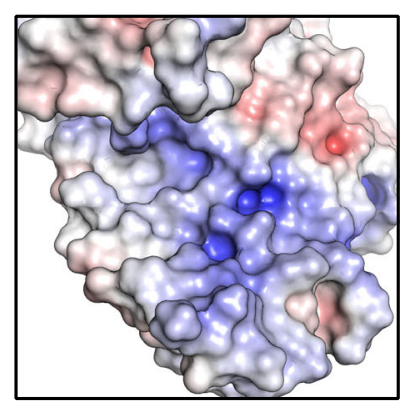

$-10 \mathrm{kT} / \mathrm{e} \square+10 \mathrm{kT} / \mathrm{e}$

i $\quad \operatorname{DDX} 19$

- $\mathrm{Gle} 1^{\mathrm{CTD}} \cdot \mathrm{Nup} 42^{\mathrm{GBM}}+\mathrm{IP}_{6}$

- $\mathrm{DDX} 19+\mathrm{Gle}^{\mathrm{CTD}} \cdot \mathrm{Nup} 42^{\mathrm{GBM}}+\mathrm{IP}_{6}$

- Gle $1^{{ }^{C T D} \cdot N u p 42^{\mathrm{GBM}} \text { no IP }}$

- DDX19+ Gle $1^{\text {CTD }} \cdot$ Nup42 $^{6}{ }^{\mathrm{GBM}}$ no $\mathrm{IP}_{6}$
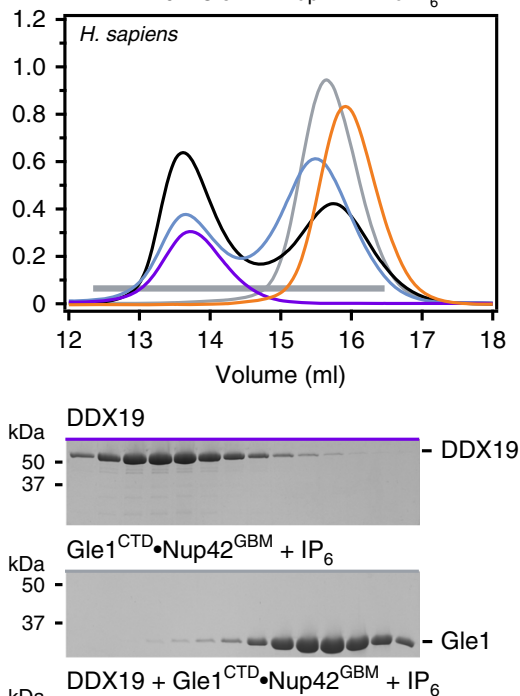

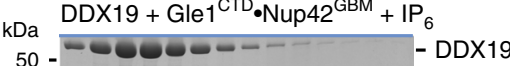

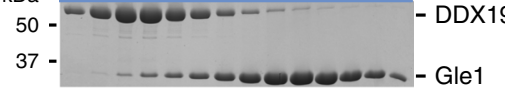

$\mathrm{kDa} \mathrm{Gle}^{\mathrm{CTD}} \cdot \mathrm{Nup}^{\mathrm{GBM}}$ no IP 6

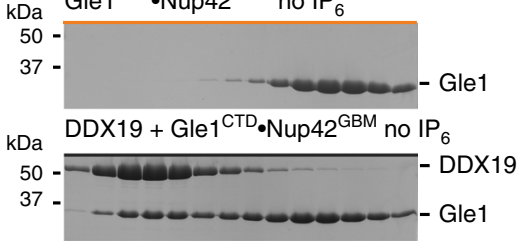


electrostatic potential in this pocket may be a general feature of metazoan Gle1 (Supplementary Fig. 12a). Although there are two positions in human Gle1 that contained lysine residues not present in the fungal proteins, sequence conservation analysis also indicated that the positively charged residues in Dbp5 that bind $\mathrm{IP}_{6}$ were not conserved in metazoans (Supplementary Fig. 12b). Combined, these structural observations raised the question of what roles Nup42 and $\mathrm{IP}_{6}$ had on the activation of human DDX19.

The roles of $\mathrm{IP}_{6}$ and Nup42 in DDX19/Dbp5 stimulation. To assess the role of $\mathrm{IP}_{6}$ in DDX19 activation, we first tested whether complex formation between human DDX19 and Gle1 was dependent on $\mathrm{IP}_{6}$ in SEC experiments. Consistent with previous reports, S. cerevisiae Dbp 5 and Gle ${ }^{\mathrm{CTD}} \cdot \mathrm{Nup} 42^{\mathrm{GBM}}$ only formed a complex in the presence of $\mathrm{IP}_{6}$ (Fig. $3 \mathrm{~g}$ ) ${ }^{10}$. The interaction between $C$. thermophilum Gle1 ${ }^{\mathrm{CTD}} \cdot \mathrm{Nup} 42^{\mathrm{GBM}}$ and Dbp5 also required $\mathrm{IP}_{6}$, consistent with the evolutionary conservation of the $\mathrm{IP}_{6}$ binding residues among fungi (Fig. 3h; Supplementary Fig. 12a). In contrast, complex formation of the human proteins did not require $\mathrm{IP}_{6}$, and the presence of $\mathrm{IP}_{6}$ instead partially reduced complex formation (Fig. 3i).

To directly test the effect of $\mathrm{IP}_{6}$ and Nup42 on Dbp5 and DDX19 activity, we measured steady-state ATP hydrolysis rates with an $\mathrm{NADH}$-coupled reaction using conditions identical to those previously reported ${ }^{41}$. Due to concerns that observed differences in activity were due to the stabilizing effects of $\mathrm{IP}_{6}$ and Nup42 on Gle1 rather than direct roles in Dbp5/DDX19 activation, we measured ATP hydrolysis rates at multiple temperatures to decouple the effects due to stabilization from bona fide stimulatory roles. Because human DDX19 was intrinsically less active than $S$. cerevisiae Dbp5, we used fivefold higher concentrations of human DDX19, Gle1 CTD , Nup42GBM, and $\mathrm{IP}_{6}$ to ensure accurate measurements of ATPase activity. Furthermore, because Dbp5 and DDX19 are slow ATPases, we developed extensive protein purification protocols to ensure all of the measured activity was directly attributable to Dbp5 or DDX19 (Supplementary Fig. 13a, b).

In the yeast system, and across a range of RNA concentrations, the addition of Nup $42^{\mathrm{GBM}}$ to Gle $1^{\mathrm{CTD}}$ increased Dbp5 activity at $37^{\circ} \mathrm{C}$, but this stimulatory effect was greatly diminished at $30^{\circ} \mathrm{C}$, a temperature below the $T_{\mathrm{m}}$ of Gle $1^{\mathrm{CTD}} \cdot \mathrm{IP}_{6}$, which is consistent with thermostability having a detectable effect in our assays (Fig. 4a, c; Supplementary Fig. 13c). Altogether, these data indicate that Nup42 $\mathrm{GBM}$ does not have a direct role in Dbp5 stimulation in the yeast system, but rather functions primarily to ensure Gle1 stability. In the yeast system, $\mathrm{IP}_{6}$ was required for full stimulation of Dbp5 at all temperatures tested, indicating that in addition to its ability to stabilize yeast Gle1 ${ }^{\text {CTD }}$, $\mathrm{IP}_{6}$ also has a direct role in Dbp5 stimulation (Fig. 4a; Supplementary Fig. 13c, d). These results are in agreement with the observation that stable association of Gle1 $1^{\text {TD }}$ and Dbp5 requires $\mathrm{IP}_{6}$ binding. In contrast, neither Nup42 ${ }^{\mathrm{GBM}}$ nor $\mathrm{IP}_{6}$ were stimulatory in the human system at either temperature we tested (Fig. 4b, d; Supplementary Fig. 13e).
Because differences in the $\mathrm{IP}_{6}$ binding pocket in human Gle1 and DDX19 could have weakened the affinity for $\mathrm{IP}_{6}$ rather than completely abolishing binding, we tested whether higher concentrations of $\mathrm{IP}_{6}$ would stimulate DDX19. $\mathrm{IP}_{6}$ stimulated Dbp5 activity in a dose-dependent manner that saturated at $1 \mu \mathrm{M}$ (twice the Dbp5 concentration), but had no effect on human DDX19 activity up to concentrations of $100 \mu \mathrm{M}$, which is an upper estimate for the total (bound and free) $\mathrm{IP}_{6}$ concentration in human cells (Fig. $4 \mathrm{e})^{42}$. Additionally, $\mathrm{IP}_{6}$ bound tightly to $S$. cerevisiae Gle $1^{\mathrm{CTD}} \cdot \mathrm{Nup} 42^{\mathrm{GBM}}$ in isothermal titration calorimetry experiments (ITC) with a dissociation constant $\left(K_{\mathrm{d}}\right)$ of $\sim 3 \mathrm{nM}$. However, no binding of $\mathrm{IP}_{6}$ to human Gle $1^{\mathrm{CTD}} \cdot \mathrm{Nup} 42^{\mathrm{GBM}}$ was detected up to concentrations of $200 \mu \mathrm{M}$ (Supplementary Fig. 14). Taken together, our results indicate that $\mathrm{IP}_{6}$ binding is conserved in fungi but not in humans. Moreover, sequence analysis of other metazoan Gle1 and DDX19 sequences suggests that $\mathrm{IP}_{6}$ binding may not be a feature of metazoan DDX19 activation in general, as $\mathrm{IP}_{6}$-binding residues are not present in a diverse array of metazoan sequences (Supplementary Fig. 12a). These results do not exclude the possibility that another small molecule may serve a similar function in humans as $\mathrm{IP}_{6}$ does in fungi. However, unlike their fungal homologs, the human proteins alone are sufficient for complex formation.

Structural basis for $\mathrm{IP}_{6}$-independent human DDX19 activation. To understand the structural basis for $\mathrm{IP}_{6}$-independent DDX19 activation, we determined crystal structures of human Gle1 ${ }^{\text {CTD }} \cdot$ Nup $42^{\mathrm{GBM}}$ in complex with DDX19 in the presence of ADP or AMP-PNP• $\mathrm{Mg}^{2+}$ at 3.6 and $3.4 \AA$ resolution, respectively (Fig. 5a, d; Supplementary Table 3). Previous structural studies have revealed that DDX19 possesses an auto-inhibitory helix Nterminal to DDX19 ${ }^{\text {NTD }}$ (residues 54-67) that can bind between DDX19 $19^{\text {TTD }}$ and DDX19CTD, preventing RNA binding or formation of a catalytically competent active site ${ }^{43}$. This helix appears to be conserved among metazoan DDX19 sequences, but is absent in their fungal Dbp5 homologs (Supplementary Fig. 15). Therefore, we used a construct of DDX19 that contained the Nterminal auto-inhibitory helix but did not contain the flexible $\mathrm{N}$ terminal extension (DDX19 ${ }^{\Delta \mathrm{N} 53}$, residues 54-479). In addition, we determined the crystal structure of apo DDX19 ${ }^{\triangle \mathrm{N} 53}$ (AMP$\mathrm{PNP} \cdot \mathrm{Mg}^{2+}$ ) at $2.2 \AA$ resolution (Supplementary Fig. 16a; Supplementary Table 3 ).

The heterotrimeric Gle1 ${ }^{\mathrm{CTD}} \cdot \mathrm{Nup} 42^{\mathrm{GBM}} \cdot \mathrm{DDX} 19^{\Delta \mathrm{N} 53}$ complex exhibited similar conformations in the presence of ADP or AMPPNP $\bullet \mathrm{Mg}^{2+}$, with the auto-inhibitory helix still bound between DDX19 ${ }^{\text {NTD }}$ and DDX19 ${ }^{\mathrm{CTD}}$ (Fig. 5a, d). The surprising observation that AMP-PNP-bound DDX19 could also adopt the auto-inhibited conformation was confirmed by the structure of apo DDX19 ${ }^{\Delta \mathrm{N} 53}\left(\mathrm{AMP}-\mathrm{PNP} \cdot \mathrm{Mg}^{2+}\right)$, which adopted an identical conformation as apo DDX19 ${ }^{\triangle \mathrm{N} 53}$ (ADP) (Supplementary Fig. 16a $)^{43}$. The inhibited state does not differ structurally in the presence of ADP or ATP, as the nucleotide-binding pocket readily accommodates the additional phosphate and $\mathrm{Mg}^{2+}$ ion, with minor changes in the sidechain conformations of K64 from

Fig. 3 Human Gle1 ${ }^{C T D}$ binding to DDX19 is $\mathrm{IP}_{6}$ independent. a-c Zoom view of the IP 6 binding pocket of a S. cerevisiae, $\mathbf{b}$ C. thermophilum, or $\mathbf{c} H$. sapiens Gle ${ }^{\text {CTD }}$. Residues that are conserved in fungi but not metazoans are highlighted in red. See also Supplementary Figs. 7 and 12 . d-f Surface electrostatic potential analysis of $\mathrm{IP}_{6}$ binding pockets for $\mathbf{d} \mathrm{S}$. cerevisiae, $\mathbf{e}$. thermophilum, or $\mathbf{f} H$. sapiens Gle1. The same view as $\mathbf{a}-\mathbf{c}$ is shown in surface representation colored by electrostatic potential, from red $\left(-10 \mathrm{k}_{B} T / \mathrm{e}\right)$ to white $\left(0 \mathrm{k}_{\mathrm{B}} \mathrm{T} / \mathrm{e}\right)$ to blue $\left(+10 \mathrm{k}_{\mathrm{B}} \mathrm{T} / \mathrm{e}\right)$, revealing a dramatically reduced electrostatic potential for human Gle1 ${ }^{\mathrm{CTD}}$. See also Supplementary Figs. 5, 10, and 11. $\mathbf{g}-\mathbf{i}$ SEC analysis of the interaction between Dbp5/DDX19 and Gle1 ${ }^{\mathrm{CTD}} \cdot \mathrm{Nup} 42^{\mathrm{GBM}}$ for $\mathbf{g}$ S. cerevisiae, $\mathbf{h}$ C. thermophilum, or $\mathbf{i} H$. sapiens, in the presence or absence of $\mathrm{PP}_{6}$. The elution profiles for Dbp5/DDX19 are shown in purple,

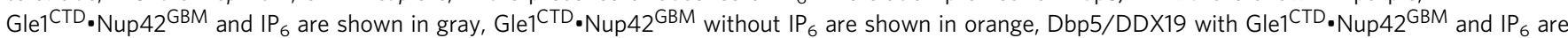
shown in light blue, and Dbp5/DDX19 with Gle1 ${ }^{\mathrm{CTD}} \cdot \mathrm{Nup} 42^{\mathrm{GBM}}$ without $\mathrm{IP}_{6}$ are shown in black. Fungal Gle1 ${ }^{\mathrm{CTD}} \cdot \mathrm{Nup} 42^{\mathrm{GBM}}$ interacts strongly with the Superdex matrix in the absence of $\mathrm{IP}_{6}$. The gray horizontal bar indicates fractions visualized with Coomassie-stained SDS-PAGE gels shown below 
the auto-inhibitory helix and E243 in the nucleotide binding pocket (Supplementary Fig. 16b).

The Gle1 ${ }^{\text {CTD }}$-DDX19 $19^{\text {TD }}$ interface involves 40 Gle1 and 35 DDX19 residues to generate an interaction interface area of almost $1300 \AA^{2}$ (Supplementary Fig. 10). As in the yeast complex, the human Nup42 GBM and DDX19 binding sites are on opposite sides of the Gle1 ${ }^{\text {CTD }}$ molecule (Fig. 5a). Most of the solvent exposed residues in helices $\alpha 2$ and $\alpha 4$ from Gle 1 CTD are buried by the interaction involving two major interaction interfaces (Fig. 5b, c). In the first interface (interface 1), Gle1 ${ }^{\mathrm{CTD}}$ residues of helix $\alpha 4$ (H495, E491, and Q487) form an extensive hydrogen bond network with each other and DDX19 ${ }^{\mathrm{CTD}}$ main chain atoms

a

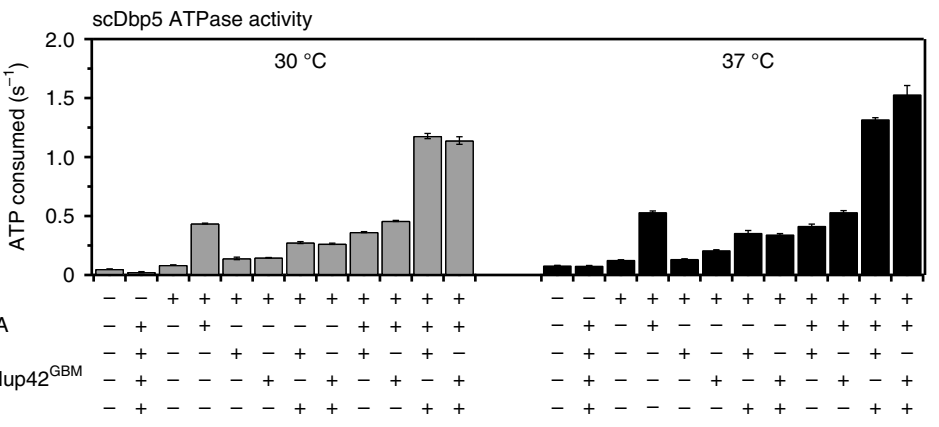

b
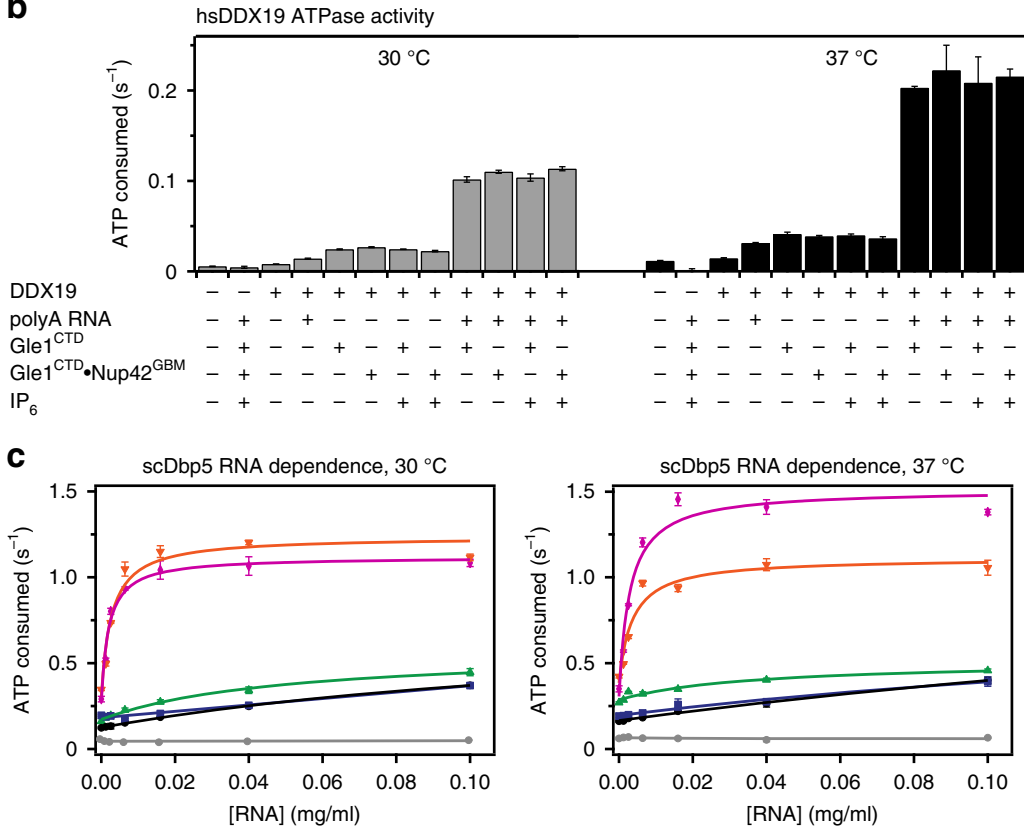

$\mathrm{Dbp} 5+\mathrm{Gle}^{\mathrm{CTD}} \cdot \mathrm{Nup} 42^{\mathrm{GBM}}+\mathrm{IP}_{6}$

$\mathrm{Dbp} 5+\mathrm{Gle}^{\mathrm{CTD}}+\mathrm{IP}_{6}$

- $\mathrm{Dbp} 5+\mathrm{Gle}^{\mathrm{CTD}} \cdot \mathrm{Nup} 42^{\mathrm{GBM}}$

$\mathrm{Dbp} 5+\mathrm{Gle} 1^{\mathrm{CTD}}$

- Dbp5

No Dbp5 control

d

hsDDX19 RNA dependence, $30^{\circ} \mathrm{C}$

$$
\text { To }
$$

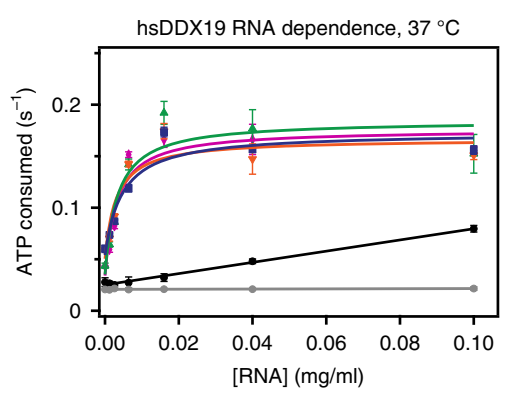

- $\mathrm{DDX} 19+\mathrm{Gle}^{\mathrm{CTD}} \cdot \mathrm{Nup} 42^{\mathrm{GBM}}+\mathrm{IP}_{6}$

$\checkmark \mathrm{DDX} 19+\mathrm{Gle} 1^{\mathrm{CTD}}+\mathrm{IP}$

DDX19+ Gle $1^{\mathrm{CTD}} \cdot \mathrm{Nup} 42^{\mathrm{GBM}}$

- DDX19+ Gle1 ${ }^{\mathrm{CTD}}$

- DDX19
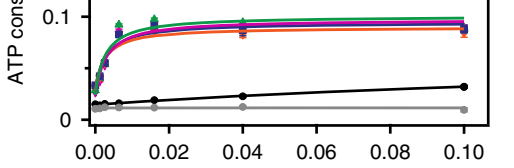

[RNA] (mg/ml)
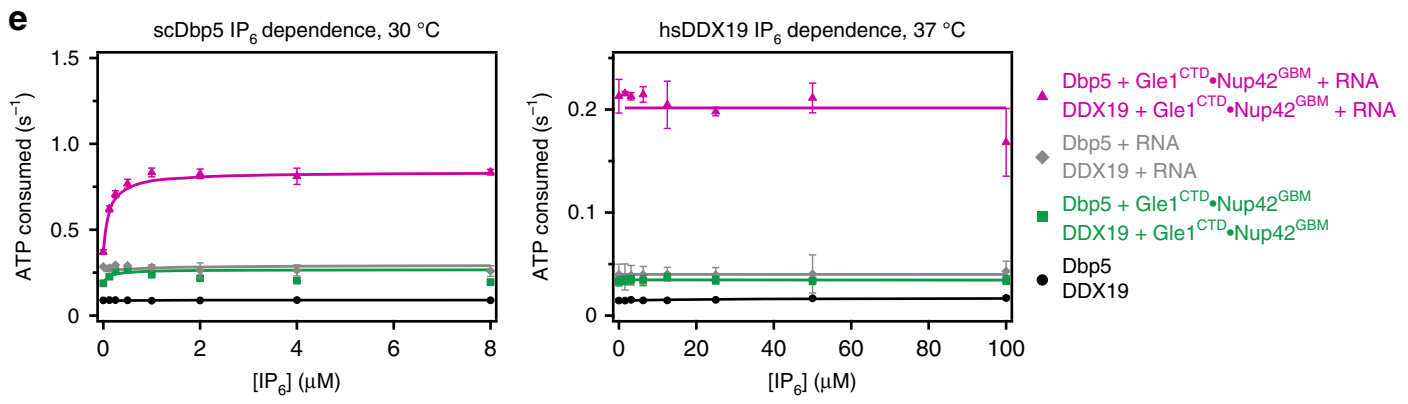
(residues 380-382), as well as a salt bridge between Gle1 ${ }^{\text {CTD }}$ residue $\mathrm{E} 491$ and $\mathrm{DDX} 19^{\mathrm{CTD}}$ residue $\mathrm{K} 385$ (Fig. 5b). In the second interface (interface 2), the acidic C-terminal helix of DDX $19^{\text {CTD }}$ is recognized by lysines on the Gle ${ }^{\text {CTD }}$ surface, with salt bridges forming between DDX19 ${ }^{\mathrm{CTD}}$ residues D470, D472, and E475 and Gle1 ${ }^{\mathrm{CTD}}$ residues K416, K419, and K479 (Fig. 5c). In several instances, DDX19 ${ }^{\text {CTD }}$ residues (G329, T332, A334, and L471) packed directly against Gle ${ }^{\mathrm{CTD}}$ helices, interdigitating between the sidechains to form hydrophobic interactions (Fig. 6b). Single amino acid substitutions in Gle $1^{\mathrm{CTD}}$ at these interfaces were sufficient to disrupt Gle ${ }^{\mathrm{CTD}}$-mediated stimulation of DDX19 (Fig. 5e).

We next searched for the structural differences between the human and yeast complexes that allow the human complex to form in the absence of $\mathrm{IP}_{6}$ (Fig. 5f). In the structure of $S$. cerevisiae Gle $1^{\mathrm{CTD}} \cdot \mathrm{IP}_{6} \cdot \mathrm{Dbp} 5^{\triangle \mathrm{N} 90}(\mathrm{ADP})$, the interface between Gle $1^{\text {CTD }}$ and Dbp5 ${ }^{\mathrm{CTD}}$ is only $700 \AA^{2}$ in surface area, compared to $\sim 1300 \AA^{2}$ for the human complex, a difference compensated for in yeast through extensive contacts made by both proteins with a bridging $\mathrm{IP}_{6}$ molecule (Supplementary Figs. 5a, 10a). For a summary of differences, see Supplementary Note 4. These observed structural differences result in a dramatic reduction of the local electrostatic potential at the human Gle1 CTD - DDX $19^{\text {CTD }}$ interface compared to the yeast Gle1 ${ }^{\text {CTD }}$ -DDX19 ${ }^{\text {CTD }}$ interface (Supplementary Fig. 17a, b). Thus, for $S$. cerevisiae Dbp5 activation, the extreme negative charge of the $\mathrm{IP}_{6}$ molecule would be necessary to overcome the electrostatic repulsion generated in forming such a positively charged pocket, but for human DDX19 this requirement no longer exists. To test whether $\mathrm{IP}_{6}$ was indeed unable to bind, we also determined crystal structures of the human Gle1 ${ }^{\mathrm{CTD}} \cdot \mathrm{Nup} 42^{\mathrm{GBM}}$. DDX19 ${ }^{\Delta \mathrm{N} 53}$ complex grown in the presence of $\mathrm{IP}_{6}$ or soaked with $\mathrm{IP}_{6}$, but observed no electron density for $\mathrm{IP}_{6}$ in these crystals (Supplementary Fig. 17d, e; Supplementary Table 4).

To gain further insight into how Gle1 ${ }^{\text {CTD }}$.Nup $42^{\mathrm{GBM}}$ binding facilitates DDX19 activation, we compared the structures of Gle1 ${ }^{\mathrm{CTD}} \cdot \mathrm{Nup} 42^{\mathrm{GBM}} \cdot \mathrm{DDX} 19^{\triangle \mathrm{N} 53}$ to those of apo DDX19 ${ }^{\Delta \mathrm{N} 53}$. The most apparent difference was a rotation of both DDX19NTD and the auto-inhibitory helix away from DDX $19^{\mathrm{CTD}}$, despite the auto-inhibitory helix still being bound between the two domains (Fig. 6a). In the structure of $S$. cerevisiae Gle ${ }^{\mathrm{CTD}} \cdot \mathrm{IP}_{6} \cdot \mathrm{Dbp} 5^{\mathrm{AN} 90}(\mathrm{ADP}), \mathrm{Dbp} 5^{\mathrm{NTD}}$ is rotated even further away from Dbp5 $5^{\mathrm{CTD}}$ leading Dbp5 $5^{\mathrm{NTD}}$ to also contact Gle 1 CTD (Fig. 5f ${ }^{10}$. In yeast, a Gle ${ }^{C T D}$ triple amino acid substitution (V513D/A516D/I520D) at the Dbp5 ${ }^{\text {NTD }}$ binding interface abolishes Gle1-mediated stimulation of $\mathrm{Dbp} 5^{10}$. A homologous triple amino acid substitution in human Gle1 ${ }^{\mathrm{CTD}}$ (G666D/I669D/ Q673D, DDD mutant) similarly abolished Gle1 ${ }^{C T D}$-mediated stimulation of DDX19, suggesting that the human proteins can also form the fully rotated conformation observed for the $S$. cerevisiae complex (Supplementary Fig. 13f). Therefore, we considered our structure as an early intermediate state that forms immediately after Gle1 ${ }^{\text {CTD }}$ binding to DDX19, but before release of the auto-inhibitory helix and separation of DDX19 NTD and DDX19CTD.
We next searched for the conformational changes in DDX19 ${ }^{C T D}$ that might explain how Gle1 ${ }^{\text {CTD }}$-binding would stimulate ATPase activity. Several differences could be attributed to Gle $1^{\mathrm{CTD}}$ binding, including contacts causing ordering of the Cterminal helix and rearrangement of the trigger loop (residues 328-335) (Fig. 6a, b). Through direct interactions between neighboring residues and relief of steric constraints, these changes propagated to the adjacent anchor loop (residues 390-403) (Fig. 6a, b). Remodeling of the anchor loop removes contacts between DDX19 ${ }^{\mathrm{CTD}}$ and the auto-inhibitory helix, resulting in partial separation of DDX $19^{\text {NTD }}$ and DDX19CTD (Fig. 6c). Remodeling of the anchor loop also results in ordering of a loop containing ATP-binding residues in DEAD-box motif VI (Fig. 6d). For details, see Supplementary Note 5. In summary, Gle ${ }^{\text {CTD }}$ binding to DDX19CTD causes a cascade of conformational changes that partially releases the auto-inhibitory helix and prepares the residues involved in nucleotide binding to form the closed, active conformation.

Human Gle1•Nup42 relieves auto-inhibition. Our structural data are consistent with a mechanism wherein relief from inhibition by the N-terminal auto-inhibitory helix is one of the primary mechanisms for Gle1 ${ }^{\text {CTD }}$ stimulation of DDX19 activity. Removal of the N-terminal 90 residues of S. cerevisiae Dbp5 increases unstimulated Dbp5 activity, but does not increase Gle1stimulated activity ${ }^{10}$. Similarly, removal of the N-terminal 53 residues also increased DDX19 activity, but activity in the presence of Gle ${ }^{\text {CTD }}$ could not be examined ${ }^{43}$. To obtain a better understanding of the role of various regulatory elements in the $\mathrm{N}$ terminal region of human DDX19, we tested the activation of a series of truncation variants that included $\mathrm{DDX} 19^{\Delta \mathrm{N} 53}$, DDX19 ${ }^{\Delta \mathrm{N} 67}, \mathrm{DDX} 19^{\Delta \mathrm{N} 91}$, and a variant of full-length DDX19, DDX19 $160 \mathrm{D} / \mathrm{K} 64 \mathrm{D}$, containing two aspartate substitutions in the auto-inhibitory helix that would disrupt the inhibited state (Supplementary Fig. 18a; See Supplementary Note 6 for a detailed description of variants).

All four variants had higher basal ATPase activity than wildtype DDX19, consistent with inhibitory roles for the disrupted sequences (Fig. 7a). Removal of the entire unstructured $\mathrm{N}$ terminal extension, DDX19 ${ }^{\Delta \mathrm{N} 53}$, yielded $\sim 2.5$-fold higher basal ATPase activity, which was similar to the reported $\sim 3$-fold higher basal ATPase activity upon removal of the entire Dbp5 $\mathrm{N}$ terminal extension (Fig. 7a) ${ }^{10}$. Further N-terminal truncations, DDX $19^{\Delta \mathrm{N} 67}$ and DDX19 ${ }^{\Delta \mathrm{N} 91}$, as well as the DDX19 $60 \mathrm{D} / \mathrm{K} 64 \mathrm{D}$ double amino acid substitution, exhibited $\sim 7.5$-fold higher basal activity (Fig. 7a). Strikingly, in contrast to wild-type DDX19, the activity of all four DDX19 variants was not stimulated by Gle1 ${ }^{\mathrm{CTD}} \cdot \mathrm{Nup} 42^{\mathrm{GBM}}$, but instead was inhibited to an activity level comparable to wild-type DDX19 (Fig. 7a). Moreover, RNA stimulated DDX19 activity in the absence of Gle1 $1^{\mathrm{CTD}} \cdot \mathrm{Nup} 42^{\mathrm{GBM}}$ for the DDX19 variants, yielding rates between $\sim 2$-fold to $\sim 10$ fold faster than wild-type DDX19 (Fig. 7a). For wild-type DDX19, addition of both RNA and Gle1 ${ }^{\text {TTD }}$-Nup42 $42^{\mathrm{GBM}}$ resulted in greater stimulation than either alone. However, for the variants

Fig. 4 Role of Nup42, RNA, and IP 6 in Dbp5/DDX19 activation. a Steady-state colorimetric ATPase assay with S. cerevisiae Dbp5 performed at 30 and $37^{\circ}$ $\mathrm{C}$ with either purified S. cerevisiae Gle1 ${ }^{\mathrm{CTD}}$ or Gle1 $1^{\mathrm{CTD}} \cdot \mathrm{Nup} 42^{\mathrm{GBM}}$. Reactions were performed with $0.5 \mu \mathrm{M}$ Dbp5, $1.0 \mu \mathrm{M}$ Gle $1^{\mathrm{CTD}}$ or Gle1 $1^{\mathrm{CTD}} \cdot \mathrm{Nup} 42^{\mathrm{GBM}}$, $0.1 \mathrm{mg} / \mathrm{ml}$ polyA RNA, and $2.0 \mu \mathrm{M} \mathrm{IP}_{6}$. Values shown are the average of three experiments. Error bars indicate the standard deviation. See also Supplementary Fig. 13. b Steady-state colorimetric ATPase assay with $\mathrm{H}$. sapiens DDX19 performed at 30 and $37^{\circ} \mathrm{C}$ with either purified $\mathrm{H}$. sapiens Gle $1^{\mathrm{CTD}}$ or Gle $1^{\mathrm{CTD}} \cdot \mathrm{Nup}_{2} 2^{\mathrm{GBM}}$. Reactions were performed with $2.5 \mu \mathrm{M}$ DDX19, $5.0 \mu \mathrm{M}$ Gle1 ${ }^{\mathrm{CTD}}$ or Gle1 $1^{\mathrm{CTD}} \cdot \mathrm{Nup}_{2} 2^{\mathrm{GBM}}, 0.1 \mathrm{mg} / \mathrm{ml}$ polyA RNA, and $10.0 \mu \mathrm{M}$ IP 6 . Values shown are the average of three experiments. Error bars indicate the standard deviation. See also Supplementary Fig. 13. c RNA dependence of $S$. cerevisiae Dbp5 activation using the same conditions as in a, but with the indicated amounts of RNA performed at 30 and $37^{\circ} \mathrm{C}$. d RNA dependence of $\mathrm{H}$. sapiens DDX19 activation using the same conditions as in $\mathbf{b}$, but with the indicated amounts of RNA performed at 30 and $37^{\circ} \mathrm{C}$. e IP ${ }_{6}$ dependence of (left) S. cerevisiae Dbp5 or (right) H. sapiens DDX19 activation using the same conditions as in $\mathbf{a}$ or $\mathbf{b}$, respectively, but with the indicated amounts of IP 6 
that perturbed the auto-inhibitory helix, addition of both RNA and Gle1 ${ }^{\mathrm{CTD}} \cdot \mathrm{Nup} 42^{\mathrm{GBM}}$ yielded only a barely detectable further stimulation over RNA-mediated levels, resulting in fully stimulated activities $\sim 2$ - to 3-fold faster than wild-type DDX19 (Fig. 7a). In contrast, the truncation variant that still possessed an intact auto-inhibitory helix, DDX19 $9^{\Delta \mathrm{N} 53}$, exhibited a $\sim 2$-fold slower fully stimulated activity than wild-type.
These data explain several features of DDX19 activation. First, although human DDX19 has 7.5-fold lower ATPase activity than Dbp5, a large part of this difference can be attributed to the auto-inhibitory helix present in human DDX19 but not yeast Dbp5, as disruption of this helix yields activities only $\sim 3$-fold slower than fully stimulated Dbp5. Second, the N-terminal 53 residues of DDX19 that precede the auto-inhibitory helix have a a

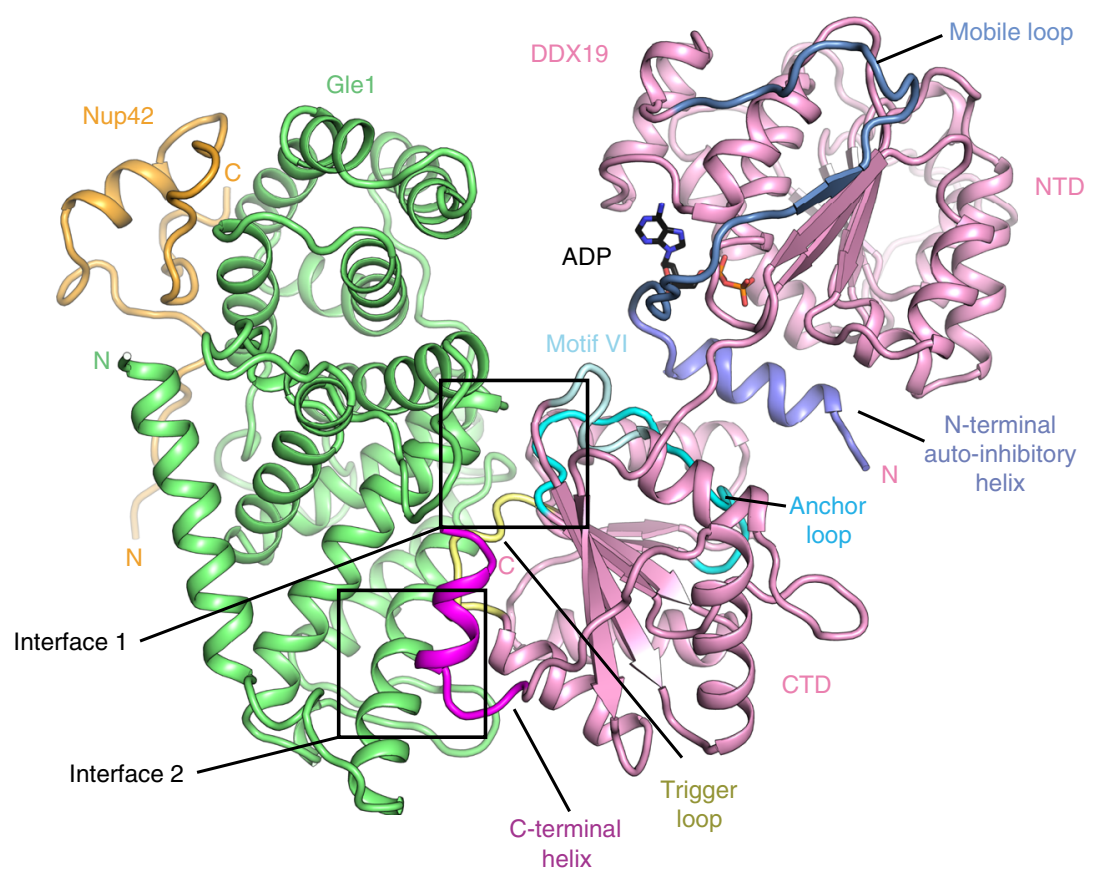

d

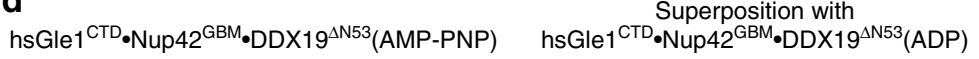

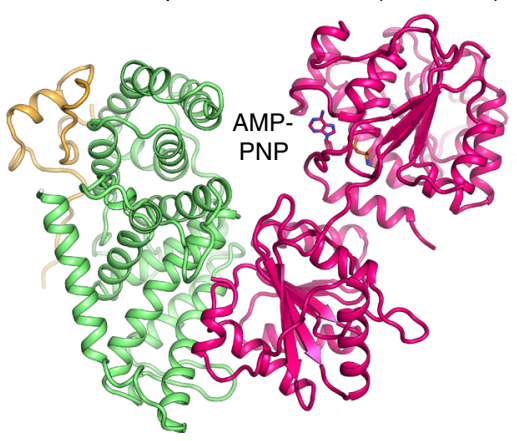

f

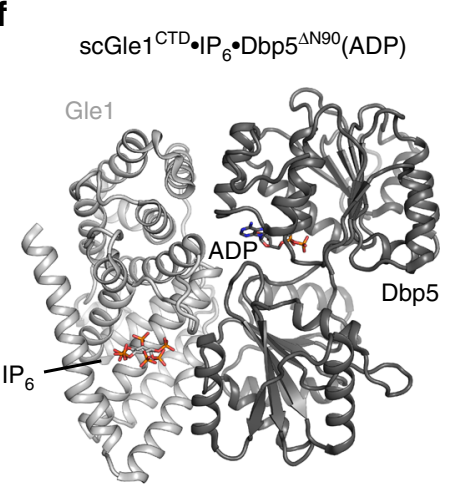

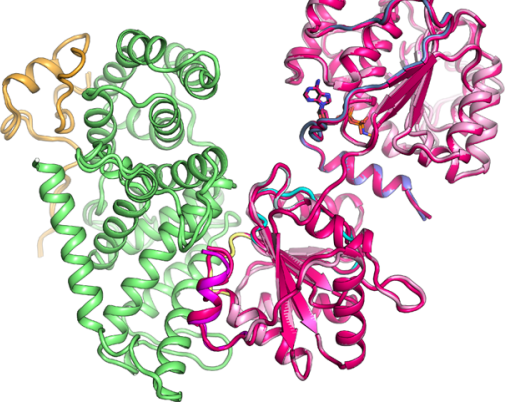

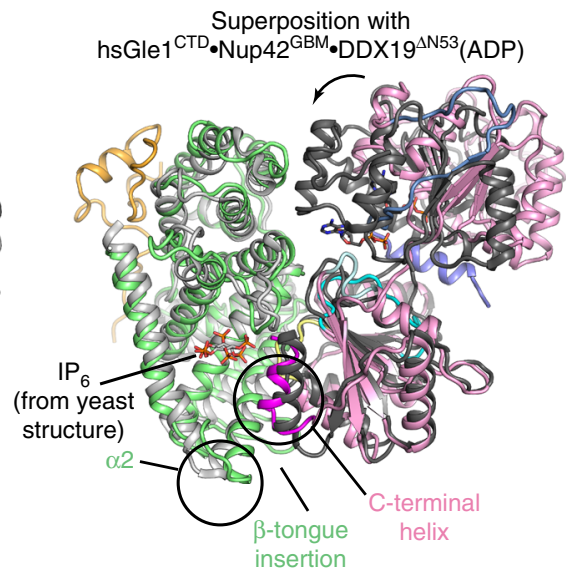

b

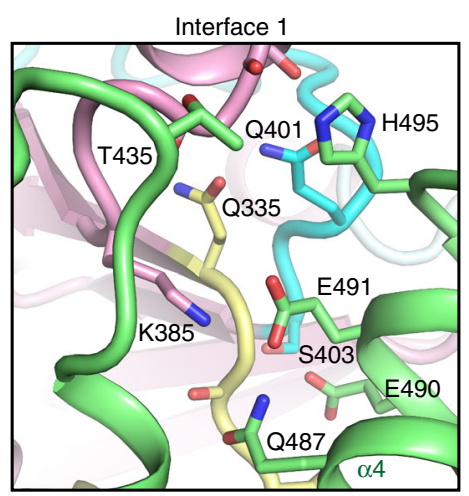

C

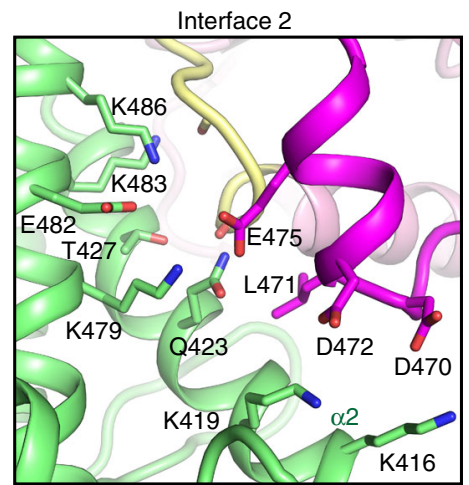

e

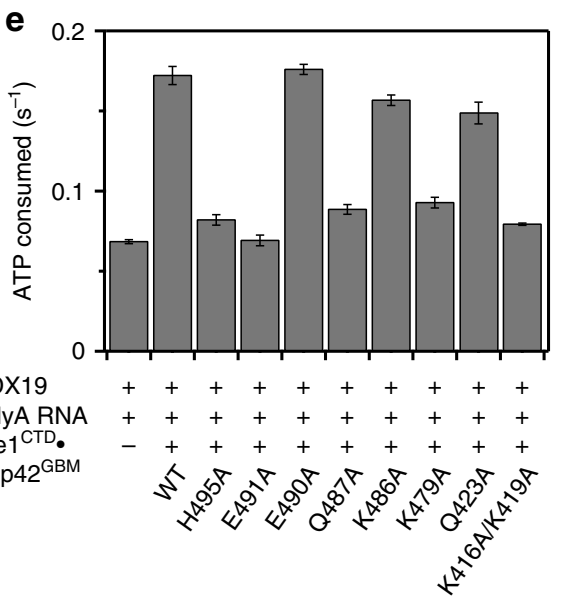


subtle but distinct role, possibly similar to the role of the $\mathrm{N}$ terminal residues in yeast Dbp5. Lastly, the weak Gle1-mediated stimulation of the hyperactive variants in the presence of RNA suggests that relief from auto-inhibition is indeed a major mechanism for Gle1-mediated stimulation.

Human Nup214 is stimulatory in the presence of Gle1. We next analyzed the effect of the nucleoporin and mRNA export factor Nup214 on DDX19 activation in the context of Gle1 ${ }^{\mathrm{CTD}}$-Nup42 ${ }^{\mathrm{GBM}}$ stimulation. Nup214 ${ }^{\mathrm{NTD}}$ binds to DDX $19^{\text {NTD }}$ via an interface that partially overlaps with the RNA binding interface, and consequently, binding of Nup214 ${ }^{\mathrm{NTD}}$ to DDX19 $19^{\text {NTD }}$ impairs RNA binding and RNA-mediated stimulation of DDX19 ATPase activity ${ }^{14,15}$. In yeast, Nup214 ${ }^{\text {NTD }}$ enhances ADP release from Dbp5 but the consequence of this effect is unclear, as Gle1 ${ }^{\mathrm{CTD}}$ stimulates Dbp5 to the same activity levels in the presence and absence of Nup214 $4^{\mathrm{NTD} 10,44}$.

In the human system, addition of Nup214 ${ }^{\mathrm{NTD}}$ did not affect basal DDX19 ATPase activity or activity in the presence of Gle1 ${ }^{\mathrm{CTD}} \cdot \mathrm{Nup} 42^{\mathrm{GBM}}$ (Fig. 7b). Consistent with previous reports, Nup214 ${ }^{\text {TTD }}$ inhibited RNA-mediated stimulation (Fig. 7b) ${ }^{14,15}$. However, when DDX19 was stimulated by both Gle1 ${ }^{\mathrm{CTD}} \cdot \mathrm{Nup} 42^{\mathrm{GBM}}$ and RNA, the addition of Nup214 ${ }^{\mathrm{NTD}}$ further increased ATPase activity (Fig. 7b). This effect was concentration dependent and more pronounced when Gle1 ${ }^{\mathrm{CTD}}$ Nup42 ${ }^{\mathrm{GBM}}$ was present in substoichiometric amounts (Fig. 7c). Thus, unlike what was found for the yeast system, Nup214 ${ }^{\text {NTD }}$ can have a stimulatory effect in the context of Gle1-mediated DDX19 stimulation ${ }^{10}$. We next utilized an electrophoretic mobility shift assay to probe the effects of Gle1 ${ }^{\mathrm{CTD}} \cdot \mathrm{Nup} 42^{\mathrm{GBM}}$ and Nup214 NTD on RNA binding by DDX19. Whereas Gle1 ${ }^{\mathrm{CTD}}$-Nup42GBM enhanced DDX19 binding to RNA, Nup214 ${ }^{\text {NTD }}$ inhibited DDX19 binding to a 53-nucleotide single-stranded RNA (Fig. 7d). However, Gle1 ${ }^{\mathrm{CTD}} \cdot \mathrm{Nup} 42^{\mathrm{GBM}}$ rescued RNA binding in the presence of Nup214 2 NTD , consistent with its ability to rescue DDX19 from Nup214 ${ }^{\mathrm{NTD}}$ inhibition (Fig. 7b, d). Thus, Nup214 not only recruits DDX19 to the cytoplasmic face of the NPC, but can also play an active role in promoting DDX19 ATPase activity (See Supplementary Note 7).

Human disease mutations in Gle1. Several human diseases have been linked to Gle1 dysfunction, including ALS, Huntington's disease, and the related disorders LCCS1 and LAAHD, which lead to spinal cord motor neuron atrophy and premature death, often prior to birth ${ }^{30,33,34}$. For ALS and LCCS1/LAAHD, specific mutations have been mapped to Gle1 ${ }^{\text {CTD }}$. In ALS, three mutations have been associated with Gle1: a nonsense mutation that results in a truncated protein after residue 70 , a splice site mutation that replaces the C-terminal 44 residues of Gle 1 CTD with a novel 88-residue sequence, and a missense mutation leading to the amino acid substitution R697C $\mathrm{C}^{34}$. LCCS1 and LAAHD are related disorders, in which the more phenotypically severe LCCS1 patients are typically homozygous for a 3-residue insertion at position 144 in the coiled-coil region of Gle1 $\left(\right.$ Fin $\left._{\text {Major }}\right)$ and the less phenotypically severe LAAHD patients are compound heterozygous for the Fin $_{\text {Major }}$ mutation and a mutation in Gle1 ${ }^{\mathrm{CTD}}$ (V617M and I684T) ${ }^{33}$. The $\mathrm{R} 569 \mathrm{H}$ variant in Gle1 ${ }^{\mathrm{CTD}}$ was identified in a patient diagnosed with the more severe LCCS1, suggesting it has a more potent effect than the $\mathrm{V} 617 \mathrm{M}$ and I684T variants.

When mapped onto the structure of Gle1 ${ }^{\mathrm{CTD}} \cdot \mathrm{Nup} 42^{\mathrm{GBM}} \cdot \mathrm{DDX} 19^{\Delta \mathrm{N} 53}$, none of the four amino acid substitutions directly participated in binding to Nup42 or DDX19 (Fig. 7e; Supplementary Fig. 19a-d). We next evaluated the Gle1 ${ }^{\mathrm{CTD}}$-Nup42 ${ }^{\mathrm{GBM}}$ variants for thermostability and ability to stimulate DDX19. All three LCCS1/LAAHD mutations possessed altered thermostability that correlated with their phenotypic disease manifestation, with the $\mathrm{R} 569 \mathrm{H}$ variant exhibiting the largest difference in $T_{\mathrm{m}}$, from $50^{\circ} \mathrm{C}$ for wild-type protein to $40^{\circ} \mathrm{C}$ for the disease variant (Fig. $7 \mathrm{f}$ ). In contrast, there were no substantial defects in ATPase stimulation for any of the disease variants (Fig. 7g). In our crystal structures, R569 is involved in an extensive network of intra-molecular interactions (Supplementary Fig. 19a), whereas V617 and I684 are both buried in hydrophobic cores (Supplementary Fig. 19b, c), supporting the conclusion that these mutations reduce the stability of Gle1 rather than affecting their ability to stimulate the activity of DDX19. Future work will need to address whether Gle1 stability is also a contributing factor in human disease.

\section{Discussion}

Using an interdisciplinary approach, we have garnered insight into the mRNA export events that occur at the cytoplasmic face of the NPC. Gle1 ${ }^{\mathrm{CTD}}$ plays an important organizational role by providing spatially separated binding sites for Nup $42^{\mathrm{GBM}}$ and the DEAD-box helicase DDX19/scDbp5. Strikingly, the Gle ${ }^{\mathrm{CTD}} \cdot \mathrm{Nup} 42^{\mathrm{GBM}}$ interaction mechanism is virtually identical in species separated by more than a billion years of evolution. A comprehensive structure-function analysis of DDX19 indicates that binding of Gle $1^{\mathrm{CTD}} \cdot$ Nup $42^{\mathrm{GBM}}$ induces a conformational change in DDX19, thereby stimulating its ATPase activity. Biochemical analyses of Glel variants associated with human disease suggest that nucleoporin stability is a contributing factor in motor neuron disease.

While this paper was in revision, another group reported that both Nup42 and $\mathrm{IP}_{6}$ directly affect Gle1-mediated DDX19 stimulation ${ }^{45}$. Informed by our studies of Gle1 $1^{\text {CTD }}$ thermostability, we attribute the observed stimulation by Nup $42^{\mathrm{GBM}}$ to its role in increasing Gle ${ }^{\mathrm{CTD}}$ stability, rather than a direct role in activation. In the yeast system, we also observed apparent stimulation by Nup $42^{\mathrm{GBM}}$ at $37^{\circ} \mathrm{C}$, which is the temperature used in the other study ${ }^{46}$. However, our thermostability experiments indicate that at $37^{\circ} \mathrm{C}$, Gle $1^{\mathrm{CTD}}$ solubility is compromised (Fig. 2b). In contrast, stimulation by $\mathrm{Nup}_{4} 2^{\mathrm{GBM}}$ at $30^{\circ}$ C was largely undetectable (Supplementary Fig. 13c). This conclusion is further supported by examination of the crystal

Fig. 5 Structure of the human Gle1 ${ }^{\mathrm{CTD}} \cdot \mathrm{Nup} 42^{\mathrm{GBM}} \cdot \mathrm{DDX} 19^{\Delta \mathrm{N} 53}$ complex. a Crystal structure of $H$. sapiens Gle1 ${ }^{\mathrm{CTD}} \cdot \mathrm{Nup} 42^{\mathrm{GBM}} \cdot \mathrm{DDX} 19^{\Delta \mathrm{N} 53}(\mathrm{ADP})$. Motifs of interest are colored and labeled: auto-inhibitory helix (residues 54-67, purple); mobile loop (residues 68-91, blue); trigger loop (residues 328-335, yellow); anchor loop (residues 390-403, cyan); motif VI (residues 429-435, light cyan); C-terminal helix (residues 468-479, magenta). Boxes indicate the regions shown to the right. b, c Close-up views of critical complex-forming interactions in interfaces 1 and 2 . $\mathbf{d}$ Left: crystal structure of $H$. sapiens Gle1 ${ }^{\mathrm{CTD}} \cdot \mathrm{Nup} 42^{\mathrm{GBM}} \cdot \mathrm{DDX} 19^{\Delta \mathrm{N} 53}\left(\mathrm{AMP}-\mathrm{PNP} \cdot \mathrm{Mg}^{2+}\right.$ ). DDX19 is colored magenta for clarity. Right: Superposition of the ADP and AMP-PNP・Mg${ }^{2+}$ bound structures. e Analysis of the effect of single amino acid substitutions in the Gle1-DDX19 interface on Gle1-mediated stimulation of DDX19, using the same conditions as in Fig. $4 \mathrm{~b}$ at $37^{\circ} \mathrm{C}$. Values shown are the average of three experiments. Error bars indicate standard deviation. $\mathbf{f}$ Left: crystal structure of $S$. cerevisiae Gle1 ${ }^{C T D} \cdot I_{6} \cdot D_{b p} 5^{\Delta N 90}(A D P)(P D B ~ I D ~ 3 R R N){ }^{10}$. Right: superposition of the $S$. cerevisiae and $H$. sapiens structures. The arrow indicates the rotation relating the conformations observed in the two crystal structures. Circles highlight structural differences. See also Supplementary Fig. 17 
structures, which revealed that Nup42 ${ }^{\mathrm{GBM}}$ binds Gle1 ${ }^{\mathrm{CTD}}$ on the opposite face as the scDbp5/DDX19-binding interfaces. Furthermore, we did not detect any stimulatory effect of Nup $42^{\mathrm{GBM}}$ in the human system.

In addition, we found that unlike yeast Dbp5, human DDX19 activation by Gle ${ }^{\mathrm{CTD}}$ does not require $\mathrm{IP}_{6}$. This conclusion was supported by multiple lines of evidence: (1) robust and indistinguishable ATPase stimulation of human DDX19 by Gle1 CTD both in the presence and absence of $\mathrm{IP}_{6},(2)$ human Gle1 ${ }^{\mathrm{CTD}}$ and
DDX19 formed a complex in SEC experiments in the absence of $\mathrm{IP}_{6}$, (3) no binding of $\mathrm{IP}_{6}$ to human Gle ${ }^{\mathrm{CTD}} \cdot \mathrm{Nup} 42^{\mathrm{GBM}}$ was detected in ITC experiments, (4) crystal structures uncover that the human Gle1 pocket corresponding to the yeast Gle1 $\mathrm{IP}_{6}$ binding pocket possesses a dramatically reduced positive electrostatic surface potential, (5) $\mathrm{IP}_{6}$ coordinating residues in yeast Dbp5 were not conserved in human DDX19, and (6) no electron density for $\mathrm{IP}_{6}$ was observed in crystal structures of human Gle1 ${ }^{\mathrm{CTD}} \cdot$ Nup42 $2^{\mathrm{GBM}} \cdot \mathrm{DDX} 19^{\mathrm{N} 53}$ determined using crystals a

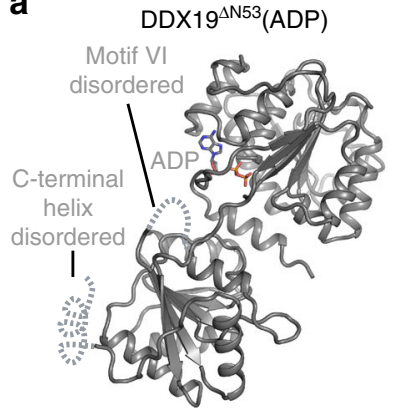

b

DDX19 $9^{\Delta N 53}(A D P)$ inhibited state

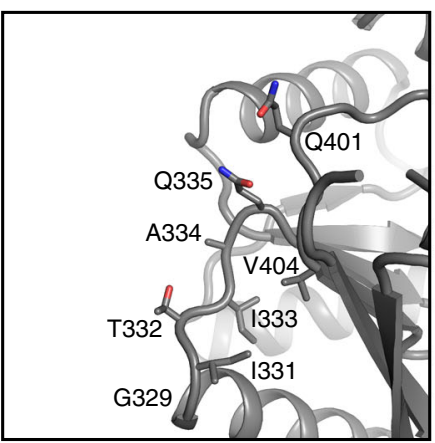

C $\mathrm{DDX} 19^{\Delta \mathrm{N} 53}(\mathrm{ADP})$ inhibited state

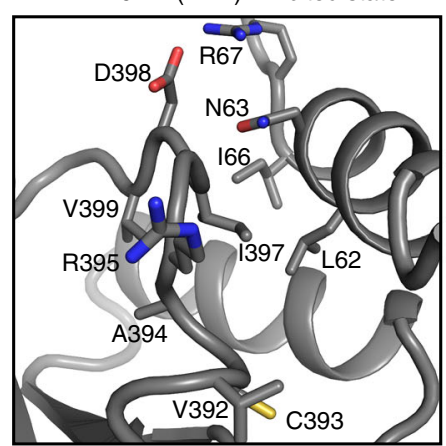

d

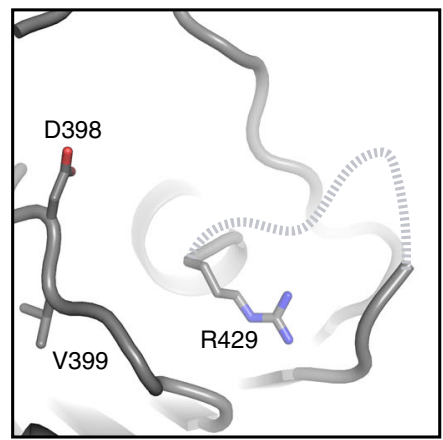

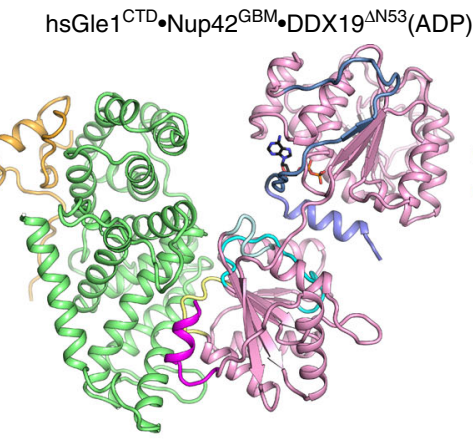

$\mathrm{DDX} 19^{\Delta \mathrm{N} 53}(\mathrm{ADP})$ Gle1-bound state

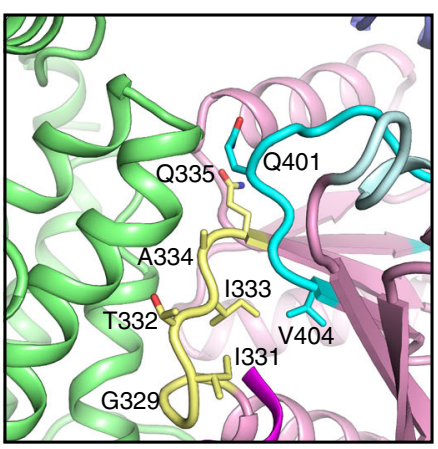

DDX19 ${ }^{\Delta N 53}(A D P)$ Gle1-bound state

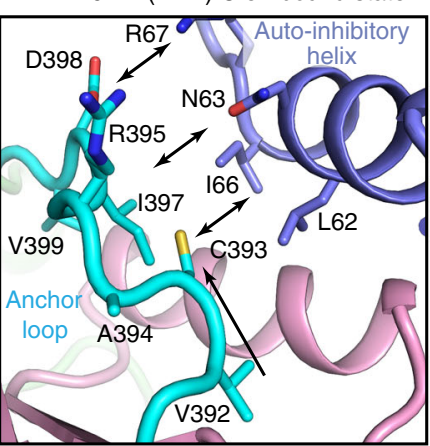

DDX $19^{\Delta \mathrm{N} 53}(\mathrm{ADP})$ Gle1-bound state

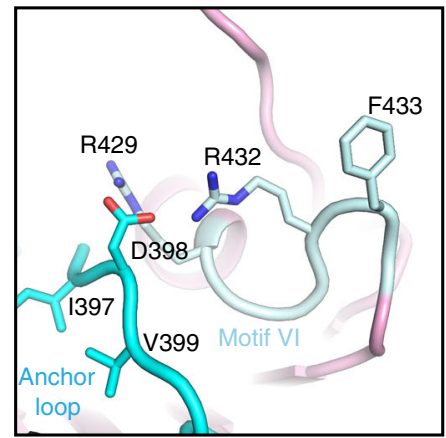

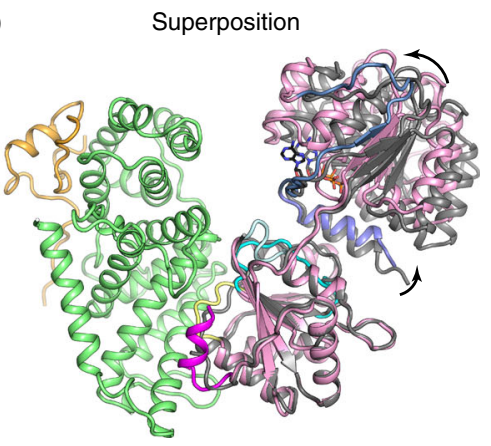
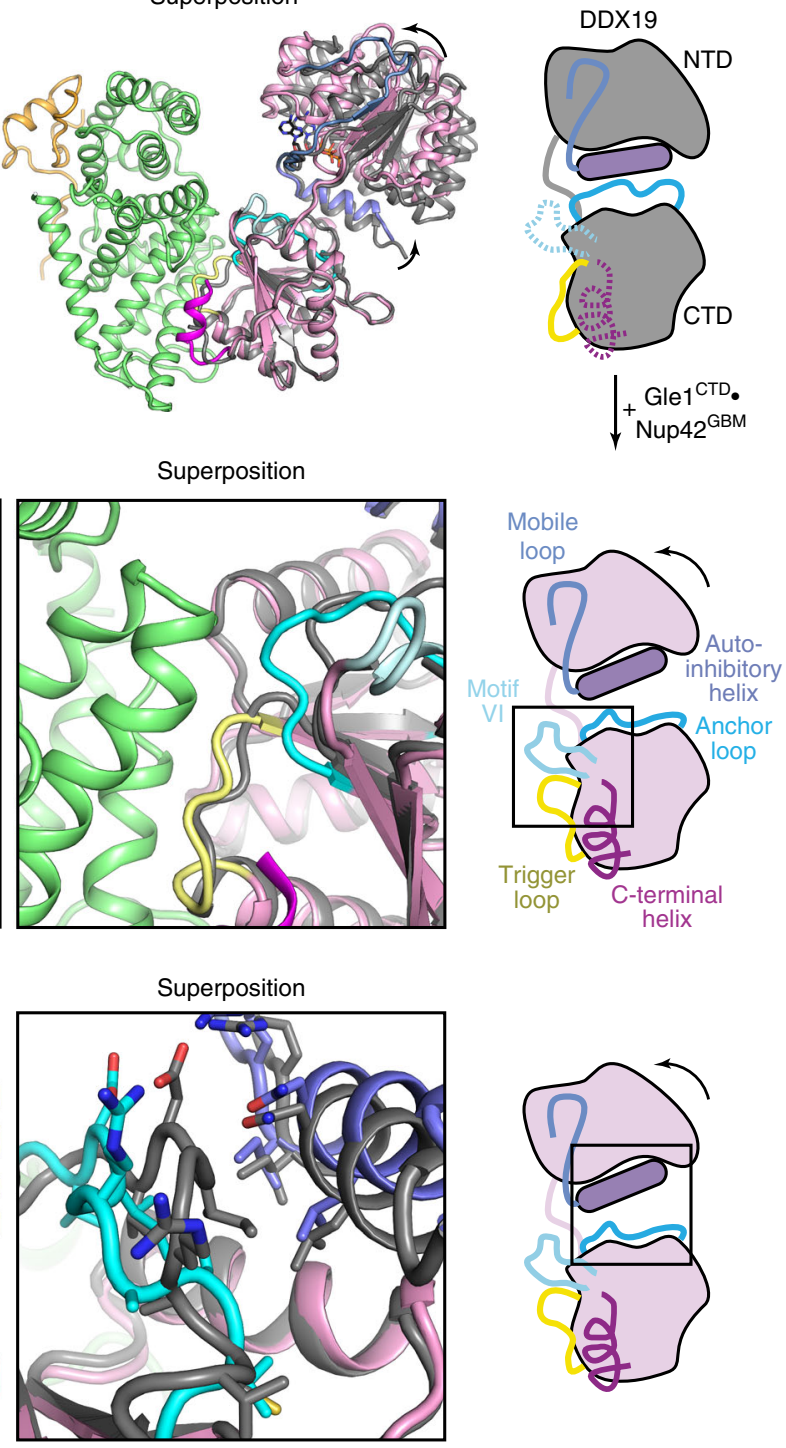

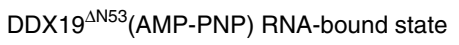

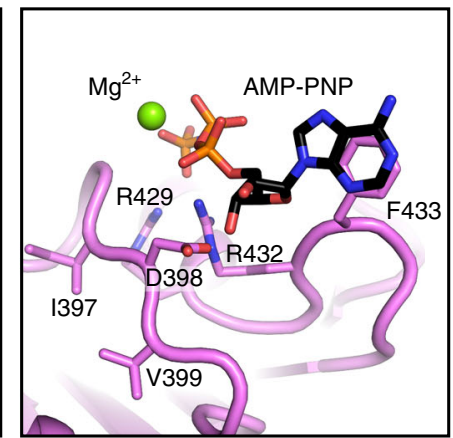

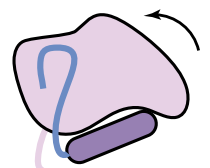

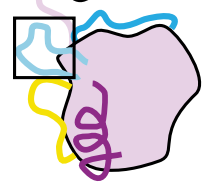


soaked or co-crystallized with $\mathrm{IP}_{6}$. We note that our studies were all performed with extensively purified proteins recombinantly expressed in bacteria (Supplementary Fig. 13a, b) whereas DDX19 was purified from an insect cell expression system in the other study ${ }^{45}$. Future work needs to assess whether other proteins, small molecules, or post-translational modifications play a role in regulating DDX19 activity.

Combining these results, we can propose a working model of the DDX19 catalytic cycle (Fig. 8; Supplementary Movie 3). DDX19 is predominantly trapped in the auto-inhibited state, which can form in the presence of either ATP or ADP, although the ATP- and ADP-bound states could exhibit different dynamics for release of the auto-inhibitory helix. Gle1 binding facilitates release from auto-inhibition by first inducing conformational rearrangements in DDX19CTD that partially open DDX19 and generate a cleft between DDX19 ${ }^{\text {NTD }}$ and DDX19 ${ }^{\mathrm{CTD}}$ (Fig. 8, step 1). Nup214 ${ }^{\mathrm{NTD}}$ binding can accelerate the opening of the domains leading to complete separation of the DDX19 $9^{\mathrm{NTD}}$ and DDX $19^{\text {CTD }}$, forming the conformation observed in the structure of S. cerevisiae Gle ${ }^{\text {CTD }} \cdot \mathrm{IP}_{6} \cdot \mathrm{Dbp} 5^{\Delta \mathrm{N} 90}$ (Fig. 8, step 2). Separation of DDX $19^{\mathrm{NTD}}$ and DDX19CTD opens the nucleotide-binding pocket and enables exchange of ADP for ATP (Fig. 8, step 3). The auto-inhibitory helix could rebind and DDX19 would cycle between open and closed conformations until it encounters RNA (Fig. 8, step 4). RNA binding favors the formation of the closed, catalytically active state and based on crystallographic data, would also trigger release of Gle1 due to rearrangements in DDX19. Specifically, the auto-inhibitory helix displaces DDX19's Cterminal helix and the mobile loop connecting the autoinhibitory helix resulting in a conformation that is incompatible with Gle1 binding (Fig. 8, step 5). This process leads to displacement of Nxf1•Nxt1, although future studies are necessary to establish how DDX19 specifically removes Nxf1•Nxt1. After ATP hydrolysis and subsequent dissociation of $P_{\mathrm{i}}$ and RNA, DDX19 would then recycle back to the inhibited state and another cycle of ATP hydrolysis could then occur (Fig. 8, step 6).

There remains a substantial gap between rates of ATP hydrolysis measured in vitro $(\sim 1 \mathrm{ATP} /$ second $)$ and rates of mRNA export termination observed in vivo $(<0.1 \mathrm{~s} \text { per mRNA })^{46,47}$. A portion of this gap could be explained by a specific spatial organization at the cytoplasmic face of the NPC that efficiently accelerates the DDX19 cycle. Mapping of the Gle1-binding site on Nup155 provides a critical spatial restraint for the location of Gle1 and the entire cytoplasmic filament subcomplex in the NPC. Attempts to dock the newly determined structures of the human $\mathrm{Gle1}{ }^{\mathrm{CTD}} \cdot \mathrm{Nup} 42^{\mathrm{GBM}} \cdot \mathrm{DDX} 19^{\Delta \mathrm{N} 53}$ into the cryoelectron tomographic reconstruction of the intact human NPC did not identify any unambiguous placements, although the rapid binding kinetics of DDX19 at the NPC suggest that it may not be present in the reconstructions (Supplementary Fig. 20 ${ }^{48,49}$. Furthermore, all of the cytoplasmic filament proteins studied here contain additional domains that may play important roles in DDX19 activity regulation. However, a complete characterization of these effects is expected to require the reconstitution of a fully assembled cytoplasmic filament nucleoporin complex, including the remaining domains of Nup42, Nup214, Gle1, their FG repeats, and their binding partners. This complex will need to be assembled onto the human $\mathrm{CNC}$ rings that serve as a scaffold in the intact NPC and assayed with Nxf1 •Nxt1-bound mRNAs. The results presented here provide a rich foundation for the design of these experiments.

Lastly, the effect of Nup42 on Gle1 stability highlights protein instability as a potent modifier of Gle1 function, as the Gle1 CTD fold is unstable at physiological temperatures in vitro in the absence of its cofactors. The effects of mutations associated with human disease in our thermostability experiments largely correlated with their phenotypic severity, suggesting that protein stability may be a contributing factor in these diseases. Interestingly, measurements of $S$. cerevisiae Gle ${ }^{\mathrm{CTD}}{ }^{\mathrm{IP}} \mathrm{I}_{6}$ thermostability in the absence of Nup $42^{\mathrm{GBM}}$ in vitro matched the temperatures at which we observed mislocalization of Gle1 in yeast cells, presumably a result of misfolding and subsequent dissociation from the NPC (Fig. 2a). A similar phenomenon occurs in human cells, as the mutations that destabilize human Gle ${ }^{\mathrm{CTD}}$ have previously been found to possess NPC localization defects ${ }^{49}$. Overall, our results reinforce the link between mislocalization or aggregation of proteins involved in RNA metabolism and nucleocytoplasmic transport with human disease. Future studies that build upon the results reported here to determine the contribution of protein destabilization in disease models should provide greater insight into the mechanisms underlying motor neuron disease.

\section{Methods}

Chemicals and reagents. Chemicals were purchased from Sigma at the highest purity available unless otherwise noted.

Construct generation. DNA fragments were amplified using the polymerase chain reaction. SUMO-tagged proteins were cloned into a modified pET28a vector ${ }^{50}$. GST-tagged proteins were cloned into a pGEX-6P-1 vector. His $_{6}$-tagged proteins were cloned into a modified pET28a vector ${ }^{51}$. S. cerevisiae and $H$. sapiens Gle $1^{\mathrm{CTD}} \cdot$ Nup $42^{\mathrm{GBM}}$ were cloned into a modified pETDuet-1 vector with Nup $42^{\mathrm{GBM}}$ in the first site and Gle1 ${ }^{\mathrm{CTD}}$ in the second site. Mutants were generated using the QuikChange mutagenesis protocol and confirmed by DNA sequencing. Details of bacterial expression constructs and expression conditions are shown in Supplementary Table 5 .

Protein expression and purification. Proteins were expressed in E. coli BL21CodonPlus(DE3)-RIL cells (Stratagene) in Luria-Bertani media and induced at an $\mathrm{OD}_{600}$ of $\sim 0.6$ with $0.5 \mathrm{mM}$ IPTG (Gold Biotechnology). Unless indicated otherwise, cells were harvested by centrifugation and resuspended in a buffer containing $20 \mathrm{mM}$ TRIS (pH 8.0), $500 \mathrm{mM} \mathrm{NaCl}, 4 \mathrm{mM}$ 2-mercaptoethanol ( $\beta$-ME), and 15 mM imidazole, supplemented with complete EDTA-free protease inhibitor cocktail (Roche) and flash frozen in liquid nitrogen. Cells were supplemented with $1 \mathrm{mg}$ deoxyribonuclease I (Roche), lysed with a cell disruptor (Avestin), and centrifuged at $4{ }^{\circ} \mathrm{C}$ and $30,000 \times g$ for $1 \mathrm{~h}$. Supernatants were loaded onto an Ni-NTA affinity column (GE Healthcare) equilibrated in a buffer containing $20 \mathrm{mM}$ TRIS (pH 8.0), $500 \mathrm{mM} \mathrm{NaCl}, 4 \mathrm{mM} \beta$-ME, and $15 \mathrm{mM}$ imidazole and eluted with a linear gradient of imidazole concentration to $500 \mathrm{mM}$. Eluted proteins were dialyzed overnight with a buffer containing $20 \mathrm{mM}$ TRIS ( $\mathrm{pH} 8.0$ ), $100 \mathrm{mM} \mathrm{NaCl}, 4 \mathrm{mM} \beta-\mathrm{ME}$, and $15 \mathrm{mM}$ imidazole and subsequently purified through affinity, ion exchange, and SEC.

hsGle1 ${ }^{\text {CTD }} \cdot \mathrm{His}_{6}$-hsNup42 ${ }^{\mathrm{GBM}}$ variants, scGle1 ${ }^{\mathrm{CTD}} \cdot \mathrm{His}_{6}$-scNup42 ${ }^{\mathrm{GBM}}$, and $\mathrm{His}_{6}$-scGle1 ${ }^{\mathrm{CTD}}$ were grown for $18 \mathrm{~h}$ at $18^{\circ} \mathrm{C}$. His ${ }_{6}$-ctGle $1^{\mathrm{CTD}}$ was co-expressed with GST-ctNup $42^{\mathrm{GBM}}$ and grown for $3 \mathrm{~h}$ at $37^{\circ} \mathrm{C}$. After elution from the Ni-NTA column, the $\mathrm{His}_{6}$ tag and the GST tag were removed by cleavage with PreScission

\footnotetext{
Fig. 6 Conformational changes in DDX19 induced by Gle1 binding. a Left: crystal structure of $H$. sapiens DDX19 ${ }^{\Delta N 53}($ ADP) (PDB ID 3EWS) 44 . Disordered regions (C-terminal helix and motif $\mathrm{VI}$ ) are indicated with dashed lines. Middle: crystal structure of $H$. sapiens Gle1 ${ }^{\mathrm{CTD}} \cdot \mathrm{Nup} 42^{\mathrm{GBM}} \cdot \mathrm{DDXX19}{ }^{\Delta \mathrm{N} 53}(\mathrm{ADP})$ shown in the same orientation and colored as in Fig. 5a. Right: superposition of the two structures. Arrows indicate the rotation relating the conformations of $\mathrm{DDX} 19^{\mathrm{N} 53}(\mathrm{ADP})$ in the presence and absence of Gle $1^{\mathrm{CTD}} \cdot \mathrm{Nup} 42^{\mathrm{GBM}}$. The cartoon on the right schematizes the transition from the inhibited state to the Gle1-bound state. See also Supplementary Fig. 16. b Zoom view of the DDX19 trigger loop (yellow) in (left) the inhibited state (PDB ID 3EWS), (middle) the Gle1-bound state, and (right) their superposition. The cartoon on the right indicates the region of DDX19 shown. c Zoom view of the DDX19 anchor loop (cyan) and auto-inhibitory helix (purple) in the (left) inhibited state (PDB ID 3EWS), (middle) the Gle1-bound state, and (right) their superposition. The cartoon on the right indicates the region of DDX19 shown. d Zoom view of DDX19 Motif VI in (left) the inhibited state (PDB ID 3EWS), (middle) the Gle1-bound state, and (right) the RNA-bound state (PDB ID 3GOH) ${ }^{44}$. The cartoon on the right indicates the region of DDX19 shown
} 
a

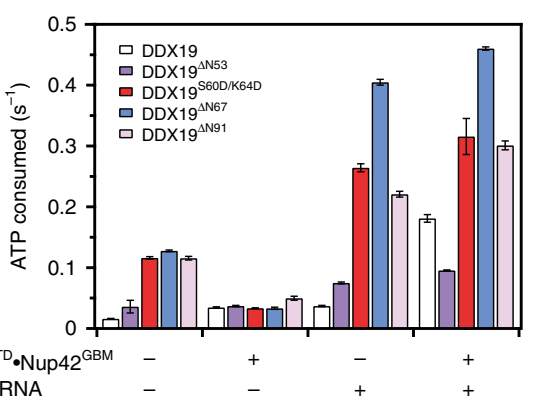

C

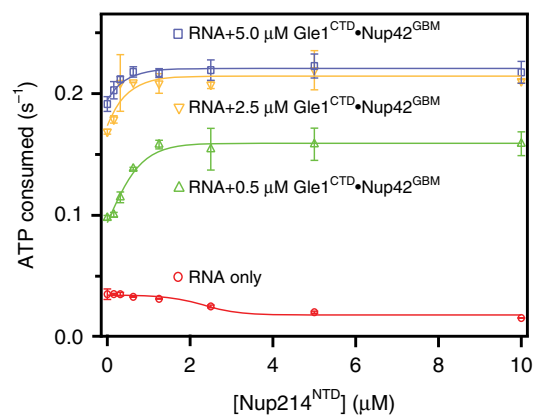

e

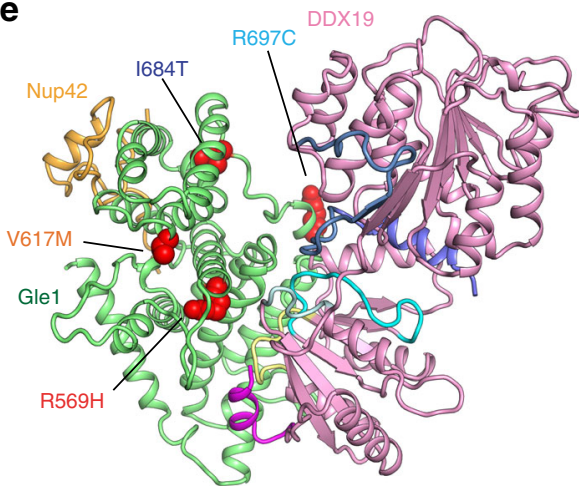

f

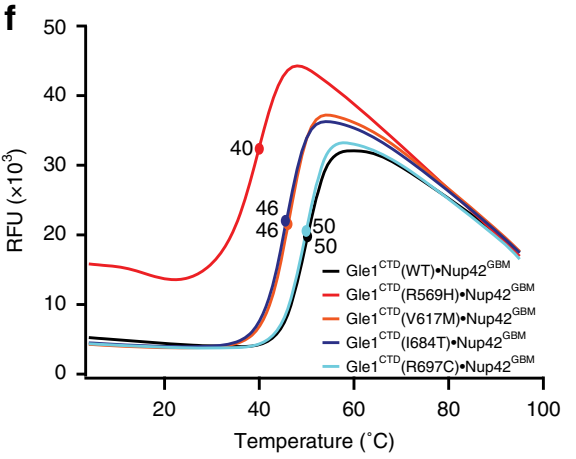

b
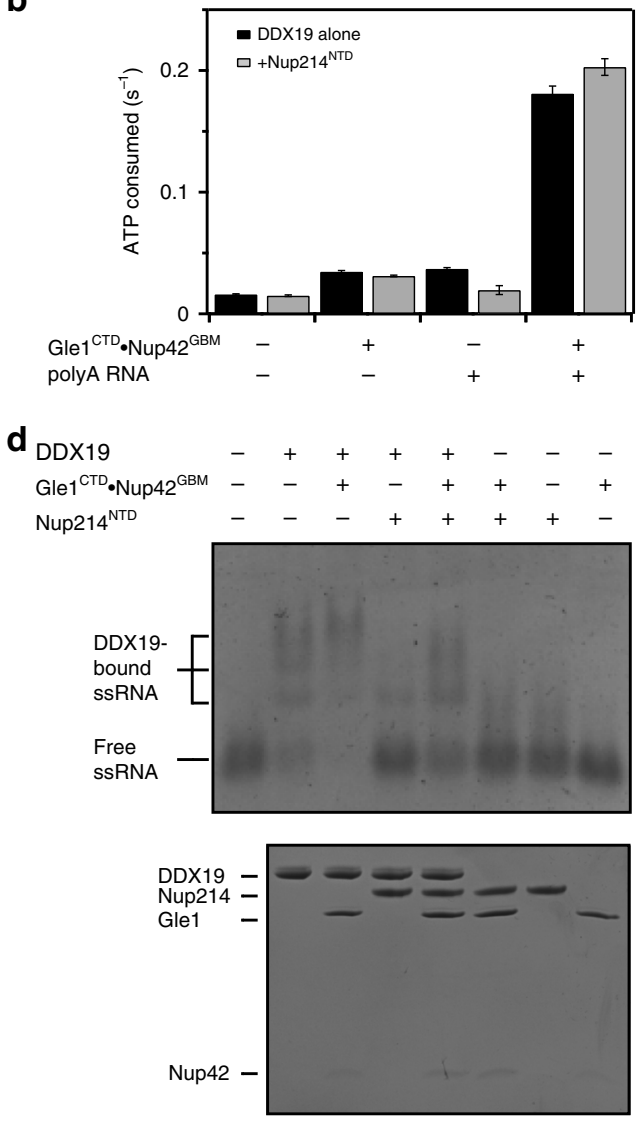

g

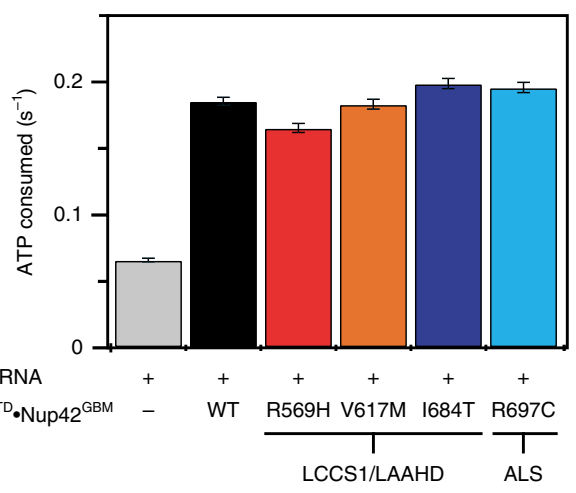

Fig. 7 Biochemical analysis of DDX19 activity. a Steady-state ATPase activity of DDX19 variants in the presence and absence of RNA and Gle $1^{\mathrm{CTD}} \cdot \mathrm{Nup} 42^{\mathrm{GBM}}$. For schematics of the various truncation constructs, see Supplementary Fig. 18a. b Analysis of the effect of Nup214 NTD on DDX19 stimulation. See also Supplementary Fig. 18. c Analysis of concentration dependence of Nup214NTD on DDX19 stimulation in the presence of RNA and Gle ${ }^{\text {CTD }} \cdot$ Nup42 ${ }^{\mathrm{GBM}}$. d Electrophoretic mobility shift assay analysis of the effect of Gle $1^{\mathrm{CTD}} \cdot \mathrm{Nup} 42^{\mathrm{GBM}}(1 \mu \mathrm{M})$ and Nup214 ${ }^{\mathrm{NTD}}(2 \mu \mathrm{M})$ on DDX19 $(1$ $\mu \mathrm{M}$ ) binding to a 53-nucleotide ssRNA. RNA was visualized by staining with SYBR gold. The proteins loaded in each lane were also visualized with a Coomassie-stained SDS-PAGE gel, shown below. e Mapping single amino acid substitutions associated with human diseases LCCS1/LAAHD and ALS onto the structure of Gle1 ${ }^{\mathrm{CTD}} \cdot \mathrm{Nup} 42^{\mathrm{GBM}} \cdot \mathrm{DDX} 19^{\Delta \mathrm{N} 53}$ (ADP). Coloring is the same as in Fig. 5a. See also Supplementary Fig. 19. f Differential scanning fluorimetry analysis of the effect of human disease mutations on Gle ${ }^{\mathrm{CTD}} \cdot \mathrm{Nup} 42^{\mathrm{GBM}}$ stability. Exposure of hydrophobic residues monitored by an increase in relative fluorescence units (RFUs). Curves represent the average of three experiments. $\mathbf{g}$ Steady-state ATPase activity of DDX19 stimulation by Gle1 ${ }^{\text {CTD }}$ variants containing single amino acid substitutions associated with human disease. All reported values are the average of three experiments. Error bars indicate standard deviation 
a
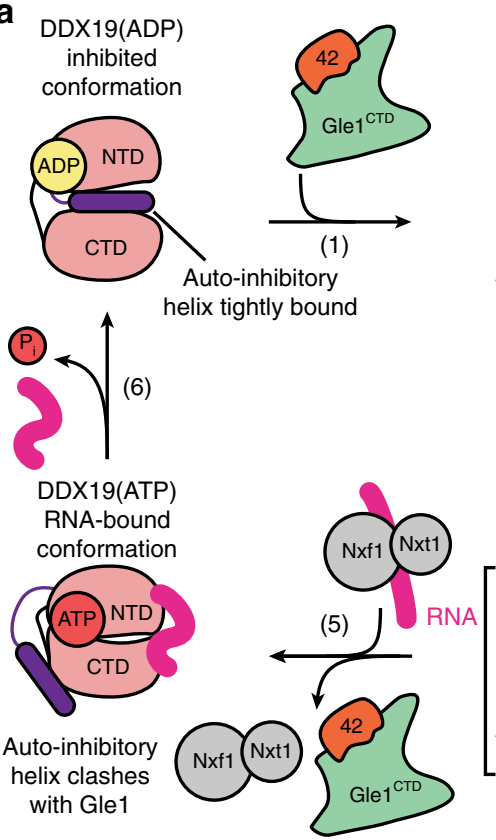

b
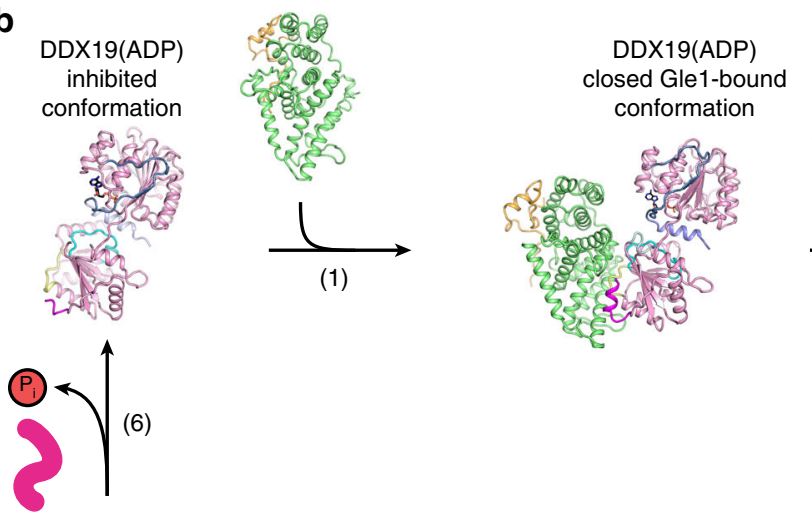

DDX19(ATP)

RNA-bound

conformation closed Gle1-bound conformation
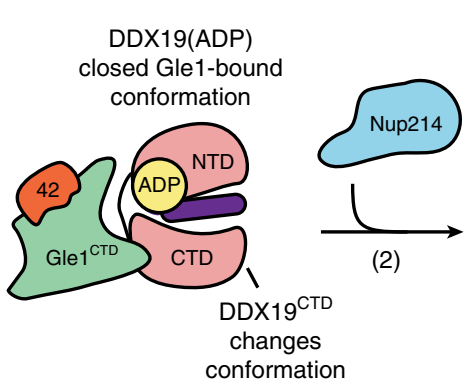

(2)
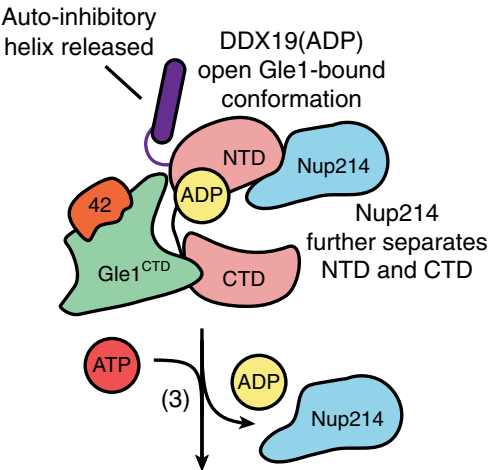

DDX19(ATP)

DDX19(ATP)

closed Gle1-bound

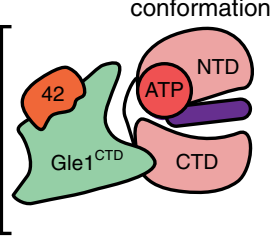

(4)

DDX19 may cycle between open and closed conformations

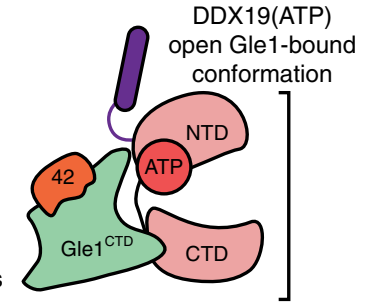

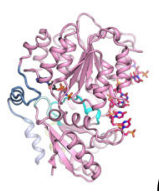

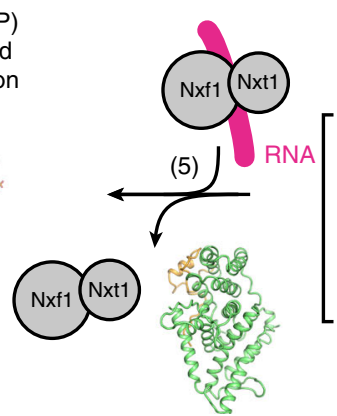

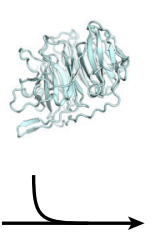

(2)

(4)

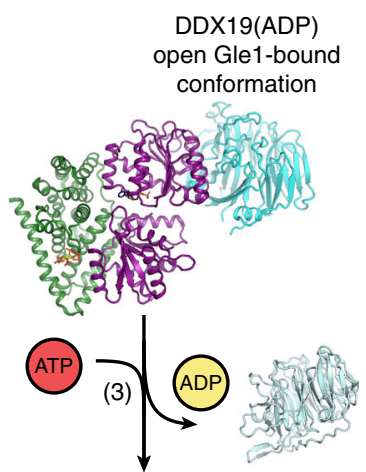

DDX19(ATP) open Gle1-bound conformation
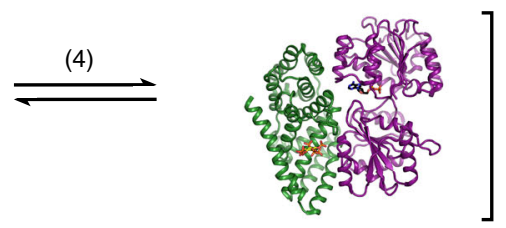

Fig. 8 Proposed working model for the DDX19 catalytic cycle. a Schematic cartoon of the DDX19 catalytic cycle. b Schematic of the DDX19 catalytic cycle with crystal structures of each state. The inhibited conformation corresponds to the crystal structure of DDX19 ${ }^{\Delta N 53}(A D P)$ (PDB ID 3EWS) ${ }^{44}$. The closed Gle1-bound conformations correspond to the crystal structures of Gle1 ${ }^{\mathrm{CTD}} \cdot \mathrm{Nup} 42^{\mathrm{GBM}} \cdot \mathrm{DDX} 19^{\Delta \mathrm{N} 53}\left(\mathrm{AMP}-\mathrm{PNP} \cdot \mathrm{Mg}^{2+}\right)$ and

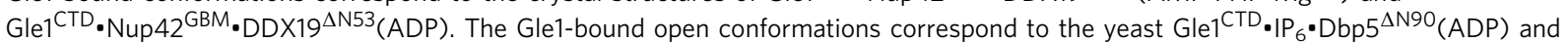
Gle1 ${ }^{\mathrm{CTD}} \cdot \mathrm{IP}_{6} \cdot \mathrm{Dbp}^{\mathrm{NN}}{ }^{\mathrm{N}}(\mathrm{ADP}) \cdot \mathrm{Nup} 159^{\mathrm{NTD}}$ (PDB IDs 3RRM and 3RRN) ${ }^{10}$. The RNA bound conformation corresponds to the crystal structure of DDX19 ${ }^{\Delta N 53}\left(\right.$ AMP-PNP $\left.\cdot \mathrm{Mg}^{2+}\right) \cdot \mathrm{U}_{10}$ RNA (PDB IDs 3RRM and PDB ID $\left.3 \mathrm{GOH}\right)^{44}$. Gle1 ${ }^{\mathrm{CTD}} \cdot \mathrm{Nup}_{2}{ }^{\mathrm{GBM}}$ and Nup214 ${ }^{\mathrm{NTD}}$ correspond to the apo structures (PDB ID 2OIT) 69

protease concurrent with dialysis. Dialyzed protein was loaded onto an Ni-NTA column equilibrated in a buffer containing $20 \mathrm{mM}$ TRIS ( $\mathrm{pH}$ 8.0), $100 \mathrm{mM} \mathrm{NaCl}, 4$ $\mathrm{mM} \beta-\mathrm{ME}$, and $15 \mathrm{mM}$ imidazole. Protein-containing fractions were pooled and loaded onto a HiTrap Heparin HP column (GE Healthcare) equilibrated in a buffer containing $20 \mathrm{mM}$ TRIS ( $\mathrm{pH} 8.0$ ), $100 \mathrm{mM} \mathrm{NaCl}$, and $5 \mathrm{mM}$ dithiothreitol (DTT) and eluted with a linear gradient of $\mathrm{NaCl}$ concentration to $2 \mathrm{M}$. Protein-containing fractions were concentrated and loaded onto a HiLoad Superdex 75 16/60 PG column (GE Healthcare) equilibrated in a buffer containing $20 \mathrm{mM}$ TRIS (pH 8.0), $100 \mathrm{mM} \mathrm{NaCl}$, and $5 \mathrm{mM}$ DTT.
$\mathrm{His}_{6}-\mathrm{SUMO}-\mathrm{hsGle} 1^{\mathrm{CTD}}$ was grown for $18 \mathrm{~h}$ at $18^{\circ} \mathrm{C}$ and purified as hsGle1 ${ }^{\mathrm{CTD}} \cdot \mathrm{His}_{6}$-hsNup42 ${ }^{\mathrm{GBM}}$, except the $\mathrm{His}_{6}$-SUMO tag was removed by Ulp1 cleavage.

$\mathrm{His}_{6}$-hsDDX19 variants, $\mathrm{His}_{6}$-scDbp5 and $\mathrm{His}_{6}$-SUMO-ctDbp5 were grown for $18 \mathrm{~h}$ at $18^{\circ} \mathrm{C}$. Cells were harvested by centrifugation and resuspended in a buffer containing $20 \mathrm{mM}$ TRIS (pH 8.0), $500 \mathrm{mM} \mathrm{NaCl}, 4 \mathrm{mM} \beta$-ME, $15 \mathrm{mM}$ imidazole, and $5 \%(\mathrm{v} / \mathrm{v})$ glycerol, supplemented with Complete EDTA-free protease inhibitor cocktail (Roche) and flash frozen in liquid nitrogen. After lysis and centrifugation, the supernatant was loaded onto an Ni-NTA column equilibrated in a buffer 
containing $20 \mathrm{mM}$ TRIS ( $\mathrm{pH} 8.0$ ), $500 \mathrm{mM} \mathrm{NaCl}, 4 \mathrm{mM} \beta$-ME, $15 \mathrm{mM}$ imidazole, and $5 \%(\mathrm{v} / \mathrm{v})$ glycerol. Protein was eluted with a linear gradient of imidazole concentration to $500 \mathrm{mM}$ and protein-containing fractions were dialyzed overnight in a buffer containing $20 \mathrm{mM}$ TRIS (pH 8.0), $100 \mathrm{mM} \mathrm{NaCl}, 4 \mathrm{mM} \beta$-ME, $15 \mathrm{mM}$ imidazole, and $5 \%(\mathrm{v} / \mathrm{v})$ glycerol. The $\mathrm{His}_{6}$ tags of $\mathrm{His}_{6}{ }^{-}$DDX19 variants and $\mathrm{His}_{6}-$ scDbp5 were cleaved using PreScission protease concurrent with overnight dialysis. The $\mathrm{His}_{6}$-SUMO tag of $\mathrm{His}_{6}$-SUMO-ctDbp5 was cleaved with Ulp1 protease and the cleaved protein was desalted with dialysis buffer immediately after elution from the Ni-NTA column. The dialyzed/desalted protein was loaded onto an Ni-NTA column equilibrated in a buffer containing $20 \mathrm{mM}$ TRIS ( $\mathrm{pH} 8.0$ ), $100 \mathrm{mM} \mathrm{NaCl}, 4$ $\mathrm{mM} \beta$-ME, $15 \mathrm{mM}$ imidazole, and 5\% (v/v) glycerol. Protein-containing flowthrough fractions were loaded onto a HiTrap Q HP column (GE Healthcare) equilibrated in a buffer containing $20 \mathrm{mM}$ TRIS (pH 8.0), $100 \mathrm{mM} \mathrm{NaCl}, 5 \mathrm{mM}$ DTT, and $5 \%(v / v)$ glycerol and eluted with a linear gradient of $\mathrm{NaCl}$ concentration to $2 \mathrm{M}$. Protein-containing fractions were concentrated and loaded onto a HiLoad Superdex 200 16/60 PG column (GE Healthcare) equilibrated in a buffer containing $20 \mathrm{mM}$ TRIS (pH 8.0), $100 \mathrm{mM} \mathrm{NaCl}, 5 \mathrm{mM}$ DTT, and 5\% (v/v) glycerol.

$\mathrm{His}_{6}$-SUMO-hsGle1 ${ }^{\mathrm{N}}$ and variants were grown at $30^{\circ} \mathrm{C}$ for $2 \mathrm{~h}$ after IPTG induction. After elution from the Ni-NTA column, proteins were dialyzed overnight in a buffer containing $20 \mathrm{mM}$ TRIS (pH 8.0), $100 \mathrm{mM} \mathrm{NaCl}$, and $5 \mathrm{mM}$ DTT. After dialysis, proteins were loaded onto a HiTrap Q HP column and eluted with a linear gradient of $\mathrm{NaCl}$ concentration to $2 \mathrm{M}$. Protein-containing fractions were concentrated and loaded onto a Superdex 200 10/300 GL column (GE Healthcare) equilibrated in a buffer containing $20 \mathrm{mM}$ TRIS ( $\mathrm{pH} 8.0$ ), $100 \mathrm{mM}$ $\mathrm{NaCl}$, and $5 \mathrm{mM}$ DTT.

$\mathrm{His}_{6}$-SUMO-scNup42 ${ }^{\mathrm{GBM}}-\mathrm{His}_{6}$ and variants were grown at $37^{\circ} \mathrm{C}$ for $2 \mathrm{~h}$ after IPTG induction. After elution from the Ni-NTA column, the $\mathrm{His}_{6}$-SUMO tag was removed by cleavage with Ulp1 concurrent with overnight dialysis into a buffer containing $20 \mathrm{mM}$ TRIS ( $\mathrm{pH} \mathrm{8.0)}, 100 \mathrm{mM} \mathrm{NaCl}$, and $5 \mathrm{mM} \mathrm{DTT}$. After dialysis, proteins were injected onto a HiTrap Q HP column and collected in the flowthrough. Protein-containing fractions were concentrated and loaded onto a Superdex Peptide 10/300 GL column (GE Healthcare).

$\mathrm{His}_{6}$-Nup155 ${ }^{\mathrm{CTD}}$ and $\mathrm{His}_{6}$-Nup214 ${ }^{\mathrm{NTD}}$ were grown for $18 \mathrm{~h}$ at $18^{\circ} \mathrm{C}$ after IPTG induction. After elution from the Ni-NTA column, proteins were dialyzed overnight in $20 \mathrm{mM}$ TRIS ( $\mathrm{pH} 8.0$ ), $500 \mathrm{mM} \mathrm{NaCl}, 4 \mathrm{mM} \beta$-ME, and $15 \mathrm{mM}$ imidazole. $\mathrm{His}_{6}$ tags were removed by cleavage with PreScission protease concurrent with dialysis. Dialyzed protein was loaded onto an Ni-NTA column equilibrated in a buffer containing $20 \mathrm{mM}$ TRIS (pH 8.0), $100 \mathrm{mM} \mathrm{NaCl}, 4 \mathrm{mM} \beta$ $\mathrm{ME}$, and $15 \mathrm{mM}$ imidazole. Protein-containing fractions were pooled and loaded onto a HiTrap Q HP column equilibrated in a buffer containing $20 \mathrm{mM}$ TRIS ( $\mathrm{pH}$ $8.0), 100 \mathrm{mM} \mathrm{NaCl}$, and $5 \mathrm{mM}$ DTT and eluted with a linear gradient of $\mathrm{NaCl}$ concentration to $2 \mathrm{M}$. Protein-containing fractions were concentrated and loaded onto a HiLoad Superdex 200 16/60 PG column equilibrated in a buffer containing $20 \mathrm{mM}$ TRIS (pH 8.0), $100 \mathrm{mM} \mathrm{NaCl}$, and $5 \mathrm{mM}$ DTT.

$\mathrm{His}_{6}$-SUMO-Nup98 ${ }^{\Delta \mathrm{FG}}$ was purified as Nup155 ${ }^{\mathrm{CTD}}$ and Nup214 ${ }^{\mathrm{NTD}}$, except the $\mathrm{His}_{6}$-SUMO tag was removed by cleavage with Ulp1.

GST-Nup155 CTD was grown for $18 \mathrm{~h}$ at $18^{\circ} \mathrm{C}$ after IPTG induction. After harvesting, lysis, and centrifugation, supernatant was loaded onto a Glutathione Sepharose 4 Fast Flow column (GE Healthcare) equilibrated in a buffer containing $20 \mathrm{mM}$ TRIS (pH 8.0), $150 \mathrm{mM} \mathrm{NaCl}$, and $5 \mathrm{mM}$ DTT. GST-Nup155 ${ }^{\mathrm{CTD}}$ was eluted with a linear gradient of reduced glutathione concentration to $10 \mathrm{mM}$. Protein-containing fractions were loaded onto a HiTrap Q HP column equilibrated in a buffer containing $20 \mathrm{mM}$ TRIS ( $\mathrm{pH} 8.0$ ), $100 \mathrm{mM} \mathrm{NaCl}$, and $5 \mathrm{mM}$ DTT and eluted with a linear gradient of $\mathrm{NaCl}$ concentration to $2 \mathrm{M}$. Protein-containing fractions were concentrated and loaded onto a HiLoad Superdex 200 16/60 PG column equilibrated in a buffer containing $20 \mathrm{mM}$ TRIS ( $\mathrm{pH} 8.0$ ), $100 \mathrm{mM} \mathrm{NaCl}$, and $5 \mathrm{mM}$ DTT.

Crystallization and structure determination. S. cerevisiae $\mathrm{Gle} 1^{\mathrm{CTD}} \cdot \mathrm{Nup} 42^{\mathrm{GBM}}$ was crystallized at $23^{\circ} \mathrm{C}$ with the hanging drop method using $1 \mu \mathrm{l}$ of protein solution $(22.5 \mathrm{mg} / \mathrm{ml})$ and $1 \mu \mathrm{l}$ of reservoir solution, containing $0.1 \mathrm{M}$ HEPES $(\mathrm{pH}$ 8.2 ), $11 \%$ (w/v) PEG 3350, and $0.2 \mathrm{M} \mathrm{L}$-Proline. Crystals were cryoprotected with a solution identical to the reservoir solution, but supplemented with $30 \%(\mathrm{v} / \mathrm{v})$ ethylene glycol. X-ray diffraction data were collected at beamline 12-2 at the Stanford Synchotron Radiation Lightsource (SSRL) with a wavelength of $0.9795 \AA$ and processed with the XDS package ${ }^{52}$. The structure was solved by molecular replacement with Phaser, using the structure of Gle1 ${ }^{C T D}$ (PDB ID 3RRN) as a search model ${ }^{10,53}$. The structure was refined using the PHENIX package with TLS refinemen ${ }^{54}$. One of the Glel molecules in the asymmetric unit displays two distinct conformations for half the molecule and was modeled as two alternate conformations for the entire residue range. The final structure was refined to $R_{\text {work }}$ and $R_{\text {free }}$ values of 18.5 and $21.1 \%$, respectively, with excellent geometry $(98.3 \%$ of residues in favored region of the Ramachandran plot, $1.7 \%$ in the allowed region, and $0.0 \%$ outliers; MolProbity clashscore 1.92; MolProbity score 0.96$)^{55}$.

H. sapiens Gle1 ${ }^{\mathrm{CTD}} \cdot \mathrm{Nup} 42^{\mathrm{GBM}}$ was crystallized at $23^{\circ} \mathrm{C}$ with the hanging drop method using $1 \mu \mathrm{l}$ of protein solution $(20 \mathrm{mg} / \mathrm{ml})$ and $1 \mu \mathrm{l}$ of reservoir solution, containing $0.2 \mathrm{M}$ sodium potassium phosphate ( $\mathrm{pH} 7.6$ ) and 26\% (w/v) PEG 3350. Crystals were cryoprotected by gradual supplementation of ethylene glycol in 5\% steps to a final concentration of $30 \%(\mathrm{v} / \mathrm{v})$. X-ray diffraction data were collected at beamline 23-ID-D at the Advanced Photon Source (APS) with a wavelength of
$0.9794 \AA$ and processed with the XDS package ${ }^{52}$. The diffraction data were anisotropic, with diffraction limits along the three principal components of 2.8, 3.1, and $3.1 \AA$. The structure was solved by molecular replacement with Phaser, using the structure of $S$. cerevisiae Gle1 ${ }^{\text {CTD }}$ (PDB ID 3RRN) as a search model ${ }^{10,53}$. Refinement was performed using torsion NCS restraints with the PHENIX package using anisotropically truncated and scaled data generated using the UCLA-DOE anisotropy server ${ }^{54,56}$. The final structure was refined to $R_{\text {work }}$ and $R_{\text {free }}$ values of 24.5 and $27.4 \%$, respectively, with excellent geometry $(95.2 \%$ of residues in favored region of the Ramachandran plot, $4.8 \%$ in the allowed region, and $0.0 \%$ outliers; MolProbity clashscore 1.88; MolProbity score 1.31$)^{55}$.

C. thermophilum Gle $1^{\mathrm{CTD}} \cdot \mathrm{Nup} 42^{\mathrm{GBM}}$ was crystallized at $23^{\circ} \mathrm{C}$ with the hanging drop method using $1 \mu \mathrm{l}$ of protein solution $(10 \mathrm{mg} / \mathrm{ml})$ and $1 \mu \mathrm{l}$ of reservoir solution, containing $0.1 \mathrm{M}$ MES ( $\mathrm{pH} 6.3$ ) and $12 \%$ (w/v) PEG 20,000. Crystals were cryoprotected by gradual supplementation of ethylene glycol in 5\% steps to a final concentration of $25 \%(\mathrm{v} / \mathrm{v})$. X-ray diffraction data were collected at beamline 23-ID-D at APS with a wavelength of $1.0332 \AA$ and processed with the XDS package ${ }^{52}$. The structure was solved by molecular replacement with Phaser, using the structure of $H$. sapiens Gle $1^{\mathrm{CTD}}$ as a search model ${ }^{53}$. The structure was refined with torsion NCS restraints using the PHENIX package ${ }^{54}$. The final structure was refined to $R_{\text {work }}$ and $R_{\text {free }}$ values of 24.0 and $27.7 \%$, respectively, with excellent geometry ( $97.5 \%$ of residues in favored region of the Ramachandran plot, $2.5 \%$ in the allowed region, and $0.0 \%$ outliers; MolProbity clashscore 3.34; MolProbity score 1.22$)^{55}$

C. thermophilum $\mathrm{Gle} 1^{\mathrm{CTD}} \cdot \mathrm{Nup} 42^{\mathrm{GBM}} \cdot \mathrm{IP}_{6}$ was crystallized at $23^{\circ} \mathrm{C}$ with the hanging drop method using $1 \mu \mathrm{l}$ of protein solution $(7.5 \mathrm{mg} / \mathrm{ml})$ and $1 \mu \mathrm{lof}$ reservoir solution, containing $10 \mathrm{mM}$ zinc sulfate heptahydrate, $0.1 \mathrm{M} \mathrm{MES} \mathrm{(pH}$ 6.3), and $18 \%(\mathrm{v} / \mathrm{v})$ Polyethylene glycol monomethyl ether 550. Crystals were improved by microseeding. Crystals were cryoprotected by gradual supplementation of ethylene glycol in 5\% steps to a final concentration of $25 \%$ (v/ v). SeMet-labeled crystals were grown using the same conditions. X-ray diffraction data were collected at beamline 12-2 at SSRL with a wavelength of $0.9792 \AA$ for SeMet crystals and $1.0332 \AA$ for native crystals, and processed with the XDS package ${ }^{52}$. The structure was solved using Crank2, using the structure of H. sapiens Gle1 ${ }^{\text {CTD }}$ as an initial search model ${ }^{57,58}$. The structure was refined using the PHENIX package ${ }^{54}$. The presence of $\mathrm{Zn}^{2+}$ ions was confirmed using anomalous difference Fourier maps. The final structure was refined to $R_{\text {work }}$ and $R_{\text {free }}$ values of 19.3 and $23.0 \%$, respectively, with excellent geometry ( $98.3 \%$ of residues in favored region of the Ramachandran plot, $1.7 \%$ in the allowed region, and $0.0 \%$ outliers; MolProbity clashscore 0.56; MolProbity score 0.69$)^{55}$.

For crystallization of the H. sapiens Gle $1^{\mathrm{CTD}} \cdot \mathrm{Nup} 42^{\mathrm{GBM}} \cdot \mathrm{DDX} 19^{\Delta \mathrm{N} 53}$, the complex was reconstituted by mixing equimolar amounts of purified Gle1 ${ }^{\mathrm{CTD}} \cdot \mathrm{Nup} 42^{\mathrm{GBM}}$ and DDX19 ${ }^{\Delta \mathrm{N} 53}$ to form a $400 \mu \mathrm{M}$ stock solution. The stock solution was supplemented with $400 \mu \mathrm{M}$ ADP or AMP-PNP and $400 \mu \mathrm{M} \mathrm{MgCl}_{2}$. Protein stock solutions were diluted with a buffer containing $20 \mathrm{mM}$ TRIS ( $\mathrm{pH}$ 8.0), $100 \mathrm{mM} \mathrm{NaCl}, 5 \mathrm{mM} \mathrm{DTT}, 1 \mathrm{mM} \mathrm{MgCl}$, and $1 \mathrm{mM}$ ADP or AMP-PNP. Crystals of Gle1 ${ }^{\mathrm{CTD}} \cdot \mathrm{Nup} 42^{\mathrm{GBM}} \cdot \mathrm{DDX} 19^{\Delta \mathrm{N} 53}(\mathrm{ADP})$ were grown at $4{ }^{\circ} \mathrm{C}$ with the hanging drop method using $1 \mu \mathrm{l}$ of protein solution $(7.5 \mathrm{mg} / \mathrm{ml})$ and $1 \mu \mathrm{l}$ of reservoir solution, containing $13 \%$ (w/v) PEG 3350 and $0.2 \mathrm{M}$ sodium potassium phosphate. Crystals of Gle ${ }^{\mathrm{CTD}} \cdot \mathrm{Nup} 42^{\mathrm{GBM}} \cdot \mathrm{DDX} 19^{\Delta \mathrm{N} 53}\left(\mathrm{AMP}-\mathrm{PNP} \bullet \mathrm{Mg}^{2+}\right)$ were grown at $4{ }^{\circ} \mathrm{C}$ with the hanging drop method using $1 \mu \mathrm{l}$ of protein solution $(5 \mathrm{mg} /$ $\mathrm{ml}$ ) and $1 \mu \mathrm{l}$ of reservoir solution in 15\% (w/v) PEG 3350 and $0.3 \mathrm{M}$ sodium potassium phosphate ( $\mathrm{pH}$ 6.6). Crystals were cryoprotected by gradual supplementation of ethylene glycol to a final concentration of $25 \%(\mathrm{v} / \mathrm{v})$ in $5 \%(\mathrm{v} / \mathrm{v})$ steps.

Diffraction data for Gle1 ${ }^{\mathrm{CTD}} \cdot \mathrm{Nup} 42^{\mathrm{GBM}} \cdot \mathrm{DDX} 19^{\Delta \mathrm{N} 53}(\mathrm{ADP})$ were collected at beamline 23-ID-D at APS with a wavelength of $1.0333 \AA$ and processed with $\mathrm{XDS}^{52}$. The diffraction data were anisotropic, with diffraction limits along the three principal components of 3.6, 3.7, and $4.0 \AA$. The crystal structure was solved by molecular replacement with Phaser, using the structure of H. sapiens Gle1 ${ }^{\mathrm{CTD}} \cdot$ Nup42 ${ }^{\mathrm{GBM}}$ and H. sapiens DDX19 (PDB ID 3EWS) as search models ${ }^{43}$ Refinement was performed using torsion NCS restraints with the PHENIX package using anisotropically truncated and scaled data generated using the UCLA-DOE anisotropy server ${ }^{54,56}$. The final structure was refined to $R_{\text {work }}$ and $R_{\text {free }}$ values of 23.2 and $28.1 \%$, respectively, with excellent geometry $(95.9 \%$ of residues in favored region of the Ramachandran plot, $4.1 \%$ in the allowed region, and $0.0 \%$ outliers; MolProbity clashscore 3.86; MolProbity score 1.45$)^{55}$

Diffraction data for Gle1 ${ }^{\mathrm{CTD}} \cdot \mathrm{Nup} 42^{\mathrm{GBM}} \cdot \mathrm{DDX} 19^{\Delta \mathrm{N} 53}\left(\mathrm{AMP}-\mathrm{PNP} \bullet \mathrm{Mg}^{2+}\right)$ were collected at the Frontier Microfocusing Macromolecular Crystallography beamline (FMX) at the National Synchotron Lightsource-II (NSLS-II) with a wavelength of $0.9793 \AA$. The crystals grew in space group $\mathrm{P} 2{ }_{1}$ but were non-merohedrally twinned with the twin domains related by a $180^{\circ}$ rotation along $a$. Diffraction data were integrated with DIALS and scaled with AIMLESS ${ }^{59,60}$. The structure was solved by molecular replacement with Phaser, using the structures of H. sapiens Gle $1^{\mathrm{CTD}} \cdot \mathrm{Nup} 42^{\mathrm{GBM}}$ and H. sapiens DDX19 (PDB ID 3EWS) as search models ${ }^{43,53}$. The diffraction data were anisotropic, with diffraction limits along the three principal components of 3.4, 3.7, and $4.2 \AA$. Refinement was performed with PHENIX using anisotropically truncated and scaled data generated with the UCLA-DOE anisotropy server ${ }^{54,56}$. The final structure was refined to $R_{\text {work }}$ and $R_{\text {free }}$ values of 26.1 and $31.3 \%$, respectively, with excellent geometry $(95.0 \%$ of residues in favored region of the Ramachandran plot, $5.0 \%$ in the allowed region, and $0.0 \%$ outliers; MolProbity clashscore 2.72; MolProbity score 1.43$)^{55}$. 
For the structures of Gle1 ${ }^{\mathrm{CTD}} \cdot \mathrm{Nup} 42^{\mathrm{GBM}} \cdot \mathrm{DDX} 19^{\Delta \mathrm{N} 53}\left(\mathrm{AMP}-\mathrm{PNP} \bullet \mathrm{Mg}^{2+}\right.$ ) grown in the presence of or soaked with $\mathrm{IP}_{6}$, crystals of Gle ${ }^{\mathrm{CTD}} \cdot \mathrm{Nup} 42^{\mathrm{GBM}} \cdot \mathrm{DDX} 19^{\Delta \mathrm{N} 53}\left(\mathrm{AMP}-\mathrm{PNP} \cdot \mathrm{Mg}^{2+}\right)$ were grown in a drop additionally supplemented with $0.5 \mathrm{mM} \mathrm{IP}_{6}$ or soaked for 4 days with $0.5 \mathrm{mM} \mathrm{IP}_{6}$, respectively. Crystals grown or soaked with $\mathrm{IP}_{6}$ were cryoprotected with solutions supplemented with $0.5 \mathrm{mM} \mathrm{IP}_{6}$. Diffraction data were collected at beamline 23-ID$\mathrm{D}$ at APS, integrated with DIALS and scaled with AIMLESS ${ }^{59,60}$. The structures were solved by direct substitution of the coordinates of the structure of Gle ${ }^{\mathrm{CTD}} \cdot \mathrm{Nup} 42^{\mathrm{GBM}} \cdot \mathrm{DDX} 19^{\mathrm{NN} 53}\left(\mathrm{AMP}-\mathrm{PNP} \cdot \mathrm{Mg}^{2+}\right)$ and refined with the PHENIX package ${ }^{54}$. The structure of Gle1 ${ }^{\mathrm{CTD}} \cdot \mathrm{Nup}^{\mathrm{GBM}} \cdot \mathrm{DDX}^{\mathrm{G}} 9^{\triangle \mathrm{N} 53}$ (AMPPNP. $\mathrm{Mg}^{2+}$ ) soaked with $\mathrm{IP}_{6}$ was refined to $R_{\text {work }}$ and $R_{\text {free }}$ values of 24.6 and $29.7 \%$, respectively, with a MolProbity score of $1.38^{55}$. The structure of Gle1 ${ }^{\mathrm{CTD}} \cdot \mathrm{Nup} 42^{\mathrm{GBM}} \cdot \mathrm{DDX} 19^{\Delta \mathrm{N} 53}\left(\mathrm{AMP}-\mathrm{PNP} \bullet \mathrm{Mg}^{2+}\right)$ co-crystallized with $\mathrm{IP}_{6}$ was refined to $R_{\text {work }}$ and $R_{\text {free }}$ values of 25.8 and $31.3 \%$, respectively, with a MolProbity score of $1.41^{55}$. Simulated annealing omit maps were calculated using the PHENIX package by omitting all ligand molecules ${ }^{54}$.

Crystals of DDX19 $9^{\triangle \mathrm{N} 53}\left(\mathrm{AMP}-\mathrm{PNP} \cdot \mathrm{Mg}^{2+}\right.$ ) grew during crystallization trials of Gle $1^{\mathrm{CTD}} \cdot \mathrm{Nup} 42^{\mathrm{GBM}} \cdot \mathrm{DDX} 19^{\mathrm{N} 53}\left(\mathrm{AMP}-\mathrm{PNP} \cdot \mathrm{Mg}^{2+}\right)$ in heavy precipitate. The reservoir solution contained $0.1 \mathrm{M}$ malonate, imidazole, borate (MIB) buffer $(\mathrm{pH}$ $5.0)$ and $13 \%(\mathrm{w} / \mathrm{v})$ PEG 1500. Crystals were cryoprotected with the reservoir solution supplemented with $20 \%(\mathrm{v} / \mathrm{v})$ ethylene glycol. X-ray diffraction data were collected at beamline 23-ID-D at APS with a wavelength of $1.0333 \AA$ and the data were integrated with DIALS and scaled with AIMLESS ${ }^{59,60}$. The crystal structure was solved by molecular replacement using the structure of DDX19 ${ }^{\triangle \mathrm{N} 53}$ (ADP) (PDB ID 3EWS ${ }^{43}$. The structure was refined with TLS groups using the PHENIX package ${ }^{54}$. The final structure was refined to $R_{\text {work }}$ and $R_{\text {free }}$ values of 20.7 and $24.8 \%$, respectively, with excellent geometry ( $98.9 \%$ of residues in favored region of the Ramachandran plot, $1.1 \%$ in the allowed region, and $0.0 \%$ outliers; MolProbity clashscore 2.04; MolProbity score 0.97$)^{55}$.

For details of the data collection and refinement statistics for all structures, see Supplementary Tables 1-4. For representative views of electron density for all structures, see Supplementary Figure 21.

Analytical size-exclusion chromatography. Protein-protein interaction experiments were carried out on a Superdex 200 10/300 GL or Superdex 75 10/300 GL gel filtration column equilibrated in a buffer containing $20 \mathrm{mM}$ TRIS ( $\mathrm{pH} 8.0$ ), 100 $\mathrm{mM} \mathrm{NaCl}$, and $5 \mathrm{mM}$ DTT (when present, $0.5 \mathrm{mM} \mathrm{IP}_{6}$ was added to the buffer). The different combinations were mixed and incubated for $30 \mathrm{~min}$ on ice using a twofold molar excess of the smaller component. Complex formation was evaluated by comparing the mobility on the gel filtration column of pre-incubated proteins versus individual proteins. Complex formation was confirmed by SDS-PAGE of the protein-containing fractions, followed by Coomassie brilliant blue staining.

GST pull-down interaction analysis. Glutathione-S-transferase (GST) pull-down experiments were performed with purified GST-Nup155 ${ }^{\mathrm{CTD}}$, Nup $98^{\Delta \mathrm{FG}}$, and SUMO-Gle ${ }^{\mathrm{N}}$. $25 \mu \mathrm{l}$ of Glutathione Sepharose 4 Fast Flow beads (GE Healthcare) were equilibrated with a buffer containing $20 \mathrm{mM}$ TRIS (pH 8.0), $100 \mathrm{mM} \mathrm{NaCl}$ and $5 \mathrm{mM}$ DTT. GST-Nup $155^{\mathrm{CTD}}(20 \mu \mathrm{M})$ was preincubated for $30 \mathrm{~min}$ with a twofold molar ratio of either Nup9 $98^{\Delta \mathrm{FG}}$ or SUMO-Gle $1^{\mathrm{N}}$ on ice. Preincubated mixtures were subsequently incubated with $0,0.5,1,1.5,2$, 4, or 8 -fold molar ratios of the other protein for another $30 \mathrm{~min}$ on ice. Mixtures were then incubated with pre-equilibrated glutathione-coupled sepharose beads for $30 \mathrm{~min}$ and washed five times with a buffer containing $20 \mathrm{mM}$ TRIS ( $\mathrm{pH} 8.0$ ), $100 \mathrm{mM} \mathrm{NaCl}$ and $5 \mathrm{mM}$ DTT and centrifuged at $500 \times g$ at $4{ }^{\circ} \mathrm{C}$. Bound protein was eluted from the beads with $25 \mu$ l buffer containing $20 \mathrm{mM}$ TRIS ( $\mathrm{pH} 8.0$ ), $100 \mathrm{mM} \mathrm{NaCl}, 5 \mathrm{mM} \mathrm{DTT}$, and $10 \mathrm{mM}$ reduced glutathione.

Yeast strain generation. The nup42A/gle1-GFP strain was generated in a haploid BY4741 parental strain by first introducing the natNT2 cassette by homologous recombination into the nup42 gene, followed by three rounds of selection on yeast extract peptone dextrose (YPD) plates containing Nourseothricin (Gold Biotechnology ${ }^{61}$. Subsequently, a GFP-kanMX cassette was inserted into the Cterminus of Gle1 followed by three rounds of selection on YPD plates containing G418 ${ }^{61}$. Nup42-mCherry-3xHA variants were introduced using a modified pRS415 plasmid followed by two rounds of selection on plates containing leucine-depleted synthetic dextrose complete medium (SDC-LEU). For details of yeast strains and constructs, see Supplementary Table 6.

Yeast live cell fluorescence. Cells were grown in SDC-LEU medium to mid-log phase at $30^{\circ} \mathrm{C}$ and shifted to $42^{\circ} \mathrm{C}$ for $3 \mathrm{~h}$. For fluorescence imaging, cells were pelleted by centrifugation for $2 \mathrm{~min}$ at $650 \times g$, resuspended in water, and imaged using a Carl Zeiss Observer Z.1 equipped with a Hamamatsu camera C10600 Orca-R2.

Yeast growth assay. For growth analysis, cells were grown in SDC-LEU medium at $30^{\circ} \mathrm{C}$ to an $\mathrm{OD}_{600}$ of 0.2 . Fifteen microliters of a tenfold dilution series was spotted onto plates containing SDC-LEU medium, which were incubated at 30 and $37^{\circ} \mathrm{C}$.
Western blot analysis. The expression levels of Nup42-mCherry-3xHA variants were assessed for the S. cerevisiae nup42A/gle1-GFP strain. Transformed cells were selected twice on SDC-LEU plates before analysis. Protein extraction from cells was performed via $\mathrm{NaOH}$ and SDS treatment, using a modified protocol ${ }^{62}$. Specifically, cells were grown at $30^{\circ} \mathrm{C}$ to an $\mathrm{OD}_{600}$ of $\sim 1.0$ before harvesting $10 \mathrm{ml}$ of culture by centrifugation for $5 \mathrm{~min}$ at $3000 \times \mathrm{g}$. Cell pellets were resuspended in $100 \mu \mathrm{l}$ of 0.3 $\mathrm{M} \mathrm{NaOH}$ and incubated for $5 \mathrm{~min}$ on ice, pelleted by centrifugation at $3000 \times g$, washed with water twice, and resuspended in a buffer containing $20 \mathrm{mM}$ TRIS ( $\mathrm{pH}$ 8.0), $250 \mathrm{mM} \mathrm{NaCl}$ and $2 \%(\mathrm{w} / \mathrm{v}) \mathrm{SDS}$, incubated at $80^{\circ} \mathrm{C}$ for $10 \mathrm{~min}$ followed by centrifugation at $30,000 \times g$ for $4 \mathrm{~min}$. The supernatant was collected, diluted with SDS loading dye, and boiled for $3 \mathrm{~min}$ prior to loading on a SDS-PAGE gel. Western blot analysis of Nup42-mCherry-3xHA variants was performed with a $1 \mathrm{~h}$ incubation at room temperature with mouse anti-HA antibody (Covance; MMS101P; 1:5000 dilution) and a $1 \mathrm{~h}$ incubation at room temperature with an antimouse antibody coupled to alkaline phosphatase (Promega; S3721; 1:5000 dilution) visualized by color development using SIGMAFAST 5-bromo-4-chloro-3-indolyl phosphate (BCIP)/nitro blue tetrazolium (NBT) tablets (Sigma; B5655). Equal loading was established with an overnight incubation at $4{ }^{\circ} \mathrm{C}$ with rabbit antihexokinase antibody (US Biological; H2035-02; 1:10,000 dilution) and $1 \mathrm{~h}$ incubation at room temperature with a goat anti-rabbit antibody fused to an IR800 fluorescent probe (Li-Cor, 926-32211; 1:10,000 dilution) imaged with an IR imager (Li-Cor Odyssey) using the $800 \mathrm{~nm}$ channels in a single scan at $169 \mu \mathrm{m}$ resolution and a scan intensity of 5 . Antibodies were diluted in TBS-T supplemented with $3 \%$ $(\mathrm{w} / \mathrm{v})$ milk powder and washes were carried out in TBS-T.

Differential scanning fluorimetry assay. Differential scanning fluorimetry was performed using a previously described protocol ${ }^{63}$. Using a real-time PCR instrument (Bio-Rad C1000 96-well Thermal Cycler), fluorescence of a $20 \mu \mathrm{l}$ mixture of $5 \mu \mathrm{M}$ purified protein and $5 \times$ SYPRO orange dye (Invitrogen) was measured once per minute while the temperature was increased $1^{\circ} \mathrm{C} / \mathrm{min}$ from 4 to $95^{\circ} \mathrm{C}$. Reactions were performed in $20 \mathrm{mM}$ TRIS ( $\mathrm{pH} 8.0$ ), $100 \mathrm{mM} \mathrm{NaCl}$, and 5 mM DTT. When present, $\mathrm{IP}_{6}$ was supplemented to $25 \mu \mathrm{M}$ for yeast proteins and $100 \mu \mathrm{M}$ for human proteins. The reported $T_{\mathrm{m}}$ values were determined by finding the temperature corresponding to the maximum of the first derivative of the thermal melting curve. Traces represent the average of three experiments.

Pelleting thermostability assay. Fifty-microliter samples of purified protein (10 $\mu \mathrm{g}$ each) were incubated for $30 \mathrm{~min}$ at indicated temperatures between 25 and $55^{\circ}$ C. Soluble and pellet fractions were isolated by centrifugation at $30,000 \times \mathrm{g}$ for 35 min at $4{ }^{\circ} \mathrm{C}$. Reactions were performed in a buffer containing $20 \mathrm{mM}$ TRIS (pH $8.0), 100 \mathrm{mM} \mathrm{NaCl}$, and $5 \mathrm{mM}$ DTT. When present, $\mathrm{IP}_{6}$ was added to a final concentration of $20 \mu \mathrm{M}$. Proteins were resolved by SDS-PAGE gel and visualized with Coomassie brilliant blue staining.

NADH-coupled ATPase assay. Steady-state ATPase activity rates were determined at 30 and $37^{\circ} \mathrm{C}$ for scDbp5 and hsDDX19 using previously established conditions ${ }^{41}$. The reaction mixture $(80 \mu \mathrm{l})$ contained purified scDbp5 and hsDDX19 (WT and variants) at 0.5 and $2.5 \mu \mathrm{M}$, respectively. Unless otherwise noted, all other S. cerevisiae and $H$. sapiens proteins (Gle1 ${ }^{\mathrm{CTD}}$, Gle1 ${ }^{\mathrm{CTD}}{ }_{\bullet}-$ Nup42 ${ }^{\mathrm{GBM}}$, or Nup214 ${ }^{\mathrm{NTD}}$ ) were present at concentrations of 1 and $5 \mu \mathrm{M}$, respectively. When present, polyA RNA with length ranging between 465 and 660 bases (GE Healthcare, 27411001) was added to a final concentration of $0.1 \mathrm{mg} / \mathrm{ml}$. When present, $\mathrm{IP}_{6}$ was supplemented to a final concentration of 2 and $10 \mu \mathrm{M}$ for yeast and human, respectively, unless otherwise noted. The reaction mixture contained $30 \mathrm{mM}$ HEPES (pH 7.5), $100 \mathrm{mM} \mathrm{NaCl}, 2 \mathrm{mM} \mathrm{MgCl}, 1 \mathrm{mM}$ DTT, 6 $\mathrm{mM}$ phosphoenolpyruvate (PEP, Alfa Aesar), 1.2 mM NADH, $1.6 \mu \mathrm{l}$ pyruvate kinase $(\mathrm{PK}) /$ lactate dehydrogenase enzyme solution (LDH), and $2.5 \mathrm{mM} \mathrm{ATP}$, unless otherwise noted.

For each reaction, two separate mixtures were prepared and kept separate until initiation of the reaction. The first mixture, containing the protein components, $\mathrm{IP}_{6}$, polyA RNA, and buffer (HEPES, $\mathrm{NaCl}$, and $\mathrm{MgCl}_{2}$ ), was prepared to a final volume of $20 \mu \mathrm{l}$ and incubated on ice. The second mixture, containing buffer, DTT, PEP, NADH, ATP, and PK/LDH, was prepared to a final volume of $60 \mu \mathrm{l}$ and dispensed into a 96-well plate. Reactions were initiated by addition of the protein mixture. Plates were centrifuged at $4000 \times g$ for $2 \mathrm{~min}$ at $4{ }^{\circ} \mathrm{C}$ prior to being loaded in the pre-warmed plate reader. $\mathrm{A}_{340}$ was measured every $30 \mathrm{~s}$ for $30 \mathrm{~min}$ using a FlexStation 3 microplate reader (Molecular Devices). Rates were calculated by fitting the linear portion of the reaction. Reported rates were determined by dividing the rate of ATP consumption by the concentration of DDX19/Dbp5 in the reaction. All values reported are the average of three experiments.

Isothermal titration calorimetry experiments. ITC measurements were performed at $21{ }^{\circ} \mathrm{C}$ using a MicroCal ITC200 Calorimeter (GE Healthcare/Malvern) in a buffer containing $100 \mathrm{mM}$ HEPES (pH 7.4), $100 \mathrm{mM} \mathrm{NaCl}, 2 \mathrm{mM} \mathrm{MgCl}$, and 4 $\mathrm{mM} \beta$-ME. Protein solutions were dialyzed overnight against ITC buffer and $\mathrm{IP}_{6}$ was dissolved in the dialysate. All measurements were performed in triplicate. Because of the acidic nature of $\mathrm{IP}_{6}$, the heat generated from dilution was subtracted for baseline correction. Baseline corrected data were analyzed with Origin 7.0 software. For S. cerevisiae Gle1 ${ }^{\mathrm{CTD}} \cdot \mathrm{Nup} 42^{\mathrm{GBM}}$, cell and syringe concentrations 
of 5 and $50 \mu \mathrm{M}$ were used for Gle ${ }^{\mathrm{CTD}} \cdot \mathrm{Nup} 42^{\mathrm{GBM}}$ and $\mathrm{IP}_{6}$, respectively. For human Gle1 ${ }^{\mathrm{CTD}} \cdot \mathrm{Nup} 42^{\mathrm{GBM}}$, measurements were made at identical conditions to $S$. cerevisiae $\mathrm{Glel}^{\mathrm{CTD}}{ }^{\mathrm{N}} \mathrm{Nup} 42^{\mathrm{GBM}}$, as well as at cell and syringe concentrations of 200 $\mu \mathrm{M}$ and $2 \mathrm{mM}$ for Gle $1^{\mathrm{CTD}} \cdot \mathrm{Nup} 42^{\mathrm{GBM}}$ and $\mathrm{IP}_{6}$, respectively.

Electrophoretic mobility shift assay. The electrophoretic mobility of free or DDX19-bound RNA was evaluated on native $1.4 \%(\mathrm{w} / \mathrm{v})$ agarose gels using a 53nucleotide single-stranded RNA probe (5'-GUUUU UUUUU UUUUU UUUUU UCUCG AUCCG UAGUG AUCUA CUGAG CAUCU CCC- $3^{\prime}$ ). The RNA was prepared by in vitro transcription using T7 polymerase and according to the MEGAscript protocol (Ambion). The transcribed RNA was loaded on a $8 \%$ denaturing polyacrylamide-urea gel (19:1 acryl:bisacryl ratio and $8.3 \mathrm{M}$ urea). The RNA band was cut, eluted, and extracted with phenol:chloroform, followed by ethanol precipitation. The pellet was resuspended in $10 \mathrm{mM}$ TRIS (pH 8.5) buffer and the concentration was detected by measuring the absorbance at $260 \mathrm{~nm}$. The RNA-protein reactions were carried out in $20 \mathrm{mM}$ TRIS ( $\mathrm{pH} 8.0$ ), $100 \mathrm{mM} \mathrm{NaCl}, 2$ $\mathrm{mM} \mathrm{MgCl}, 1 \mathrm{mM}$ DTT, $10 \%$ (v/v) glycerol, and $1 \mathrm{mM}$ AMP-PNP. The recombinant proteins used in each assay were incubated in binding buffer containing AMP-PNP and then mixed with $25 \mathrm{ng}$ of RNA. The final reaction volume was $10 \mu \mathrm{l}$ and the final protein concentrations were $1 \mu \mathrm{M}$ Gle $1^{\mathrm{CTD}} \cdot \mathrm{Nup} 42^{\mathrm{GBM}}, 2 \mu \mathrm{M}$ Nup214 ${ }^{\mathrm{NTD}}$, and $1 \mu \mathrm{M}$ DDX19. After mixing, samples were incubated on ice for $20 \mathrm{~min}$ before being loaded onto a $1.4 \%(\mathrm{w} / \mathrm{v})$ native agarose gel using $0.25 \times$ TRIS borate EDTA (TBE) buffer. Electrophoresis was carried out at a constant voltage of $9 \mathrm{~V} / \mathrm{cm}$ at room temperature in $0.25 \times \mathrm{TBE}$ buffer for $40 \mathrm{~min}$. The gel was stained with SYBR gold (1:10,000 dilution in $0.25 \times$ TBE buffer) for $3 \mathrm{~min}$ and imaged.

Crystal structure docking. Searches using the structures of

Gle1 ${ }^{\mathrm{CTD}} \cdot \mathrm{Nup} 42^{\mathrm{GBM}} \cdot \mathrm{DDX} 19^{\Delta \mathrm{N} 53}\left(\mathrm{AMP}-\mathrm{PNP} \cdot \mathrm{Mg}^{2+}\right)$ or Gle1 ${ }^{\mathrm{CTD}} \cdot \mathrm{Nup} 42^{\mathrm{GBM}}$ were performed in a previously reported cryo-electron tomography reconstruction of the intact human NPC (EMD-3103) using the Chimera FitMap tool ${ }^{48,64}$. Searches in unaccounted cytoplasmic density were performed in a map generated by removing density in the composite structure of the symmetric core of the NPC ${ }^{2}$. Searches were performed with 50,000 initial placements within $100 \AA$ of the cytoplasmic outer ring that were locally optimized and scored based on correlation to a $25 \AA$ simulated map of the structures.

Illustrations and figures. All structural figures and movies were ray traced in PyMol (Schrödinger). Surface electrostatic potential plots were calculated using Adaptive Poisson-Boltzmann Solver (APBS) ${ }^{65}$. Secondary structure predictions were generated with the PSIPRED server ${ }^{66}$. Sequence alignments were generated using MUSCLE and visualized with ALSCRIPT ${ }^{67,68}$.

Data availability. Atomic coordinates and related structure factors have been deposited in the Protein Data Bank with accession codes 6B4E, 6B4F, 6B4G, 6B4H, $6 \mathrm{~B} 4 \mathrm{I}, 6 \mathrm{~B} 4 \mathrm{~J}$, and $6 \mathrm{~B} 4 \mathrm{~K}$ for the structures of $S$. cerevisiae Gle1 ${ }^{\mathrm{CTD}} \cdot \mathrm{Nup} 42^{\mathrm{GBM}}, H$. sapiens Gle1 $1^{\mathrm{CTD}} \cdot \mathrm{Nup} 42^{\mathrm{GBM}}$, C. thermophilum Gle $1^{\mathrm{CTD}} \cdot \mathrm{Nup} 42^{\mathrm{GBM}}, \mathrm{C}$. thermophilum Gle1 ${ }^{\mathrm{CTD}} \cdot \mathrm{Nup} 42^{\mathrm{GBM}} \cdot \mathrm{IP}_{6}$, H. sapiens $\mathrm{Gle} 1^{\mathrm{CTD}} \cdot \mathrm{Nup} 42^{\mathrm{GBM}} \cdot \mathrm{DDX} 19^{\Delta \mathrm{N} 53}$ (ADP), H. sapiens $\mathrm{Gle}^{\mathrm{CTD}} \cdot \mathrm{Nup}^{\mathrm{G}}{ }^{\mathrm{GBM}} \cdot \mathrm{DDX} 19^{\mathrm{N} 53}(\mathrm{AMP} \cdot \mathrm{PNP})$, and $H$. sapiens DDX $19^{\Delta \mathrm{N} 53}(\mathrm{AMP} \bullet \mathrm{PNP})$, respectively. Other data are available from the corresponding author upon reasonable request.

Received: 20 July 2017 Accepted: 27 April 2018

Published online: 13 June 2018

\section{References}

1. Hoelz, A., Debler, E. W. \& Blobel, G. The structure of the nuclear pore complex. Annu. Rev. Biochem. 80, 613-643 (2011).

2. Lin, D. H. et al. Architecture of the symmetric core of the nuclear pore. Science 352, aaf1015 (2016).

3. Kosinski, J. et al. Molecular architecture of the inner ring scaffold of the human nuclear pore complex. Science 352, 363-365 (2016).

4. Stuwe, T. et al. Architecture of the fungal nuclear pore inner ring complex. Science 350, 56-64 (2015).

5. Fischer, J., Teimer, R., Amlacher, S., Kunze, R. \& Hurt, E. Linker Nups connect the nuclear pore complex inner ring with the outer ring and transport channel. Nat. Struct. Mol. Biol. 22, 774-781 (2015).

6. Stewart, M. Nuclear export of mRNA. Trends Biochem. Sci. 35, 609-617 (2010).

7. Katahira, J. et al. The Mex67p-mediated nuclear mRNA export pathway is conserved from yeast to human. EMBO J. 18, 2593-2609 (1999).

8. Lund, M. K. \& Guthrie, C. The DEAD-box protein Dbp5p is required to dissociate Mex67p from exported mRNPs at the nuclear rim. Mol. Cell 20, 645-651 (2005).

9. Alcazar-Roman, A. R., Tran, E. J., Guo, S. \& Wente, S. R. Inositol hexakisphosphate and Gle1 activate the DEAD-box protein Dbp5 for nuclear mRNA export. Nat. Cell Biol. 8, 711-716 (2006).

10. Montpetit, B. et al. A conserved mechanism of DEAD-box ATPase activation by nucleoporins and InsP6 in mRNA export. Nature 472, 238-242 (2011).
11. Weirich, C. S. et al. Activation of the DExD/H-box protein Dbp5 by the nuclear-pore protein Gle1 and its coactivator InsP6 is required for mRNA export. Nat. Cell Biol. 8, 668-676 (2006).

12. Dossani, Z. Y., Weirich, C. S., Erzberger, J. P., Berger, J. M. \& Weis, K. Structure of the C-terminus of the mRNA export factor Dbp5 reveals the interaction surface for the ATPase activator Gle1. Proc. Natl. Acad. Sci. USA 106, 16251-16256 (2009)

13. Folkmann, A. W., Noble, K. N., Cole, C. N. \& Wente, S. R. Dbp5, Gle1-IP6 and Nup159: a working model for mRNP export. Nucleus 2, 540-548 (2011).

14. von Moeller, H., Basquin, C. \& Conti, E. The mRNA export protein DBP5 binds RNA and the cytoplasmic nucleoporin NUP214 in a mutually exclusive manner. Nat. Struct. Mol. Biol. 16, 247-254 (2009).

15. Napetschnig, J. et al. Structural and functional analysis of the interaction between the nucleoporin Nup214 and the DEAD-box helicase Ddx19. Proc. Natl. Acad. Sci. USA 106, 3089-3094 (2009).

16. Schmitt, C. et al. Dbp5, a DEAD-box protein required for mRNA export, is recruited to the cytoplasmic fibrils of nuclear pore complex via a conserved interaction with CAN/Nup159p. EMBO J. 18, 4332-4347 (1999).

17. Hodge, C. A., Colot, H. V., Stafford, P. \& Cole, C. N. Rat8p/Dbp5p is a shuttling transport factor that interacts with Rat7p/Nup159p and Glelp and suppresses the mRNA export defect of xpo1-1 cells. EMBO J. 18, 5778-5788 (1999).

18. Saavedra, C. A., Hammell, C. M., Heath, C. V. \& Cole, C. N. Yeast heat shock mRNAs are exported through a distinct pathway defined by Riplp. Genes Dev. 11, 2845-2856 (1997).

19. Kendirgi, F., Rexer, D. J., Alcazar-Roman, A. R., Onishko, H. M. \& Wente, S. R. Interaction between the shuttling mRNA export factor Glel and the nucleoporin hCG1: a conserved mechanism in the export of Hsp70 mRNA. Mol. Biol. Cell 16, 4304-4315 (2005).

20. Hodroj, D. et al. An ATR-dependent function for the Ddx19 RNA helicase in nuclear R-loop metabolism. EMBO J. 36, 1182-1198 (2017).

21. Mikhailova, T. et al. RNA helicase DDX19 stabilizes ribosomal elongation and termination complexes. Nucleic Acids Res. 45, 1307-1318 (2017).

22. Neumann, B., Wu, H., Hackmann, A. \& Krebber, H. Nuclear export of preribosomal subunits requires Dbp5, but not as an RNA-helicase as for mRNA export. PLoS ONE 11, e0149571 (2016).

23. Alcazar-Roman, A. R., Bolger, T. A. \& Wente, S. R. Control of mRNA export and translation termination by inositol hexakisphosphate requires specific interaction with Gle1. J. Biol. Chem. 285, 16683-16692 (2010).

24. Bolger, T. A. \& Wente, S. R. Gle1 is a multifunctional DEAD-box protein regulator that modulates Ded1 in translation initiation. J. Biol. Chem. 286, 39750-39759 (2011)

25. Aditi, Folkmann, A. W. \& Wente, S. R. Cytoplasmic hGle1A regulates stress granules by modulation of translation. Mol. Biol. Cell 26, 1476-1490 (2015).

26. Freibaum, B. D. et al. GGGGCC repeat expansion in C9orf72 compromises nucleocytoplasmic transport. Nature 525, 129-133 (2015).

27. Zhang, K. et al. The C9orf72 repeat expansion disrupts nucleocytoplasmic transport. Nature 525, 56-61 (2015).

28. Grima, J. C. et al. Mutant Huntingtin disrupts the nuclear pore complex. Neuron 94, 93-107.e106 (2017).

29. Shi, K. Y. et al. Toxic PRn poly-dipeptides encoded by the C9orf72 repeat expansion block nuclear import and export. Proc. Natl. Acad. Sci. USA 114, E1111-E1117 (2017).

30. Gasset-Rosa, F. et al. Polyglutamine-expanded Huntingtin exacerbates agerelated disruption of nuclear integrity and nucleocytoplasmic transport. Neuron 94, 48-57.e44 (2017).

31. Shang, J. et al. Aberrant distributions of nuclear pore complex proteins in ALS mice and ALS patients. Neuroscience 350, 158-168 (2017).

32. Jovicic, A. et al. Modifiers of C9orf72 dipeptide repeat toxicity connect nucleocytoplasmic transport defects to FTD/ALS. Nat. Neurosci. 18, 1226-1229 (2015).

33. Nousiainen, H. O. et al. Mutations in mRNA export mediator GLE1 result in a fetal motoneuron disease. Nat. Genet. 40, 155-157 (2008).

34. Kaneb, H. M. et al. Deleterious mutations in the essential mRNA metabolism factor, hGle1, in amyotrophic lateral sclerosis. Hum. Mol. Genet. 24, 1363-1373 (2015).

35. Kendirgi, F., Barry, D. M., Griffis, E. R., Powers, M. A. \& Wente, S. R. An essential role for hGlel nucleocytoplasmic shuttling in mRNA export. J. Cell Biol. 160, 1029-1040 (2003).

36. Folkmann, A. W. et al. Gle1 functions during mRNA export in an oligomeric complex that is altered in human disease. Cell 155, 582-593 (2013).

37. Rayala, H. J., Kendirgi, F., Barry, D. M., Majerus, P. W. \& Wente, S. R. The mRNA export factor human Gle1 interacts with the nuclear pore complex protein Nup155. Mol. Cell. Proteom. 3, 145-155 (2004).

38. Strahm, Y. et al. The RNA export factor Glelp is located on the cytoplasmic fibrils of the NPC and physically interacts with the FG-nucleoporin Rip1p, the DEAD-box protein Rat8p/Dbp5p and a new protein Ymr 255p. EMBO J. 18, 5761-5777 (1999). 
39. Rollenhagen, C., Hodge, C. A. \& Cole, C. N. The nuclear pore complex and the DEAD box protein Rat8p/Dbp5p have nonessential features which appear to facilitate mRNA export following heat shock. Mol. Cell. Biol. 24, 4869-4879 (2004).

40. Adams, R. L., Terry, L. J. \& Wente, S. R. Nucleoporin FG domains facilitate mRNP remodeling at the cytoplasmic face of the nuclear pore complex. Genetics 197, 1213-1224 (2014).

41. Montpetit, B., Seeliger, M. A. \& Weis, K. Analysis of DEAD-box proteins in mRNA export. Methods Enzymol. 511, 239-254 (2012).

42. Shears, S. B. Assessing the omnipotence of inositol hexakisphosphate. Cell. Signal. 13, 151-158 (2001).

43. Collins, R. et al. The DEXD/H-box RNA helicase DDX19 is regulated by an \{alpha\}-helical switch. J. Biol. Chem. 284, 10296-10300 (2009).

44. Noble, K. N. et al. The Dbp5 cycle at the nuclear pore complex during mRNA export II: nucleotide cycling and mRNP remodeling by Dbp 5 are controlled by Nup159 and Gle1. Genes Dev. 25, 1065-1077 (2011).

45. Adams, R. L., Mason, A. C., Glass, L., Aditi \& Wente, S. R. Nup42 and IP6 coordinate Gle1 stimulation of Dbp5/DDX19B for mRNA export in yeast and human cells. Traffic 18, 776-790 (2017).

46. Ma, J. et al. High-resolution three-dimensional mapping of mRNA export through the nuclear pore. Nat. Commun. 4, 2414 (2013).

47. Grunwald, D. \& Singer, R. H. In vivo imaging of labelled endogenous betaactin mRNA during nucleocytoplasmic transport. Nature 467, 604-607 (2010).

48. von Appen, A. et al. In situ structural analysis of the human nuclear pore complex. Nature 526, 140-143 (2015).

49. Folkmann, A. W., Dawson, T. R. \& Wente, S. R. Insights into mRNA exportlinked molecular mechanisms of human disease through a Glel structurefunction analysis. Adv. Biol. Regul. 54, 74-91 (2014).

50. Mossessova, E. \& Lima, C. D. Ulp1-SUMO crystal structure and genetic analysis reveal conserved interactions and a regulatory element essential for cell growth in yeast. Mol. Cell 5, 865-876 (2000).

51. Hoelz, A., Nairn, A. C. \& Kuriyan, J. Crystal structure of a tetradecameric assembly of the association domain of $\mathrm{Ca} 2+/$ calmodulin-dependent kinase II. Mol. Cell 11, 1241-1251 (2003).

52. Kabsch, W. Xds. Acta Crystallogr. D Biol. Crystallogr. 66, 125-132 (2010).

53. McCoy, A. J. et al. Phaser crystallographic software. J. Appl. Crystallogr. 40, 658-674 (2007).

54. Adams, P. D. et al. PHENIX: a comprehensive Python-based system for macromolecular structure solution. Acta Crystallogr. D Biol. Crystallogr. 66 213-221 (2010).

55. Chen, V. B. et al. MolProbity: all-atom structure validation for macromolecular crystallography. Acta Crystallogr. D Biol. Crystallogr. 66, 12-21 (2010).

56. Strong, M. et al. Toward the structural genomics of complexes: crystal structure of a PE/PPE protein complex from Mycobacterium tuberculosis. Proc. Natl. Acad. Sci. USA 103, 8060-8065 (2006).

57. Skubak, P. \& Pannu, N. S. Automatic protein structure solution from weak Xray data. Nat. Commun. 4, 2777 (2013).

58. Skubák, P. et al. A new MR-SAD algorithm for the automatic building of protein models from low-resolution X-ray data and a poor starting model. IUCrJ 5, 166-171 (2018)

59. Waterman, D. G. et al. The DIALS framework for integration software. CCP4 Newslett. Protein Crystallogr. 49, 13-15 (2013).

60. Evans, P. R. \& Murshudov, G. N. How good are my data and what is the resolution? Acta Crystallogr. D Biol. Crystallogr. 69, 1204-1214 (2013).

61. Janke, C. et al. A versatile toolbox for PCR-based tagging of yeast genes: new fluorescent proteins, more markers and promoter substitution cassettes. Yeast 21, 947-962 (2004).

62. Zhang, T. et al. An improved method for whole protein extraction from yeast Saccharomyces cerevisiae. Yeast 28, 795-798 (2011).

63. Niesen, F. H., Berglund, H. \& Vedadi, M. The use of differential scanning fluorimetry to detect ligand interactions that promote protein stability. Nat. Protoc. 2, 2212-2221 (2007).

64. Pettersen, E. F. et al. UCSF Chimera-a visualization system for exploratory research and analysis. J. Comput. Chem. 25, 1605-1612 (2004).

65. Baker, N. A., Sept, D., Joseph, S., Holst, M. J. \& McCammon, J. A. Electrostatics of nanosystems: application to microtubules and the ribosome. Proc. Natl. Acad. Sci. USA 98, 10037-10041 (2001).

66. Buchan, D. W., Minneci, F., Nugent, T. C., Bryson, K. \& Jones, D. T. Scalable web services for the PSIPRED Protein Analysis Workbench. Nucleic Acids Res. 41, W349-W357 (2013).

67. Barton, G. J. ALSCRIPT: a tool to format multiple sequence alignments. Protein Eng. 6, 37-40 (1993).
68. Edgar, R. C. MUSCLE: multiple sequence alignment with high accuracy and high throughput. Nucleic Acids Res. 32, 1792-1797 (2004).

69. Napetschnig, J., Blobel, G. \& Hoelz, A. Crystal structure of the N-terminal domain of the human protooncogene Nup214/CAN. Proc. Natl. Acad. Sci. USA 104, 1783-1788 (2007).

\section{Acknowledgements}

We thank Alina Patke for critical reading of the manuscript, Karsten Thierbach for advice on yeast experiments, and Susan Wente for helpful discussions and sharing data prior to publication. We also acknowledge Jens Kaiser and the scientific staffs of SSRL Beamline 12-2, the National Institute of General Medical Sciences and National Cancer Institute Structural Biology Facility (GM/CA) at the Advanced Photon Source (APS), and the Frontier Microfocusing Macromolecular Crystallography (FMX) beamline at the National Synchrotron Light Source II (NSLS-II) for support with X-ray diffraction measurements. The operations at APS, SSRL, and NSLS-II are primarily supported by the Department of Energy. We acknowledge the Gordon and Betty Moore Foundation, the Beckman Institute, and the Sanofi-Aventis Bioengineering Research Program for their support of the Molecular Observatory at the California Institute of Technology. GM/CA has been funded in whole or in part with federal funds from the National Cancer Institute (grant ACB-12002) and the National Institute of General Medical Sciences (grant AGM-12006). The crystal structure of $\mathrm{ctGlel}^{\mathrm{CTD}} \cdot \mathrm{Nup} 42^{\mathrm{CTD}} \cdot \mathrm{IP}_{6}$ was determined at the CCP4/APS School for Macromolecular Crystallography (2016), which was supported by the National Cancer Institute (AGM-12006) and the National Institute of General Medical Science (ACB-12002). We acknowledge Navraj Pannu for his help. Valerie Altounian is acknowledged for creating the schematic illustration of the nuclear pore complex. D.H.L. and C.A.J. were supported by an NIH Research Service Award (5 T32 GM07616). D.H.L. and F.M.H. were supported by an Amgen Graduate Fellowship through the Caltech-Amgen Research Collaboration. S.W.C. was supported by a Margaret Leighton Summer Undergraduate Research Fellowship and a John Stauffer Summer Undergraduate Research Fellowship through the Caltech Student-Faculty Programs Office. A.H. is a Faculty Scholar of the Howard Hughes Medical Institute and an Investigator of the Heritage Medical Research Institute. A.H. was also supported by NIH grant R01-GM117360, Caltech startup funds, and a Teacher-Scholar Award of the Camille \& Henry Dreyfus Foundation.

\section{Author contributions}

A.H. and D.H.L. conceived the project, designed the experiments, and analyzed all data D.H.L., A.R.C., and S.W.C. purified proteins, performed biochemical analyses, and determined crystal structures. D.H.L., S.W.C., A.R.C., and F.M.H. generated yeast strains and performed yeast analyses. C.A.J. purified proteins and performed biochemical analysis of Nup155 amino acid substitution variants. A.H. supervised all experimental work. A.H. and D.H.L. wrote the manuscript with comments from all authors.

\section{Additional information}

Supplementary Information accompanies this paper at https://doi.org/10.1038/s41467 018-04459-3.

Competing interests: The authors declare no competing interests.

Reprints and permission information is available online at http://npg.nature.com/ reprintsandpermissions/

Publisher's note: Springer Nature remains neutral with regard to jurisdictional claims in published maps and institutional affiliations.

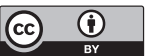

Open Access This article is licensed under a Creative Commons Attribution 4.0 International License, which permits use, sharing, adaptation, distribution and reproduction in any medium or format, as long as you give appropriate credit to the original author(s) and the source, provide a link to the Creative Commons license, and indicate if changes were made. The images or other third party material in this article are included in the article's Creative Commons license, unless indicated otherwise in a credit line to the material. If material is not included in the article's Creative Commons license and your intended use is not permitted by statutory regulation or exceeds the permitted use, you will need to obtain permission directly from the copyright holder. To view a copy of this license, visit http://creativecommons.org/ licenses/by/4.0/.

(C) The Author(s) 2018 